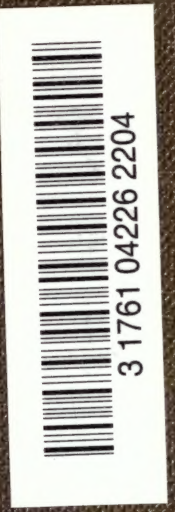





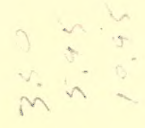


Philos

B125h

- Ed

\section{A LIBRARY OF}

UNIVERAL LITERATURE

$$
\text { IN FOUR PARTS }
$$

Comprising Science, Biography, Fiction and the Great Orations

$$
\text { PART ONE-SCIENCE }
$$

\section{NOVUM ORGANUM BY LORD BACON}

Edited by TOSEPH DEVEY, M.A.
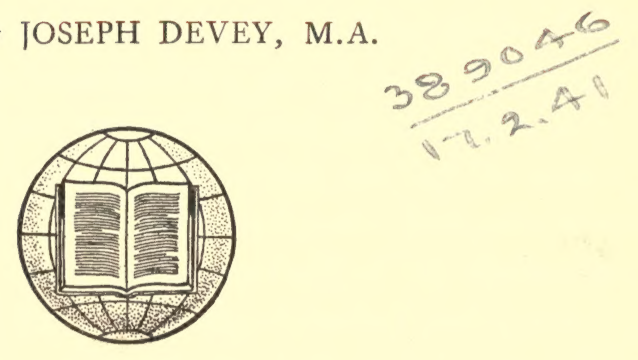

NEW YORK

P. F. COLLIER AND SON

- M C M I . 
PRESS OF

P. F. COLLIER \& SON

ALL RIGHTS RESERVED

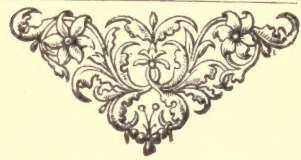




\section{NOVUM OR G A U M \\ or}

\section{TRUE SUGGESTIONS, FOR THE INTERPRETATION OF NATURE}

\section{P R E F A C E}

They who have presumed to dogmatize on nature, as on some well investigated subject, either from self-conceit or arrogance, and in the professorial style, have inflicted the greatest injury on philosophy and learning. For they have tended to stifle and interrupt inquiry exactly in proportion as they have prevailed in bringing others to their opinion: and their own activity has not counterbalanced the mischief they have occasioned by corrupting and destroying that of others. They again who have entered upon a contrary course, and asserted that nothing whatever can be known, whether they have fallen into this opinion from their hatred of the ancient sophists, or from the hesitation of their minds, or from an exuberance of learning, have certainly adduced reasons for it. which are by no means contemptible. They have not, however, derived their opinion from true sources, and, hurried on by their zeal and some affectation, have certainly exceeded due moderation. But the more ancient Greeks (whose writings have perished), held a more prudent mean, between the arrogance of dogmatism, and the despair of scepticism; and though too frequently intermingling complaints and indig- 
nation at the difficulty of inquiry, and the obscurity of things, and champing, as it were, the bit, have still persisted in pressing their point, and pursuing their intercourse with nature; thinking, as it seems, that the better method was not to dispute upon the very point of the possibility of anything being known, but to put it to the test of experience. Yet they themselves, by only employing the power of the understanding, have not adopted a fixed rule, but have laid their whole stress upon intense meditation, and a continual exercise and perpetual agitation of the mind.

Our method, though difficult in its operation, is easily explained. It consists in determining the degrees of certainty, while we, as it were, restore the senses to their former rank, but generally reject that operation of the mind which follows close upon the senses, and open and establish a new and certain course for the mind from the first actual perceptions of the senses themselves. This, no doubt, was the view taken by those who have assigned so much to logic; showing clearly thereby that they sought some support for the mind, and suspected its natural and spontaneous mode of action. But this is now employed too late as a remedy, when all is clearly lost, and after the mind, by the daily habit and intercourse of life, has come prepossessed with corrupted doctrines, and filled with the vainest idols. The art of logic therefore being (as we have mentioned), too late a precaution, ${ }^{1}$ and in no way remedy-

1 Because it was idle to draw a logical conclusion from false principles, error being propagated as much by false premises, which logic does not pretend to examine, as by illegitimate inference. Hence, as Bacon says further on, men being easily led to confound legitimate inference with truth, were confirmed in their errors by the very subtilty of their genius. - Ed. 
ing the matter, has tended more to confirm errors, than to disclose truth. Our only remaining hope and salvation is to begin the whole labor of the mind again; not leaving it to itself, but directing it perpetually from the very first, and attaining our end as it were by mechanical aid. If men, for instance, had attempted mechanical labors with their hands alone, and without the power and aid of instruments, as they have not hesitated to carry on the labors of their understanding with the unaided efforts of their mind, they would have been able to move and overcome but little, though they had exerted their utmost and united powers. And just to pause awhile on this comparison, and look into it as a mirror; let us ask, if any obelisk of a remarkable size were perchance required to be moved, for the purpose of gracing a triumph or any similar pageant, and men were to attempt it with their bare hands, would not any sober spectator avow it to be an act of the greatest madness? And if they should increase the number of workmen, and imagine that they could thus succeed, would he not think so still more? But if they chose to make a selection, and to remove the weak, and only employ the strong and vigorous, thinking by this means, at any rate, to achieve their object, would he not say that they were more fondly deranged? Nay, if not content with this, they were to determine on consulting the athletic art, and were to give orders for all to appear with their hands, arms, and muscles regularly oiled and prepared, would he not exclaim that they were taking pains to rave by method and design? Yet men are hurried on with the same senseless energy and useless combination in intellectual matters, as long as they expect great results either from the number and agreement, or the excellence and acuteness of their wits; or even 
strengthen their minds with logic, which may be con. sidered as an athletic preparation, but yet do not desist (if we rightly consider the matter) from applying their own understandings merely with all this zeal and effort. While nothing is more clear, than that in every great work executed by the hand of man without machines or implements, it is impossible for the strength of individuals to be increased, or for that of the multitude to combine.

Having premised so much, we lay down two points on which we would admonish mankind, lest they should fail to see or to observe them. The first of these is, that it is our good fortune (as we consider it), for the sake of extinguishing and removing contradiction and irritation of mind, to leave the honor and reverence due to the ancients untouched and undiminished, so that we can perform our intended work, and yet enjoy the benefit of our respectful moderation. For if we should profess to offer something better than the ancients, and yet should pursue the same course as they have done, we could never, by any artifice, contrive to avoid the imputation of having engaged in a contest or rivalry as to our respective wits, excellences, or talents; which, though neither inadmissible nor new (for why should we not blame and point out anything that is imperfectly discovered or laid down by them, of our own right, a right common to all?), yet however just and allowable, would perhaps be scarcely an equal match, on account of the disproportion of our strength. But since our present plan leads up to open an entirely different course to the understanding, and one unattempted and unknown to them, the case is altered. There is an end to party zeal, and we only take upon ourselves the character of a guide, which requires a moderate share of authority and good fortune, 
rather than talents and excellence. The first admonition relates to persons, the next to things.

We make no attempt to disturb the system of philosophy that now prevails, or any other which may or will exist, either more correct or more complete. For we deny not that the received system of philosophy, and others of a similar nature, encourage discussion, embellish harangues, are employed, and are of service in the duties of the professor, and the affairs of civil life. Nay, we openly express and declare that the philosophy we offer will not be very useful in such respects. It is not obvious, nor to be understood in a cursory view, nor does it flatter the mind in its preconceived notions, nor will it descend to the level of the generality of mankind unless by its advantages and effects.

Let there exist then (and may it be of advantage to both), two sources, and two distributions of learning, and in like manner two tribes, and as it were kindred families of contemplators or philosophers, without any hostility or alienation between them; but rather allied and united by mutual assistance. Let there be in short one method of cultivating the sciences, and another of discovering them. And as for those who prefer and more readily receive the former, on account of their haste or from motives arising from their ordinary life, or because they are unable from weakness of mind to comprehend and embrace the other (which must necessarily be the case with by far the greater number), let us wish that they may prosper as they desire in their undertaking, and attain what they pursue. But if any individual desire, and is anxious not merely to adhere to, and make use of present discoveries, but to penetrate still further, and not to overcome his adversaries in disputes, but nature by labor, not in short to give elegant 
and specious opinions, but to know to a certainty and dem. onstration, let him, as a true son of science (if such be his wish), join with us; that when he has left the antechambers of nature trodden by the multitude, an entrance may at last be discovered to her inner apartments. And in order to be better understood, and to render our meaning more familiar by assigning determinate names, we have accustomed ourselves to call the one method the anticipation of the mind, and the other the interpretation of nature.

We have still one request left. We have at least reflected and taken pains in order to render our propositions not only true, but of easy and familiar access to men's minds, however wonderfully prepossessed and limited. Yet it is but just that we should obtain this favor from mankind (especially in so great a restoration of learning and the sciences), that whosoever may be desirous of forming any determination upon an opinion of this our work either from his own perceptions, or the crowd of authorities, or the forms of demonstrations, he will not expect to be able to do so in a cursory manner, and while attending to other matters; but in order to have a thorough knowledge of the subject, will himself by degrees attempt the course which we describe and maintain; will be accustomed to the subtilty of things which is manifested by experience; and will correct the depraved and deeply rooted habits of his mind by a seasonable, and, as it were, just hesitation: and then, finally (if he will), use his judgment when he has begun to be master of himself. 


\section{APHORISMS-BOOK I}

\section{ON THE INTERPRETATION OF NATURE AND THE EMPIRE OF MAN}

I. MAN, as the minister and interpreter of nature, does and understands as much as his observations on the order of nature, either with regard to things or the mind, permit him, and neither knows nor is capable of more.

II. The unassisted hand and the understanding left to itself possess but little power. Effects are produced by the means of instruments and helps, which the understanding requires no less than the hand; and as instruments either promote or regulate the motion of the hand, so those that are applied to the mind prompt or protect the understanding.

III. Knowledge and human power are synonymous, since the ignorance of the cause frustrates the effect; for nature is only subdued by submission, and that which in contemplative philosophy corresponds with the cause in practical science becomes the rule.

IV. Man while operating can only apply or withdraw natural bodies; nature internally performs the rest.

V. Those who become practically versed in nature are, the mechanic, the mathematician, the physician, the alchemist, and the magician, ${ }^{1}$ but all (as matters now stand) with faint efforts and meagre success.

1 Bacon uses the term in its ancient sonse, and means one who, knowing the occult properties of bodies, is able to startle the ignorant by drawing out of them wonderful and unforeseen changes. See the 85 th aphorism of this book, and the 5th cap. book iii. of the De Augmentis Scientiarum, where he speaks more clearly-Ed. 
VI. It would be madness and inconsistency to suppose that things which have never yet been performed can be performed without employing some hitherto untried means.

VII. The creations of the mind and hand appear very numerous, if we judge by books and manufactures; but all that variety consists of an excessive refinement, and of deductions from a few well known matters-not of a number of axioms. ${ }^{2}$

VIII. Even the effects already discovered are due to chance and experiment rather than to the sciences; for our present sciences are nothing more than peculiar arrangements of matter's already discóvered, and not methods for discovery or plans for new operations.

IX. The sole cause and root of almost every defect in the sciences is this, that while we falsely admire and extol the powers of the human mind, we do not search for its real helps.

$\mathrm{X}$. The subtilty of nature is far beyond that of sense or of the understanding: so that the specious meditations, speculations, and theories of mankind are but a kind of insanity, only there is no one to stand by and observe it.

XI. As the present sciences are useless for the discovery of effects, so the present system of $\operatorname{logic}^{3}$ is useless for the discovery of the sciences.

2 By this term axiomatit, Bacon liere speaks of general principles, or universal laws. In the 19 th aphorism he employs the term to express any proposition collected from facts by induction, and thus fitted to become the starting-point of deductive reasoning. In the last and more rigorous sense of the term, Batcon licld they arose from experience. Sce Whewell's "Philosophy of the Inductive Sciences," vol. i. p. 74; and Mill's "Logic," vol. i. p. 311; and the June "Quarterly," 1841, for the modern phase of the discussion.-Ed.

: Bacon here attributes to the Aristotelian logic the erroncous consequences which sprung out of its abuse. The demonstrative forms it exhibits, whether verbally or mathematically expressed, are necessury to the support, veritication, 


\section{The present system of logic rather assists in con-} firming and rendering inveterate the errors founded on vulgar notions than in searching after truth, and is therefore more hurtful than useful.

XIII. The syllogism is not applied to the principles of the sciences, and is of no avail in intermediate axioms, ${ }^{4}$ as

and extension of induction, and when the propositions they embrace are founded on an accurate and close observation of facts, the conclusions to which they lead, even in moral science, may be regarded as certain as the facts wrested out of nature by direct experiment. In physics such forms are absolutely required to generalize the results of experience, and to connect intermediate axioms with laws still more general, as is sufficiently attested by the fact, that no science since Bacon's day has ceased to be experimental by the mere method of induction, and that all become exact only so far as they rise above experience, and connect their isolated phenomena with general laws by the principles of deductive reasoning. So far, then, are these forms from being useless, that they are absolutely essential to the advancement of the sciences, and in no case can be looked on as detrimental, except when obtruded in the place of direct experiment, or employed as a means of deducing conclusions about nature from imaginary hypotheses and abstract conceptions. This had been unfortunately the practice of the Greeks. From the rapid development geometry received in their hands, they imagined the same method would lead to results equally brilliant in natural science, and snatching up some abstract principle, which they carefully removed from the test of experiment, imagined they could reason out from it all the laws and external appearances of the universe. The scholastics were im. pelled along the same path, not only by precedent, but by profession. Theology was the only science which received from them a consistent development, and the $a$ priori grounds on which it rested prevented them from employing any other method in the pursuit of natural phenomena. Thus, forms of demonstration, in themselves accurate, and of momentous value in their proper sphere, became confounded with fable, and led men into the idea they were exploring truth when they were only accurately deducing error from error. One principle ever so slightly deflected, like a false quantity in an equation, could be sufficient to infect the whole series of conclusions of which it was the base; and though the philosopher might subsequently deduce a thousand consecutive inferences with the utmost accuracy or precision, he would only succeed in drawing out very methodically nine hundred and ninety-nine errors. $-E d$.

${ }^{4}$ It would appear from this and the two preceding aphorisms, that Bacon fell into the error of denying the utility of the syllogism in the very part of inductive science where it is essentially required. Logic, like mathematics, is 
being very unequal to the subtilty of nature. It forces assent, therefore, and not things.

XIV. The syllogism consists of propositions; propositions of words; words are the signs of notions. If, therefore, the notions (which form the basis of the whole) be confused and carelessly abstracted from things, there is no solidity in the superstructure. Our only hope, then, is in genuine induction.

XV. We have no sound notions either in logic or physics; substance, quality, action, passion, and existence are not clear notions; much less weight, levity, density, tenuity, moisture, dryness, generation, corruption, attraction,

purely a formal process, and must, as the scaffolding to the building, be employed to arrange facts in the structure of a science, and not to form any portion of its groundwork, or to supply the materials of which the system is to be composed. The word syllogism, like most other pyschological terms, has no fixed or original signification, but is sometimes employed, as it was by the Greeks, to denote general reasoning, and at others to point out the formal method of deducing a particular inference from two or more general propositions. Bacon does not confine the term within the boundaries of express defl. nition, but leaves us to infer that he took it in the latter sense, from his custom of associating the term with the wranglings of the schools. The scholasties, it is true, abused the deductive syllogism, by employing it in its naked, skeletonlike form, and confounding it with the whole breadth of logical theory; but their errors are not to be visited on Aristotle, who never dreamed of playing with formal syllogisms, and, least of all, mistook the descending for the ascending series of inference. In our mind we are of accord with the Stagyrite, who propounds, as far as we can interpret him, two modes of investigating truththe one by which we ascend from particular and singular facts to general laws and axions, and the other by which we descend from universal propositions to the individual cases which they virtually include. Logie, therefore, must equally vindicate the formal purity of the synthetic illation by which it ascends to the whole, as the analytic process by which it descends to the parts. The deductive and inductive syllogism are of equal significance in building up any body of truth, and whoever restricts logic to either process, mistakes one-half of its province for the whole; and if he acts upon his error, will paralyze his methods, and strike the noblest part of science with sterility. $-E d$. 
repulsion, element, matter, form, and the like. They are all fantastical and ill-defined.

XVI. The notions of less abstract natures, as man, dog, dove, and the immediate perceptions of sense, as heat, cold, white, black, do not deceive us materially, yet even these are sometimes confused by the mutability of matter and the intermixture of things. All the rest which men have hitherto employed are errors, and improperly abstracted and deduced from things.

XVII. There is the same degree of licentiousness and error in forming axioms as in abstracting notions, and that in the first principles, which depend on common induction; still more is this the case in axioms and inferior propositions derived from syllogisms.

XVIII. The present discoveries in science are such as lie immediately beneath the surface of common notions. It is necessary, however, to penetrate the more secret and remote parts of nature, in order to abstract both notions and axioms from things by a more certain and guarded method.

XIX. There are and can exist but two ways of investi. gating and discovering truth. The one hurries on rapidly from the senses and particulars to the most general axioms, and from them, as principles and their supposed indisputable truth, derives and discovers the intermediate axioms. This is the way now in use. The other constructs its axioms from the senses and particulars, by ascending continually and gradually, till it finally arrives at the most general axioms, which is the true but unattempted way.

$\mathrm{XX}$. The understanding when left to itself proceeds by the same way as that which it would have adopted under the guidance of logic, namely, the first; for the mind is fond of starting off to generalities, that it may avoid labor, and 
after dwelling a little on a subject is fatigued by experiment. But those evils are augmented by logic, for the sake of the ostentation of dispute.

XXI. The understanding, when left to itself in a man of a steady, patient, and reflecting disposition (especially when unimpeded by received doctrines), makes some attempt in the right way, but with little effect, since the understanding, undirected and unassisted, is unequal to and unfit for the task of vanquishing the obscurity of things.

XXII. Each of these two ways begins from the senses and particulars, and ends in the greatest generalities. But they are immeasurably different; for the one merely touches cursorily the limits of experiment and particulars, while the other runs duly and regularly through them-the one from the very outset lays down some abstract and useless generalities, the other gradually rises to those principles which are really the most common in nature. ${ }^{5}$

XXIII. There is no small difference between the idols of the human mind and the ideas of the Divine mind-that is to say, between certain idle dogmas and the real stamp and impression of created objects, as they are found in nature.

XXIV. Axioms determined upon in argument can never assist in the discovery of new effects; for the subtilty of nature is vastly superior to that of argument. But axioms properly and regularly abstracted from particulars easily

5 The Latin is, ad ea qua revera sunt natura notiora. This expression, naturce notiora, naturce notior, is so frequently employed by Bacon, that we may conclude it to point to some distinguishing feature in the Baconian plysies. It properly refers to the most evident principles and laws of nature, and springs from that system which regards the material universe as endowed with intelligence, and acting according to rules either fashioned or clearly understood by itself. $-E d$. 
point out and define new particulars, and therefore impart activity to the sciences.

$X X V$. The axioms now in use are derived from a scanty handful, as it were, of experience, and a few particulars of frequent occurrence, whence they are of much the same dimensions or extent as their origin. And if any neglected or unknown instance occurs, the axiom is saved by some frivolous distinction, when it would be more consistent with truth to amend it.

XXVI. We are wont, for the sake of distinction, to call that human reasoning which we apply to nature the anticipation of nature (as being rash and premature), and that which is properly deduced from things the interpretation of nature.

XXVII. Anticipations are sufficiently powerful in producing unanimity, for if men were all to become even uniformly mad, they might agree tolerably well with each other.

XXVIII. Anticipations again, will be assented to much more readily than interpretations, because being deduced from a few instances, and these principally of familiar occurrence, they immediately hit the understanding and satisfy the imagination; while, on the contrary, interpretations, being deduced from various subjects, and these widely dispersed, cannot suddenly strike the understanding, so that in common estimation they must appear difficult and discordant, and almost like the mysteries of faith.

XXIX. In sciences founded on opinions and dogmas, it is right to make use of anticipations and logic if you wish to force assent rather than things.

$\mathrm{XXX}$. If all the capacities of all ages should unite and combine and transmit their labors, no great progress will be 
made in learning by anticipations, because the radical errors, and those which occur in the first process of the mind, are not cured by the excellence of subsequent means and remedies.

XXXI. It is in vain to expect any great progress in the sciences by the superinducing or ingrafting new matters upon old. An instauration must be made from the very foundations, if we do not wish to revolve forever in a circle, making only some slight and contemptible progress.

XXXII. The ancient authors and all others are left in undisputed possession of their honors; for we enter into no comparison of capacity or talent, but of method, and assume the part of a guide rather than of a critic.

XXXIII. To speak plainly, no correct judgment can be formed either of our method or its discoveries by those anticipations which are now in common use; for it is not to be required of us to submit ourselves to the judgment of the very method we ourselves arraign.

XXXIV. Nor is it an easy matter to deliver and explain our sentiments; for those things which are in themselves new can yet be only understood from some analogy to what is old.

XXXV. Alexander Borgia ${ }^{6}$ said of the expedition of the French into Italy that they came with chalk in their hands to mark up their lodgings, and not with weapons to force their passage. Even so do we wish our philosophy to make its way quietly into those minds that are fit for it, and of good capacity; for we have no need of contention where we

6 This Borgia was Alexander VI., and the expedition alluded to that in which Charles VIII. overran the Italian peninsula in five months. Bacon uses the same illustration in concluding his survey of natural philosophy, in the second book of the "De Augmentis." $-E d$. 
differ in first principles, and in our very notions, and even in our forms of demonstration.

XXXVI. We have but one simple method of delivering our sentiments, namely, we must bring men to particulars and their regular series and order, and they must for a while renounce their notions, and begin to form an acquaintance with things.

XXXVII. Our method and that of the sceptics ${ }^{7}$ agree in some respects at first setting out, but differ most widely, and are completely opposed to each other in their conclu. sion; for they roundly assert that nothing can be known; we, that but a small part of nature can be known, by the present method; their next step, however, is to destroy the authority of the senses and understanding, while we invent and supply them with assistance.

XXXVIII. The idols and false notions which have already preoccupied the human understanding, and are deeply rooted in it, not only so beset men's minds that they become difficult of access, but even when access is obtained will again meet and trouble us in the instauration of the sciences, unless mankind when forewarned guard themselves with all possible care against them.

XXXIX. Four species of idols beset the human mind, ${ }^{8}$

7 Ratio corum qui acatalepsiam tenuexunt. Bacon alludes to the members

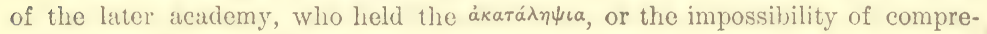
hending anytling. II is translator, however, makes him refer to the scepties, who neither dogmatized about the known or the unknown, but simply held,

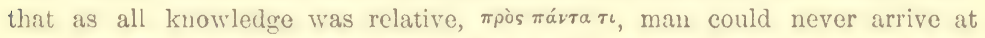
absolute truth, and therefore could not with certainty affirm or deny anything. - Ed.

8 It is argued by Hallam, with some appearance of truth, that idols is not the correct translation of ei $\delta \omega \lambda a$, from which the original idola is manifestly derived; but that Bacon used it in the literal sense attached to it by the Greeks, as a species of illusion, or false appearance, and not as a species of divinity be- 
to which (for distinction's sake) we have assigned names, calling the first Idols of the Tribe, the second Idols of the Den, the third Idols of the Market, the fourth Idols of the

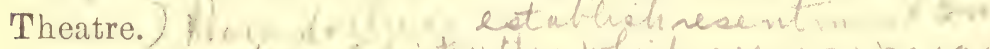

XL. The formation of notions and axioms on the foundation of true induction is the only fitting remedy by which we can ward off and expel these idols. It is, however, of great service to point them out; for the doctrine of idols bears the same relation to the interpretation of nature as that of the confutation of sophisms does to common logic. ${ }^{9}$

XLI. The idis of the tribe, are inherent in thuman nature and the very tribe or race of man; for man's sense is falsely asserted to be the standard of things; on the contrary, all the perceptions both of the senses and the mind bear refer. ence to man and not to the universe, and the human mind resembles those uneven mirrors which impart their own

fore which the mind bows down. If Hallam be right, Bacon is saved from the odium of an analogy which his foreign commentators are not far wrong in denouncing as barbarous; but this service is rendered at the expense of the men who have attached an opposite meaning to the word, among whom are Brown, Playfair and Dugald Stewart.-Ed.

${ }_{9}$ We cannot see how these idols have less to do with sophistical paralogisms than with natural philosophy. The process of scientific induction involves only the first elements of reasoning, and presents such a clear and tangible surface, as to an- w no lurking-place for prejudice; while questions of politics and morals, to which the deductive method, or common logic, as Bacon calls it, is peculiarly applicable, are ever liable to be swayed or perverted by the prejudices he enumerates. After mathematics, physical science is the least amenable to the illusions of feeling; each portion having been already tested by experiment and observation, is fitted into its place in the system, with all the rigor of the geometrical method; affection or prejudice cannot, as in matters of taste, history or religion, select fragmentary pieces, and form a system of their own. The whole must be admitted, or the structure of authoritative reason razed to the ground. It is needless to say that the idols enumerated present only another interpretation of the substance of logical fallacies. $-E d$. 
properties to different objects, from which rays are emitted and distort and disfigure them. ${ }^{10}$

XLII. The idols of the den are those of each individual; for everybody (in addition to the errors common to the race of man) has his own individual den or cavern, which intercepts and corrupts the light of nature, either from his own peculiar and singular disposition, or from his education and intercosrse with others, or from his reading, and the authority acquired by those whom he reverences and admires, or from the different impressions produced on the mind, as it happens to be preoccupied and predisposed, or equable and tranquil, and the like; so that the spirit of man (according to its several dispositions), is variable, confused, and as it were actuated by chance; and Heraclitus said well that men search for knowledge in lesser worlds, and not in the greater or common world.

XLIII. There are also idols formed by the reciprocal intercourse and society of man with man, which we call idols of the market, from the commerce and association of men with each other; for men converse by means of language, but words are formed at the will of the generality, and there arises from a bad and unapt formation of words a wonderful obstruction to the mind. Nor can the definitions and explanations with which learned men are wont to guard and protect themselves in some instances afford a complete remedy-words still manifestly force the understanding, throw everything into confusion, and lead mankind into vain and innumerable controversies and fallacies.

XLIV. Lastly, there are idols which have crept into

10 The propensity to this illusion may be viewed in the spirit of system, or hasty generalization, which is still one of the chief obstacles in the path of modern science.-Ed. 
men's minds from the various dogmas of peculiar systems of philosophy, and also from the perverted rules of demon. stration, and these we denominate idols of the theatre: for we regard all the systems of philosophy hitherto received or imagined, as so many plays brought out and performed, creating fictitious and theatrical worlds. Nor do we speak only of the present systems, or of the philosophy and sects of the ancients, since numerous other plays of a similar nature can be still composed and made to agree with each other, the causes of the most opposite errors being generally the same. Nor, again, do we allude merely to general systems, but also to many elements and axioms of sciences which have become inveterate by tradition, implicit credence, and neglect. We must, however, discuss each species of idols more fully and distinctly in order to guard the human understanding against them.

$\mathrm{XLV}$. The human understanding, from its peculiar nature, easily supposes a greater degree of order and equality in things than it really finds; and although many things in nature be sui generis and most irregular, will yet invent parallels and conjugates and relatives, where no such thing is. Hence the fiction, that all celestial bodies move in perfect circles, thus rejecting entirely spiral and serpentine lines (except as explanatory terms). ${ }^{11}$ Hence also the ele-

1 Though Kepler had, when Bacon wrote this, already demonstrated his three great laws concerning the e!liptical path of the planets, neither Bacon nor Descartes seems to have known or assented to his discoveries. Our author deemed the startling astronomical announcements of his time to be mere theoretic solutions of the phenomena of the heavens, not so perfect as those advanced by antiquity, but still deserving a praise for the ingenuity displayed in their contrivance. Bacon believed a hundred such systems might exist, and though true in their explanation of phenomena, yet might all more or less differ, according to the preconceived notions which their framers brought to the survey of the heavens. He even thought he might put in his claim to the 
ment of fire is introduced with its peculiar orbit, ${ }^{12}$ to keep square with those other three which are objects of our senses. The relative rarity of the elements (as they are called) is arbitrarily made to vary in tenfold progression, with many other dreams of the like nature. ${ }^{13}$ Nor is this folly confined to theories, but it is to be met with even in simple notions.

XLVI. The human understanding, when any proposition has been once laid down (either from general admission and belief, or from the pleasure it affords), forces everything else to add fresh support and confirmation; and although most cogent and abundant instances may exist to the contrary, yet either does not observe or despises them, or gets rid of and rejects them by some distinction, with violent and injurious prejudice, rather than sacrifice the authority of its first conclusions. It was well answered by him ${ }^{14}$ who was

notice of posterity for his astronomical ingenuity, and, as Ptolemy had labored by means of epicycles and eccentries, and Kepler with ellipses, to explain the laws of planetary motion, Bacon thought the mystery would unfold itself quite as philosophically through spiral labyrinths and serpentine lines. What the details of his system were, we are left to conjecture, and that from a very meagre but naive account of one of his inventions which he has left in his Miscellany MSS. - Ed.

12 Hinc elementum ignis cum orbe suo introductum est. Bacon saw in fire the mere result of a certain combination of action, and was consequently led to deny its elementary character. The ancient physicists attributed an orbit to each of the four elements, into which they resolved the universe, and supposed their spheres to involve each other. The orbit of the earth was in the centre, that of fire at the circumference. For Bacon's inquisition into the nature of heat, and its complete failure, see the commencement of tho second book of the Novum Organum.-Ed.

13 Robert Fludd is the theorist alluded to, who had supposed the gravity of the earth to be ten times heavier than water, that of water ten times heavier than air, and that of air ten times heavier than fire.-Ed.

14 Diagoras. The same allusion occurs in the second part of the Advance. ment of Learning, where Bacon treats of the idols of the mind. 
shown in a temple the votive tablets suspended by such as had escaped the peril of shipwreck, and was pressed as to whether he would then recognize the power of the gods, by an inquiry, But where are the portraits of those who have perished in spite of their vows? All superstition is much the same, whether it be that of astrology, dreams, omens, retributive judginent, or the like, in all of which the deluded believer's observe events which are fulfilled, but neglect and pass over their failure, though it be much more common. But this evil insinuates itself still more craftily in philosophy and the sciences, in which a settled maxim vitiates and governs every other circumstance, though the latter be much more worthy of confidence. Besides, even in the absence of that eagerness and want of thought (which we have mentioned), it is the peculiar and perpetual error of the human understanding to be more moved and excited by affirmatives than negatives, whereas it ought duly and regularly to be impartial; nay, in establishing any true axiom the negative instance is the most powerful.

XLVII. The human understanding is most excited by that which strikes and enters the mind at once and suddenly, and by which the imagination is immediately filled and inflated. It then begins almost imperceptibly to con. ceive and suppose that everything is similar to the few objects which have taken possession of the mind, while it is very slow and unfit for the transition to the remote and heterogeneous instances by which axioms are tried as by fire, unless the office be imposed upon it by severe regula. tions and a powerful authority.

XLVIII. The human understanding is active and cannot halt or rest, but even, though without effect, still presses forward. Thus we cannot conceive of any end or external 
boundary of the world, and it seems necessarily to occur to us that there must be something beyond. Nor can we imagine how eternity has flowed on down to the present day, since the usually received distinction of an infinity, a parte ante and a parte post, ${ }^{15}$ cannot hold good; for it would thence follow that one infinity is greater than another, and also that infinity is wasting away and tending to an end. There is the same difficulty in considering the infinite divisibility of lines, arising from the weakness of our minds, which weakness interferes to still greater disadvantage with the discovery of causes; for although the greatest generalities in nature must be positive, just as they are found, and in fact not causable, yet the human understanding, incapable of resting, seeks for something more intelligible. Thus, however, while aiming at further progress, it falls back to what is actually less advanced, namely, final causes; for they are clearly more allied to man's own nature, than the system of the universe, and from this source they have wonderfully corrupted philosophy. But he would be an unskilful and shallow philosopher who should seek for causes in the greatest generalities,

15 A scholastic term, to signify the two eternities of past and future duration, that stretch out on both sides of the narrow isthmus (time) occupied by man. It must be remembered that Bacon lived before the doctrine of limits gave rise to the higher calculus, and therefore could have no conception of different denominations of infinities: on the other hand he would have thought the man insane who should have talked to him about lines infinitely great, in. closing angles infinitely little; that a right line, which is a right line so long as it is finite, by changing infinitely little its direction, becomes an infinite curve, and that a curve may become infinitely less than another curve; that there are infinite squares and infinite cubes, and infinites of infinites, all greater than one wnother, and the last but one of which is nothing in comparison with the last. Yet half a century sufficed from Bacon's time, to make this nomenclature, which would have appeared to him the excess of frenzy, not only reasonable but necessary, to grasp the higher demonstrations of physical science.-Ed. 
and not be anxious to discover them in subordinate objects.

XLIX. The human understanding resembles not a dry light, but admits a tincture of the will ${ }^{16}$ and passions, which generate their own system accordingly; for man always believes more readily that which he prefers. He, therefore, rejects difficulties for want of patience in investigation; sobriety, because it limits his hope; the depths of nature, from superstition; the light of experiment, from arrogance and pride, lest his mind should appear to be occupied with common and varying objects; paradoxes, from a fear of the opinion of the vulgar; in short, his feelings imbue and corrupt his understanding in innumerable and sometimes imperceptible ways.

L. But by far the greatest impediment and aberration of the human understanding proceeds from the dulness, incompetence, and errors of the senses; since whatever strikes the senses preponderates over everything, however superior, which does not immediately strike them. Hence contemplation mostly ceases with sight, and a very scanty, or perhaps no regard is paid to invisible objects. The entire operation, therefore, of spirits inclosed in tangible bodies ${ }^{17}$ is concealed, and escapes us. All that more delicate change of formation in the parts of coarser substances (vulgarly

16 Spinoza, in his letter to Oldenberg (Op. Posth. p. 398), considers this aphorism based on a wrong conception of the origin of error, and, believing it to be fundamental, was led to reject Bacon's method altogether. Spinoza refused to acknowledge in man any such thing as a will, and resolved all his volitions into particular acts, which he corsidered to be as fatally determinei by a chain of physical causes as any effects in nature.-Ed.

17 Operatio spirituum in corporibus tangibitibus. Bacon distinguished with the schools the gross and tangible parts of bodies, from such as were volatile and intangible. These, in conformity with the scholastic language, he terms spirits, and frequently returns to their operations in the $2 d$ book. - Edd. 
called alteration, but in fact a change of position in the smallest particles) is equally unknown; and yet, unless the two matters we have mentioned be explored and brought to light, no great effect can be produced in nature. Again, the very nature of common air, and all bodies of less density (of which there are many) is almost unknown; for the senses are weak and erring, nor can instruments be of great use in extending their sphere or acuteness -all the better interpretations of nature are worked out by instances, and fit and apt experiments, where the senses only judge of the experiment, the experiment of nature and the thing itself.

LI. The human understanding is, by its own nature, prone to abstraction, and supposes that which is fluctuating to be fixed. But it is better to dissect than abstract nature: such was the method employed by the school of Democritus, ${ }^{18}$ which made greater progress in penetrating nature than the rest. It is best to consider matter, its conformation, and the changes of that conformation, its own action, ${ }^{19}$ and the law of this action or motion; for forms are a mere fiction of the human mind, unless you will call the laws of action by that name. ${ }^{30}$

18 Democritus, of Abdera, a disciple of Leucippus, born B.C. 470, died 360; all his works are destroyed. He is said to be the author of the doctrine of atoms: he denied the immortality of the soul, and first taught that the milky way was occasioned by a confused light from a multitude of stars. He may be considered as the parent of experimental philosophy, in the prosecution of which he was so ardent as to declare that he would prefer the discovery of one of the causes of natural phenomena, to the possession of the diadem of Persia. Democritus imposed on the blind credulity of his contemporaries, and, like Roger Bacon, astonished them by his inventions. - Ed.

19 The Latin is actus purus, another scholastic expression to denote the action of the substance, which composes the essence of the body apart from its accidental qualities. For an exposition of the various kinds of motions he contemplates, the reader may refer to the 48 th aphorism of the $2 d$ book. $-E d$.

20 The scholastics after Aristotle distinguished in a subject three modes of SCIENCE-Vol. $22-2$ 
LII. Such are the idols of the tribe, which arise either from the uniformity of the constitution of man's spirit, or its prejudices, or its limited faculties or restless agitation, or from the interference of the passions, or the incompetence of the senses, or the mode of their impressions.

LIII. The idols of the den derive their origin $f_{i} u m$ the peculiar nature of each individual's mind and body, and also from education, habit, and accident; and although they be various and manifold, yet we will treat of some that require the greatest caution, and exert the greatest power in polluting the understanding.

LIV. Some men become attached to particular sciences and contemplations, either from supposing themselves the authors and inventors of them, or from having bestowed the greatest pains upon such subjects, and thus become most habituated to them. ${ }^{21}$ If men of this description apply themselves to philosophy and contemplations of a universal

beings: viz., the power or faculty, the act, and the habitude, or in other words that which is able to exist, what exists actually, and what continues to exist. Bacon means that is necessary to fix our attention not on that which can or ought to be, but on that which actually is; not on the right, but on the fact. $-E d$.

${ }^{21}$ The inference to be drawn from this is to suspect that kind of evidence which is most consonant to our inclinations, and not to admit any notion as real except we can base it firmly upon that kind of demonstration which is peculiar to the subject, not to our impression. Sometimes the mode of proof may bo consonant to our inclinations, and to the sulject at the same time, as in the case of Pythagoras, when he applicd his beloved numbers to the solution of astronomical phenomena; or in that of Descartes, when he reasoned geometrically concerning the nature of the soul. Such examples cannot be censured with justice, inasmuch as the methods pursued were adapted to the end of the inquiry. The remark in the text can only apply to those philosophers who attempt to build up a moral or theological system by the instruments of induction alone, or who rush, with the geometrical axiom, and the $a$ priori syllogism, to the investigation of nature. The means in such cases are totally inadequate to the object in view. $-E d$. 
nature, they wrest and corrupt them by their preconceived tancies, of which Aristotle affords us a single instance, who made his natural philosophy completely subservient to his logic, and thus rendered it little more than useless and disputatious. The chemists, again, have formed a fanciful philosopky with the most confined views, from a few experiments of the furnace. Gilbert, ${ }^{22}$ too, having employed himself most assiduously in the consideration of the magnet, immediately established a system of philosophy to coincide with his favorite pursuit.

LV. The greatest and, perhaps, radical distinction between different men's dispositions for philosophy and the sciences is this, that some are more vigorous and active in observing the differences of things, others in observing their resemblances; for a steady and acute disposition can fix its thoughts, and dwell upon and adhere to a point, through all the refinements of differences, but those that are sublime and discursive recognize and compare even the most delicate and general resemblances; each of them readily falls into excess, by catching either at nice distinctions or shadows of resemblance.

LVI. Some dispositions evince an unbounded admira. tion of antiquity, others eagerly embrace novelty, and but few can preserve the just medium, so as neither to tear up

22 Gilbert lived toward the ciose of the sixteenth century, and was court physician to both Elizabeth and Jarnes. In his work alluded to in the text he continually asserts the advantages of the experimental over the a priori method in physical inquiry, and succeeded when his censor failed in giving a practical example of the utility of his precepts. His "De Magnete" contains all the fundamental parts of the science, and these so perfectly treated, tha we have nothing to add to them at the present day.

Gilbert adopted the Copernican system, and even spoke of the contrary theory as utterly absurd, grounding his argument on the vast velocities which such a supposition requires us to ascribe to the heavenly bodies. $-E d$. 
what the ancients have correctly laid down, nor to despise the just innovations of the moderns. But this is very prejudicial to the sciences and philosophy, and instead of a correct judgment we have but the factions of the ancients and moderns. Truth is not to be sought in the good fortune of any particular conjuncture of time, which is uncertain, but in the light of nature and experience, which is eternal. Such factions, therefore, are to be abjured, and the understanding must not allow them to hurry it on to assent.

LVII. The contemplation of nature and of bodies in their individual form distracts and weakens the understanding; but the contemplation of nature and of bodies in their general composition and formation stupefies and relaxes it. We have a good instance of this in the school of Leucippus and Democritus compared with others, for they applied themselves so much to particulars as almost to neglect the general structure of things, while the others were so astounded while gazing on the structure that they did not penetrate the simplicity of nature. These two species of contemplation must, therefore, be interchanged, and each employed in its turn, in order to render the understanding at once penetrating and capacious, and to avoid the incon. veniences we have mentioned, and the idols that result from them.

LVIII. Let such, therefore, be our precautions in con. templation, that we may ward off and expel the idols of the den, which mostly owe their birth either to some predominant pursuit, or, secondly, to an excess in synthesi: and analysis, or, thirdly, to a party zeal in favor of certain ages, or, fourthly, to the extent or narrowness of the subject. In general, he who contemplates nature should suspect whatever particularly takes and fixes his understand- 
ing, and should use so much the more caution to preserve it equable and unprejudiced.

LIX. The idols of the market are the most troublesome of all, those namely which have entwined themselves round the understanding from the associations of words and names. For men imagine that their reason governs words, while, in fact, words react upon the understanding; and this has ren. dered philosophy and the sciences sophistical and inactive. Words are generally formed in a popular sense, and define things by those broad lines which are most obvious to the vulgar mind; but when a more acute understanding or more diligent observation is anxious to vary those lines, and to adapt them more accurately to nature, words oppose it. Hence the great and solemn disputes of learned men often terminate in controversies about words and names, in regard to which it would be better (imitating the caution of mathematicians) to proceed more advisedly in the first instance, and to bring such disputes to a regular issue by definitions. Such definitions, however, cannot remedy the evil in natural and material objects, because they consist themselves of words, and these words produce others; ${ }^{23}$ so that we must necessarily have recourse to particular instances, and their regular series and arrangement, as we

23 The Latin text adds "without end"; but Bacon is scarcely right in supposing that the descent from complex ideas and propositious to those of simple nature, involve the analyst in a series of continuous and interminable detinitious. For in the gradual and andiytical scale, there is a bar beyond which we cannot go, as there is a summit bounded by the limited variations of our conceptions. Logical definitions, to fultil their conditions, or indeed to be of any avail, must be given in simpler terms than the object which is sought to be defined; now this, in the case of primordial notions and objects of sense, is impossible; therefore we are obliged to rest satisfied with the mere names of our perceptions. - Ed. 
shall mention when we come to the mode and scheme of determining notions and axioms.

LX. The idols imposed upon the understanding by words are of two kinds. They are either the names of things which have no existence (for as some objects are from inattention left without a name, so names are formed by fanciful imaginations which are without an object), or they are the names of actual objects, but confused, badly defined, and hastily and irregularly abstracted from things. Fortune, the primum mobile, the planetary orbits, ${ }^{24}$ the element of fire, and the like fictions, which owe their birth to futile and false theories, are instances of the first kind. And this species of idols is removed with greater facility, because it can be exterminated by the constant refutation or the desuetude of the theories themselves. The others, which are created by vicious and unskilful abstraction, are intricate and deeply rooted. Take some word, for instance, as moist, and let us examine how far the different significations of this word are consistent. It will be found that the word moist is nothing but a confused sign of different actions admitted of no settled and defined uniformity. For it means that which easily diffuses itself over another body; that which is indeterminable and cannot be brought to a consistency; that which

24 The ancients supposed the planets to describe an exact circle round the south. As observations increased and facts were disclosed, which were irreconcilable with this supposition, the earth was removed from the centre to some other point in the circle, and the planets were supposed to revolve in a smaller circle (epicycle) round an imaginary point, which in its turn described a circle of which the earth was the centre. In proportion as observation elicited fresh facts, contradictory to these representations, other epicycles and eccentrics were added, involving additional confusion. Though Kepler had swept away all these complicated theories in the preceding century, by the demonstration of his three laws, which established the elliptical course of the planets, Bacon regarded him and Copernicus in the same light as Ptolemy and Xenophanes. - Ed. 
yields easily in every direction; that which is easily divided and dispersed; that which is easily united and collected; that which easily flows and is put in motion; that which easily adheres to, and wets another body; that which is easily reduced to a liquid state though previously solid. When, therefore, you come to predicate or impose this name, in one sense flame is moist, in another air is not moist, in another fine powder is moist, in another glass is moist; so that it is quite clear that this notion is hastily abstracted from water only, and common ordinary liquors, without any due verification of it.

There are, however, different degrees of distortion and mistake in words. One of the least faulty classes is that of the names of substances, particularly of the less abstract and more defined species those then of chalk and mud are good, of earth bad); words signifying actions are more faulty, as to generate, to corrupt, to change; but the most faulty are those denoting qualities (except the immediate objects of sense), as heavy, light, rare, dense. Yet in all of these there must be some notions a little better than others, in proportion as a greater or less number of things come before the senses.

LXI. The idols of the theatre are not innate, nor do they introduce themselves secretly into the understanding, but they are manifestly instilled and cherished by the fictions of theories and depraved rules of demonstration. To attempt, however, or undertake their confutation would not be consistent with our declarations. For since we neither agree in our principles nor our demonstrations, all argument is out of the question. And it is fortunate that the ancients are left in possession of their honors. We detract nothing from them, seeing our whole doctrine relates only to the 
path to be pursued. The lame (as they say) in the path outstrip the swift who wander from it, and it is clear that the very skill and swiftness of him who runs not in the right direction must increase his aberration.

Our method of discovering the sciences is such as to leave little to the acuteness and strength of wit, and indeed rather to level wit and intellect. For as in the drawing of a straight line, or accurate circle by the hand, much depends on its steadiness and practice, but if a ruler or compass be em. ployed there is little occasion for either; so it is with our method. Although, however, we enter into no individual confutations, yet a little must be said, first, of the sects and general divisions of these species of theories; secondly, something further to show that there are external signs of their weakness; and, lastiy, we must consider the causes of so great a misfortune, and so long and general a unanimity in error, that we may thus render the access to truth less difficult, and that the human understanding may the more readily be purified, and brought to dismiss its idols.

LXII. The idols of the theatre, or of theories, are numerous, and may, and perhaps will, be still more so. For un. less men's minds had been now occupied for many ages in religious and theological considerations, and civil governments (especially monarchies), had been averse to novelties of that nature even in theory. (so that men must apply to them with some risk and injury to their own fortunes, and not only without reward, but subject to contumely and envy), there is no doubt that many other sects of philoso. phers and theorists would have been introduced, like those which formerly flourished in such diversified abundance among the Greeks. For as many imaginary theories of the heavens can be deduced from the phenomena of the sky, so 
it is even more easy to found many dogmas upon the phenomena of philosophy-and the plot of this our theatre resembles those of the poetical, where the plots which are invented for the stage are more consistent, elegant, and pleasurable than those taken from real history.

In general, men take for the groundwork of their philosophy either too much from a few topies, or too little from many; in either case their philosophy is founded on too narrow a basis of experiment and natural history, and decides on too scanty grounds. For the theoretic philosopher seizes various common circumstances by experiment, without reducing them to certainty or examining and frequently considering them, and relies for the rest upon meditation and the activity of his wit.

There are other philosophers who have diligently and accurately attended to a few experiments, and have thence presumed to deduce and invent systems of philosophy, forming everything to conformity with them.

A third set, from their faith and religious veneration, introduce theology and traditions; the absurdity of some among them having proceeded so far as to seek and derive the sciences from spirits and genii. There are, therefore, three sources of error and three species of false philosophy; the sophistic, empiric, and superstitious.

LXIII. A ristotle affords the most eminent instance of the first; for he corrupted natural philosophy by logicthus he formed the world of categories, assigned to the human soul, the noblest of substances, a genus determined by words of secondary operation, treated of density and rarity (by which bodies occupy a greater or lesser space), by the frigid distinctions of action and power, asserted that there was a peculiar and proper motion in all bodies, and 
that if they shared in any other motion, it was owing to an external moving cause, and imposed innumerable arbitrary distinctions upon the nature of things; being everywhere more anxious as to definitions in teaching and the accuracy of the wording of his propositions, than the internal truth of things. And this is best shown by a comparison of his philosophy with the others of greatest repute among the Greeks. For the similar parts of Anaxagoras, the atoms of Leucippus and Democritus, the heaven and earth of Parmenides, the discord and concord of Empedocles, ${ }^{26}$ the reso. lution of bodies into the common nature of fire, and their condensation according to Heraclitus, exhibit some sprinkling of natural philosophy, the nature of things, and experiment; while Aristutle's physics are inere logical terms, and he remodelled the same subject in his metaphysics under a more imposing title, and more as a realist than a nominalist. Nor is much stress to be laid on his frequent recourse to ex. periment in his books on animals, his problems, and other treatises; for he had already decided, without having properly consulted experience as the basis of his decisions and axioms, and after having so decided, he drags experiment along as a captive constrained to accommodate herself to his decisions: so that he is even more to be blamed than his modern followers (of the scholastic school) who have deserted her altogether.

25 Empedocles, of Agrigentum, flourished 444 B.C. He was the disciple of Telanges the Pythagorean, and warmly adopted the doctrine of transmigration. He resolved the universe into the four ordinary elements, the principles of whose composition were life and happiness, or coneord and amity, but whose decomposition brought forth death and evil, or discord and hatred. Heraclitus held matter to be indifferent to any peculiar form, but as it became rarer or more dense, it took the appearance of fire, air, earth and water. Fire, how. ever, he believed to be the elementary principle out of which the others were ovolved. This was also the belief of Lucretius. See book i. 783, etc. 
IXIV. The empiric school produces dogmas of a more deformed and monstrous nature than the sophistic or theoretic school; not being founded in the light of common no. tions (which, however poor and superstitious, is yet in a manner universal, and of a general tendency), but in the confined obscurity of a few experiments. Hence this species of philosophy appears probable, and almost certain to those who are daily practiced in such experiments, and have thus corrupted their imagination, but incredible and futile to others. We have a strong instance of this in the alchemists and their dogmas; it would be difficult to find another in this age, unless perhaps in the philosophy of Gilbert. ${ }^{26}$ We could not, however, neglect to caution others against this school, because we already foresee and augur, that if men be hereafter induced by our exhortations to apply seriously to experiments (bidding farewell to the sophistic doctrines), there will then be imminent danger from empirics, owing to the premature and forward haste of the understanding, and its jumping or flying to generalities and the principles of things. We ought, therefore, already to meet the evil.

LXV. The corruption of philosophy by the mixing of it up with superstition and theology, is of a much wider extent, and is most injurious to it both as a whole and in parts. For the human understanding is no less exposed to the impressions of fancy, than to those of vulgar notions. The disputatious and sophistic school entraps the understanding, while the fanciful, bombastic, and, as it were, poetical school, rather flatters it. There is a clear example of this

${ }_{26} \mathrm{It}$ is thus the Vulcanists and Neptunians have framed their opposite theories in geology. Phrenology is a modern iustance of liasty generalization. -Ed. 
among the Greeks, especially in Pythagoras, where, however, the superstition is coarse and overcharged, but it is more dangerous and refined in Plato and his school. This evil is found also in some branches of other systems of philosophy, where it introduces abstracted forms, final and first causes, omitting frequently the intermediate and the like. Against it we must use the greatest caution; for the apotheosis of error is the greatest evil of all, and when folly is worshipped, it is, as it were, a plague spot upon the understanding. Yet some of the moderns have indulged this folly with such consummate inconsiderateness, that they have endeavored to build a system of natural philosophy on the first chapter of Genesis, the book of Job, and other parts of Scripture; seeking thus the dead among the living. ${ }^{27}$ And this folly is the more to be prevented and restrained, because not only fantastical philosophy, but heretical religion spring from the absurd mixture of matters divine and lhuman. It is therefore most wise soberly to render unto faith the things that are faith's.

LXVI. Maving spoken of the vicious authority of the systems founded either on vulgar notions, or on a few ex. periments, or on superstition, we must now consider the faulty subjects for contemplation, especially in natural philosophy. The human understanding is perverted by observing the power of mechanical arts, in which bodies are very materially changed by composition or separation, and is in. duced to suppose that something similar takes place in the universal nature of things. Hence the fiction of elements,

${ }^{27}$ In Scripture everything which concerns the passing interests of the body is called dead; the only living knowledge having regard to the eternal interest of the soul. $-E d$. 
and their co-operation in forming natural bodies. ${ }^{28}$ Again, when man reflects upon the entire liberty of nature, he meets with particular species of things, as animals, plants, minerals, and is thence easily led to imagine that there exist in nature certain primary forms which she strives to produce, and that all variation from them arises from some impediment or error wlich she is exposed to in completing her work, or from the collision or metamorphosis of different species. The first hypothesis has produced the doctrine of elementary properties, the second that of occult properties and specific powers; and both lead to trifling courses of reflection, in which the mind acquiesces, and is thus diverted from more important subjects. But physicians exercise a much more useful labor in the consideration of the secondary qualities of things, and the operations of attraction, repulsion, attenuation, inspissation, dilatation, astringency, separation, maturation, and the like; and would do still more if they would not corrupt these proper observations by the two systems I have alluded to, of elementary qualities and specific powers, by which they either reduce the secondary to first qualities, and their subtile and immeas.

28 In mechanics and the general sciences, causes compound their effects, or in other words, it is generally possible to deduce à priori the consequence of introducing complex agencies into any experiment, by allowing for the effect of each of the simple causes which enter into their composition. In chemistry and physiology a contrary law holds; the causes which they embody generally uniting to form distinct substances, and to introduce unforeseen laws and combinations. The deductive method here is consequently inapplicable, and we are forced back upon experiment.

Bacon in the text is hardly consistent with himself, as he admits in the second book the doctriue, to which modern discovery points, of the reciprocal transmutation of the elements. What seemed poetic fiction in the theories of Pythagoras and Seneca, assumes the appearance of scientific fact in the handa of Baron Caynard.-Ed. 
urable composition, or at any rate neglect to advance by greater and more diligent observation to the third and fourth qualities, thus terminating their contemplation prematurely. Nor are these powers (or the like) to be investigated only among the medicines for the human body, but also in all changes of other natural bodies.

A greater evil arises from the contemplation and investigation rather of the stationary principles of things from which, than of the active by which things themselves are created. For the former only serve for discussion, the latter for practice. Nor is any value to be set on those common differences of motion which are observed in the received system of natural philosophy, as generation, corruption, aug. mentation, diminution, alteration, and translation. For this is their meaning: if a body, unchanged in other respects, is moved from its place, this is translation; if the place and species be given, but the quantity changed, it is alteration; but if, from such a change, the mass and quantity of the body do not continue the same, this is the motion of augmentation and diminution; if the change be continued so as to vary the species and substance, and transfuse them to others, this is generation and corruption. All this is merely popular, and by no means penetrates into nature; and these are but the measures and bounds of motion, and not different species of it; they merely suggest how far, and not how or whence. For they exhibit neither the affections of bodies nor the process of their parts, but merely establish a division of that motion, which coarsely exhibits to the senses matter in its varied form. Even when they wish to point out something relative to the causes of motion, and to establish a division of them, they most absurdly introduce natural and violent motion, which is also a popular notion, 
since every violent motion is also in fact natural, that is to say, the external efficient puts nature in action in a different manner to that which she had previously employed.

But if, neglecting these, any one were, for instance, to observe that there is in bodies a tendency of adhesion, so as not to suffer the unity of nature to be completely separated or broken, and a vacuum ${ }^{29}$ to be formed, or that they have a tendency to retuin to their natural dimensions or tension, so that, if compressed or extended within or beyond it, they immediately strive to recover themselves, and resume their former volume and extent; or that they have a tendency to congregate into masses with similar bodies-the dense, for instance, toward the circumference of the earth, the thin and rare toward that of the heavens. These and the like are true physical genera of motions, but the others are clearly logical and scholastic, as appears plainly from a comparison of the two.

Another considerable evil is, that men in their systems and contemplations bestow their labor upon the investigation and discussion of the principles of things and the extreme limits of nature, although all utility and means of action consist in the intermediate objects. Hence men cease not to abstract nature till they arrive at potential and shapeless matter, ${ }^{30}$ and still persist in their dissection, till

29 Galileo had recently adopted the notion that nature abhorred a vacuum for an axiomatic principle, and it was not till Torricelli, his disciple, had given practical proof of the utility of Bacon's method, by the discovery of the barom. eter (1643) that this error, as also that expressed below, and believed by Bacon, concerning the homocopathic tendencies of bodies, was destroyed.-Ed.

${ }^{30}$ Donec ad materiam potentialem et informem ventum fuerit. Nearly all the ancient philosophers admitted the existence of a certain primitive and shapeless matter as the substratum of things which the creative power had reduced to fixed proportions, and resolved into specific substances. The ex- 
they arrive at atoms; and yet were all this true, it would be of little use to advance man's estate.

LXVII. The understanding must also be cautioned against the intemperance of systems, so far as regards its giving or withholding its assent; for such intemperance appears to fix and perpetuate idols, so as to leave no means of removing them.

These excesses are of two kinds. The first is seen in those who decide hastily, and render the sciences positive and dictatorial. The other in those who have introduced scepticism, and vague unbounded inquiry. The former subdues, the latter enervates the understanding. The Aristotelian philosophy, after destroying other systems (as the Ottomans ${ }^{31}$ do their brethren) by its disputatious confutations, decided upon everything, and Aristotle himself then raises up questions at will, in order to settle them; so that everything should be certain and decided, a method now in use among his successors.

The school of Plato introduced scepticism, first, as it were in joke and irony, from their dislike to Protagoras, Hippias, ${ }^{32}$ and others, who were ashamed of appearing not

pression potential matter refers to that substance forming the basis of the Peripatetic system, which virtually contained all the forms that it was in the power of the efficient cause to draw out of it. $-E d$.

31 An allusion to the humanity of the Sultans, who, in their earlier histories are represented as signalizing their accession to the throne by the destruction of their family, to remove the danger of rivalry and the terrors of civil war. $-E d$.

32 The text is "in odium veterum sophistarum, Protagoræ, Hippiæ, et reliquorum." Those were called sophists, who, ostentationis aut questus causa philosophatantur. (Acad. Prior, ii. 22.) They had corrupted and degraded philosophy before Socrates. Protagoras of Abdera ("A $A \delta \eta \rho \alpha$ ), the most celebrated, taught that man is the measure of all things, by which he meant not only that all which can be known is known only as it related to our faculties, but also that apart from our faculties nothing can be known. The sceptics 
to doult upon any subject. But the new academy dogmatized in their scepticism, and held it as their tenet. Although this method be more honest than arbitrary decision (for its followers allege that they by no means confound all inquiry, like Pyrrho and his disciples, but hold doctrines which they can follow as probable, though they cannot maintain them to be true), yet when the human mind has once despaired of discovering truth, everything begins to languish. Hence men turn aside into pleasant controversies and discussions, and into a sort of wandering over subjects rather than sustain any rigorous investigation. But as we observed at first, we are not to deny the authority of the human senses and understanding, although weak, but rather to furnish them with assistance.

LXVIII. We have now treated of each kind of idols, and their qualities, all of which must be abjured and re. nounced with firm and solemn resolution, and the under. standing must be completely freed and cleared of them, so that the access to the kingdom of man, which is founded on the sciences, may resemble that to the kingdom of heaven, where no admission is conceded except to children.

LXIX. Vicious demonstrations are the muniments and support of idols, and those which we possess in logic, merely subject and enslave the world to human thoughts, and thoughts to words. But demonstrations are in some manner themselves systems of philosophy and science; for such as they are, and accordingly as they are regularly or im.

equaliy held that knowledge was probable only as it related to our faculties, but they stopped there, and did not, like the sophist, dogmatize about the unknown. The works of Protagoras were condemned for their impiety, and aublicly burned by the xdiles of Athens, who appear to have discharged the fice of common hangmen to the literary blasphemers of their day. $-E d$. 
properly established, such will be the resulting systems of philosophy and contemplation. But those which we employ in the whole process leading from the senses and things to axioms and conclusions, are fallacious and incompetent. This process is fourfold, and the errors are in equal number. In the first place the impressions of the senses are erroneous, for they fail and deceive us. We must supply defects by substitutions, and fallacies by their correction. Secondly, notions are improperly abstracted from the senses, and indeterminate and confused when they ought to be the reverse. Thirdly, the induction that is employed is im. proper, for it determines the principles of sciences by simple enumeration, ${ }^{33}$ without adopting exclusions and resolutions, or just separations of nature. Lastly, The usual method of discovery and proof, by first establishing the most general propositions, then applying and proving the intermediate axioms according to them, is the parent of error and the calamity of every science. But we will treat more fully

33 Bacon is hardly correct in implying that the enumerationem per simplicem was the only light in which the ancients looked upon induction, as they appear to have regarded it as only one, and that the least important, of its species. Aristolle expressly considers induction in a perfect or dialectic sense, and in an imperfect or rhetorical sense. Thus if a genus (G), contains four species $(A, B, C, D)$, the syllogism would lead us to infer, that what is true of $G$, is true of any one of the four. But perfect induction would reason, that what we can prove of $A, B, C, D$, separately, we may properly state as true of $G$, the whole genus. This is evidently a formal argument as demonstrative as the syllogism. In necessary matters, however, legitimate induction may claim a wider province, and infer of the whole genus what is only apparent in a part of the species. Such are those inductive inferences which concern the laws of nature, the immutability of forms, by which Bacon strove to erect his new system of plilosoplyy. The Stagyrite, however, looked upon enumerationem per simpli. cem. without any regard to the nature of the matter, or to the completeness of the species, with as much reprehensive caution as Bacon, and guarded his readers against it as the source of innumerable errors. $-E d$. 
of that which we now slightly touch upon, when we come to lay down the true way of interpreting nature, after having gone through the above expiatory process and purification of the mind.

LXX. But experience is by far the best demonstration, provided it adhere to the experiment actually made, for if that experiment be transferred to other subjects apparently similar, unless with proper and methodical caution it becornes fallacious. The present method of experiment is blind and stupid; hence men wandering and roaming without any determined course, and consulting mere chance, are hurried about to various points, and advance but little -at one time they are happy, at another their attention is distracted, and they always find that they want something further. Men generally make their experiments carelessly, and as it were in sport, making some little variation in a known experiment, and then if they fail they become disgusted and give up the attempt; nay, if they set to work more seriously, steadily, and assiduously, yet they waste all their time on probing sorne solitary matter, as Gilbert on the magnet, and the alchemists on gold. But such conduct shows their method to be no less unskilful than mean; for nobody can successfully investigate the nature of any object by considering that object alone; the inquiry must be more generally extended.

Even when men build any science and theory upon experiment, yet they almost always turn with premature and hasty zeal to practice, not merely on account of the advan. tage and benefit to be derived from it, but in order to seize upon some security in a new undertaking of their not employing the remainder of their labor unprofitably, and by making themselves conspicuous, to acquire a greater name 
for their pursuit. Hence, like Atalanta, they leave the course to pick up the golden apple, interrupting their speed, and giving up the victory. But in the true course of experiment, and in extending it to new effects, we should imitate the Divine foresight and order; for God on the first day only created light, and assigned a whole day to that work without creating any material substance thereon. In like manner we must first, by every kind of experiment, elicit the discovery of causes and true axioms, and seek for experiments which may afford light rather than profit. Axioms, when rightly investigated and established, prepare us not for a limited but abundant practice, and bring in their train whole troops of effects. But we will treat hereafter of the ways of experience, which are not less beset and interrupted than those of judgment; having spoken at present of common experience only as a bad species of demonstration, the order of our subject now requires some mention of those external signs of the weakness in practice of the received systems of philosophy and conteinplation ${ }^{34}$ which we referred to above, and of the causes of a circumstance at first sight so wonderful and incredible. For the knowledge of these external signs prepares the way for assent, and the explanation of the causes removes the wonder; and these two circumstances are of material use in extirpating more easily and gently the idols from the understanding.

LXXI. The sciences we possess have been principally derived from the Greeks; for the addition of the Roman, Arabic, or more modern writers, are but few and of small importance, and such as they are, are founded on the basis

${ }^{24}$ See Ax. lxi. toward the end. This subject extends to Ax. Ixxviii. 
of Greek invention. But the wisdom of the Greeks was professional and disputatious, and thus most adverse to the investigation of truth. The name, therefore, of sophists, which the contemptuous spirit of those who deemed themselves philosophers, rejected and transferred to the rhetoricians-Gorgias, ${ }^{35}$ Protagoras, Hippias, Polus-might well suit the whole tribe, such as Plato, Aristotle, Zeno, Epicurus, Theophrastus, and their successors-Chrysippus, Carneades, and the rest. There was only this difference between them - the former were mercenary vagabonds, travelling about to different states, making a show of their wisdom, and requiring pay; the latter more dignified and noble, in possession of fixed habitations, opening schools, and teaching philosophy gratuitously. Both, however (though differing in other respects), were professorial, and reduced every subject to controversy, establishing and defending certain sects and dogmas of philosophy, so that their doctrines were nearly (what Dionysius not unaptly objected to Plato) the talk of idle old men to ignorant youths. But the more ancient Greeks, as Empedocles, Anaxagoras, Leucippus, Democritus, Parmenides, Heraclitus, Xenophanes, Philolaus, and the rest ${ }^{36}$ (for I omit Pythagoras as being superstitious),

35 Gorgias of Leontium went to Athens in $42 \pm$ B.C. He and Polus were disciples of Empedocles, whom we hive already noticed (Aphorism 63), where ho - ustained the three famous propositions, that nothing exists, that nothing can be Inown, and that it is ont of the power of man to transmit or communicate intelligence. Ile is reckoned one of the earliest writers on the art of rhetoric, and firr that reason, Plato called his elegant dialogue on that subject after his name.

${ }^{35}$ Chrysippus, a stoic plilosopher of Soli in Cilicia, Campestris, born in 230 , ated in the 143d Olympiad, 208 B.C. He was equally distinguished for natural rilities and industry, seldom suffering a day to elapse without writing 500 ines. He wrote several hundred volumes, of which three hundred were on lingical subjects; but in all, borrowed largely from others. He was very fond 6) the sorites in argument, which is hence called by Persius the heap of Chry- 


\section{did not (that we are aware) open schools, but betook them.} selves to the investigation of truth with greater silence and with more severity and simplicity, that is, with less affectation and ostentation. Hence in our opinion they acted more advisedly, however their works may have been eclipsed in course of time by those lighter productions which better correspond with and please the apprehensions and passions of the vulgar; for time, like a river, ${ }^{87}$ bears down to us that

sippus. He was called the Column of the Portico, a name given to the Stoical School from Zeno, its founder, who had given bis lessons under the portico.

Carneades, born about 215, died in 130 . He attached himself to Chrysip. pus, and sustained with éclat the scepticism of the academy. The Athenianssent him with Critolans and Diogenes as ambassador to Rome, where he attracted the atteution of his new auditory by the subtilty of his reasoning, and the fluency and vehemence of his language. Before Galba and Cato the Censor, lie harangued with great variety of thought and copiousness of diction in praise of justice. The next dar, to estublish his doctrine of the uncertainty of human knowledge, he undertook to refute all his arguments. He maintained with the New Academy, that the senses, the imagination, and the understanding frequently deccive us, and therefore cannot be infallible judges of truth, but that from the impressions produced on the mind by means of the senses, we infer appearances of truth or probabilities. Nevertheless, with respect to the conduct of life, Carneades held that probable opinions are a sufficient guide.

Xenophanes, a Greek philosopher, of Colophon, born in 556, the founder of the Eleatic school, which owes its fame principally to Parmenides. Wild in his opinions about astronomy, he supposed that the stars were extinguished every morning, and rekindled at night; that eclipses were oceasioued by the temporary extinction of the sun, and that there were several suns for the couvenience of the different climates of the earth. Yet this man held the chair of philosophy at Athens for seventy years.

Philolaus, a Pythagorean philosopher of Crotona, B.C. 374 . ITe first supported the diurnal motion of the earth round its axis, and its ammal motion round the sun. Cicero (Acad. iv. 39) has ascribed this opinion to the Syractisan philosopher Nicetas, and likewise to Plato. From this passage, it is must probable that Copernicus got the idea of the system he afterward cstablished. Bacon, in the Advancement of Human Learning, charges Gillbert with restoring the doctrines of Philolaus, becanse he ventured to support the Copernican theory. $-E d$.

37 Bacon is equally conspicuous for the use and abusc of anatogical illustratious. The levity, as Stuart Mill very properly observes, by which substanees 
which is light and inflated, and sinks that which is heavy and solid. Nor were even these more ancient philosophers free from the national defect, but inclined too much to the ambition and vanity of forming a sect, and captivating public opinion, and we must despair of any inquiry after truth when it condescends to such trifles. Nor must we omit the opinion, or rather prophecy, of an Egyptian priest with regard to the Greeks, that they would forever remain children, without any antiquity of knowledge or knowledge of antiquity; for they certainly have this in common with children, that they are prone to talking, and incapable of generation, their wisdorn being loquacious and unproductive of effects. Hence the external signs derived from the origin and birthplace of our present philosophy are not favorable.

LXXII. Nor are those much better which can be deduced from the character of the time and age, than the former from that of the country and nation; for in that age the knowledge both of time and of the world was confined and meagre, which is one of the worst evils for those who rely entirely on experience-they had not a thousand years of history worthy of that name, but mere fables and ancient raditions; they were acquainted with but a small portion of the regions and countries of the world, for they indisriminately called all nations situated far toward the north cythians, all those to the west Celts; they knew nothing ? Africa but the nearest part of Ethiopia, or of Asia be-

fint on a stream, and the levity which is synonymous with worthlessness, have m.... ing beside the name in common; and to show how little value there is in th. igure, we need only change the word into buoyancy, to turn the semblance of Lacon's argument against himself-Ed. 
yond the Ganges, and had not even heard any sure and clear tradition of the regions of the New World. Besides, a vast number of climates and zones, in which innumerable nations live and breathe, were pronounced by them to be uninhabitable; nay, the travels of Democritus, Plato, and Pythagoras, which were not extensive, but rather mere excursions from home, were considered as something vast. But in our times many parts of the New World, and every extremity of the Old, are well known, and the mass of experiments has been infinitely increased; wherefore, if external signs were to be taken from the time of the nativity or procreation (as in astrology), nothing extraordinary could be predicted of these early systems of philosophy.

LXXIII. Of all signs there is none more certain or worthy than that of the fruits produced, for the fruits anci effects are the sureties and vouchers, as it were, for the truth of philosophy. Now, from the systems of the Greeks, and their subordinate divisions in particular branches of the sciences during so long a period, scarcely one single experi. ment can be culled that has a tendency to elevate or assist mankind, and can be fairly set down to the speculations and doctrines of their philosophy. Celsus candidly and wisely confesses as much, when he observes that experiments were first discovered in medicine, and that men afterward built their philosophical systems upon them, and searched for and assigned causes, instead of the inverse method of discovering and deriving experiments from philosophy and the knowledge of causes; it is not, therefore, wonderful that the Egyptians (who bestowed divinity and sacred honors on the authors of new inventions) should have consecrated more images of brutes than of men, for the brutes by their natural instinct made many discoveries, 
while men derived but few from discussion and the conclusions of reason.

The industry of the alchemists has produced some effect, by chance, however, and casualty, or from varying their experiments (as mechanics also do), and not from any regular art or theory, the theory they have imagined rather tending to disturb than to assist experiment. Those, too, who have occupied themselves with natural magic (as they term it) have made but few discoveries, and those of small import, and bordering on imposture; for which reason, in the same manner as we are cautioned by religion to show our faith by our works, we may very properly apply the principle to philosophy, and judge of it by its works, accounting that to be futile which is unproductive, and still more so if, instead of grapes and olives, it yield but the thistle and thorns of dispute and contention.

LXXIV. Other signs may be selected from the increase and progress of particular systems of philosophy and the sciences; for those which are founded on nature grow and increase, while those which are founded on opinion change and increase not. If, therefore, the theories we have mentioned were not like plants, torn up by the roots, but grew in the womb of nature, and were nourished by her, that which for the last two thousand years has taken place would never have happened, namely, that the sciences still continue in their beaten track, and nearly stationary, without having received any important increase, nay, having, on the contrary, rather bloomed under the hands of their first author, and then faded away. But we see that the case is reversed in the mechanical arts, which are founded on nature and the light of experience, for they (as long as they are popular) seem full of life, and uninterruptedly thrive and 
grow, being at first rude, then convenient, lastly polished, and perpetually improved.

LXXV. There is yet another sign (if such it may be termed, being rather an evidence, and one of the strongest nature), namely, the actual confession of those very authorities whom men now follow; for even they who decide on things so daringly, yet at times, when they reflect, betake themselves to complaints about the subtilty of nature, the obscurity of things, and the weakness of man's wit. If they would merely do this, they might perhaps deter those who are of a timid disposition from further inquiry, but would excite and stimulate those of a more active and confident turn to further advances. They are not, however, satisfied with confessing so much of themselves, but consider every. thing which has been either unknown or unattempted by themselves or their teachers, as beyond the limits of possibility, and thus, with most consummate pride and envy, convert the defects of their own discoveries into a calumny on nature and a source of despair to every one else. Hence arose the New Academy, which openly professed scepticism, ${ }^{38}$ and consigned mankind to eternal darkness; hence the notion that forms, or the true differences of things (which are in fact the laws of simple action), are beyond man's

38 We have before observed, that the New Academy did not profess skep-

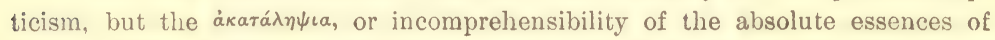
things. Even modern physicists are not wanting, to assert with this school that the utmost knowledge we can obtain is relative, and necessarily short of absolute certainty. It is not without an appearance of truth that these philosophers maintain that our ideas and perceptions do not express the nature of the things which they represent, but only the effects of the peculiar organs by which they are conveyed to the understanding, so that were these organs changed, we should have different conceptions of their nature. That constitu. tion of air which is dark to man is luminous to bats and owls. 
reach, and cannot possibly be discovered; hence those notions in the active and operative branches, that the heat of the sun and of fire are totally different, so as to prevent men from supposing that they can elicit or form, by means of fire, anything similar to the operations of nature; and again, that composition only is the work of man and mixture of nature, so as to prevent men from expecting the generation or transformation of natural bodies by art. Men will, therefore, easily allow themselves to be persuaded by this sign not to engage their fortunes and labor in speculations, which are not only desperate, but actually devoted to des. peration.

LXXVI. Nor should we omit the sign afforded by the great dissension formerly prevalent among philosophers, and the variety of schools, which sufficiently show that the way was not well prepared that leads from the senses to the understanding, since the same groundwork of philosophy (namely, the nature of things), was torn and divided into such widely differing and multifarious errors. And al. though in these days the dissensions and differences of opinions with regard to first principles and entire systems are neaily extinct, ${ }^{39}$ yet there remain innumerable questions and controversies with regard to particular branches of philosophy. So that it is manifest that there is nothing sure or sound either in the systems themselves or in the methods of demonstration. ${ }^{40}$

LXXVII. With regard to the supposition that there is a general unanimity as to the philosophy of Aristotle, because

38 Owing to the universal prevalence of Aristotelism.

40 It must be remembered, that when Bacon wrote, algebra was in its sfancy, and the doctrine of units and infinitesimals undiscovered. 
the other systems of the ancients ceased and became obsolete on its promulgation, and nothing better has been since discovered; whence it appears that it is so well determined and founded, as to have united the suffrages of both ages; we will observe-1st. That the notion of other ancient systems having ceased after the publication of the works of Aristotle is false, for the works of the ancient philosophers subsisted long after that event, even to the time of Cicero, and the subsequent ages. But at a later period, when human learning had, as it were, been wrecked in the inundation of barbarians into the Roman empire, then the systems of Aristotle and Plato were preserved in the waves of ages, like planks of a lighter and less solid nature. 2d. The notion of unanimity, on a clear inspection, is found to be fallacious. For true unanimity is that which proceeds from a free judgment, arriving at the same conclusion, after an investigation of the fact. Now, by far the greater number of those who have assented to the philosophy of Aristotle, have bound themselves down to it from prejudice and the authority of others, so that it is rather obsequiousness and concurrence than unanimity. But even if it were real and extensive unanimity, so far from being esteemed a trut and solid confirmation, it should even lead to a violent pre sumption to the contrary. For there is no worse augury iri intellectual matters than that derived from unanimity, witl the exception of divinity and politics, where suffrages are allowed to decide. For nothing pleases the multitude, un. less it strike the imagination or bind down the understand. ing, as we have observed above, with the shackles of vulga notions. Hence we may well transfer Phocion's remark from morals to the intellect: "That men should immediately examine what error or fault they have committed, when the 
multitude concurs with, and applauds them." ${ }^{41}$ This then is one of the most unfavorable signs. All the signs, therefore, of the truth and soundness of the received systems of philosophy and the sciences are unpropitious, whether taken from their origin, their fruits, their progress, the confessions of their authors, or from unanimity.

LXXVIII. We now come to the causes of errors, ${ }^{42}$ and of such perseverance in them for ages. These are sufficiently numerous and powerful to remove all wonder, that what we now offer should have so long been concealed from, and have escaped the notice of mankind, and to render it more worthy of astonishment, that it should even now have entered any one's mind, or become the subject of his thoughts; and that it should have done so, we consider rather the gift of fortune than of any extraordinary talent, and as the offspring of time rather than wit. But, in the first place, the number of ages is reduced to very narrow limits, on a proper consideration of the matter. For out of twenty-five ${ }^{43}$ centuries, with which the memory and learn-

41 Because the vulgar make up the overwhelming majority in such decisions, and generally allow their judgments to be swayed by passion or prejudice.

42 See end of Axiom lxi. The subject extends to Axiom xc.

43 If we adopt the statement of Herodotus, who places the Homeric era 400 years back from his time, Homer lived about 900 years before Christ. On adding this number to the sixteen centuries of the Christian era which had elapsed up to Bacon's time, we get the twenty-five centuries he mentions. The Homeric epoch is the furthest point in antiquity from which Bacon could reckon with any degree of certainty. Hesiod, if he were not contemporary, immediately preceded him.

The epoch of Greek philosophy may be included between Thales and Plato, that is, from the 35 th to the 88th Olympiad; that of the Roman, between Terence and Pliny. The modern revolution, in which Bacon is one of the central figures, took its rise from the timo of Dante and Petrarch, who lived at the commencement of the fourteenth century; and to which, on account of the invention of printing, and the universal spread of literature, which has ren- 
ing of man are conversant, scarcely six can be set apart and sclected as fertile in science and favorable to its progress. For there are deserts and wastes in times as in countries, and we can only reckon up three revolutions and epochs of philosophy. 1. The Greek. 2. The Roman. 3. Our own, that is the philosophy of the western nations of Europe: and scarcely two centuries can with justice be assigned to each. The intermediate ages of the world were unfortunate both in the quantity and richness of the sciences produced. Nor need we mention the Arabs, or the scholastic philoso. phy, which, in those ages, ground down the sciences by their numerous treatises, more than they increased their meight. The first cause, then, of such insignificant progress in the sciences, is rightly referred to the small proportion of time which has been favorable thereto.

LXXIX. A second cause offers itself, which is certainly of the greatest importance; namely, that in those very ages in which men's wit and literature flourished considerably, or even inoderately, but a small part of their industry was bestowed on natural philosophy, the great mother of the sciences. For every art and science torn from this root may, perhaps, be polished, and put into a serviceable shape, but can admit of little growth. It is well known, that after the Christian religion had been acknowledged, and arrived at maturity, by far the best wits were busied upon theology, where the highest rewards offered themselves, and every species of assistance was abundantly supplied, and the study of which was the principal occupation of the western European nations during the third epoch; the rather because

dered a sceond destruction of learning impossible, it is difficult to foresee any other end than the extinction of the race of man. $-E d$. 
literature flourished about the very time when controversies concerning religion first began to bud forth. 2 . In the preceding ages, during the second epoch (that of the Romans), philosophical meditation and labor was chiefly occupied and wasted in moral philosophy (the theology of the heathens): besides, the greatest minds in these times applied themselves to civil affairs, on account of the magnitude of the Roman empire, which required the labor of many. 3. The age during which natural philosophy appeared principally to flourish among the Greeks, was but a short period, since in the more ancient times the seven sages (with the exception of Thales), applied themselves to moral philosophy and politics, and at a later period, after Socrates had brought down philosophy from heaven to earth, moral philosophy became more prevalent, and diverted men's attention from natural. Nay, the very period during which physical inquiries flourished, was corrupted and rendered useless by contradictions, and the ambition of new opinions. Since, therefore, during these three epochs, natural philosophy has been materially neglected or impeded, it is not at all surprising that men should have made but little progress in it, seeing they were attending to an entirely different matter.

LXXX. Add to this that natural philosophy, especially of late, has seldom gained exclusive possession of an individual free from all other pursuits, even among those who have applied themselves to it, unless there may be an example or two of some monk studying in his cell, or some nobleman in his villa. ${ }^{44}$ She has rather been made a passage and bridge to other pursuits.

44 The allusion is evidently to Roger Bacon and Réné Descartes. - Ed. 
Thus has this great mother of the sciences been degraded. most unworthily to the situation of a handmaid, and made to wait upon medicine or mathenatical operations, and to wash the immature minds of youth, and imbue them with a first dye, that they may afterward be more ready to receive and retain another. In the meantime, let no one expect any great progress in the sciences (especially their operative part), unless natural philosophy be applied to particular sciences, and particular sciences again referred back to natural philosophy. For want of this, astronomy, optics, music, many mechanical arts, medicine itself, and (what perhaps is more wonderful), moral and political philosophy, and the logical sciences have no depth, but only glide over the surface and variety of things; because these sciences, when they have been once partitioned out and established, are no longer nourished by natural philosophy, which would have imparted fresh vigor and growth to them from the sources and genuine contemplation of motion, rays, sounds, texture, and conformation of bodies, and the affections and capacity of the understanding. But we can little wonder that the sciences grow not when separated from their roots.

LXXXI. There is another powerful and great cause of the little advancement of the sciences, which is this; it is impossible to advance properly in the course when the goal is not properly fixed. But the real and legitimate goal of the sciences is the endowment of human life with new inventions and riches. The great crowd of teachers know nothing of this, but consist of dictatorial hirelings; unless it so happen that some artisan of an acute genius, and ambitious of fame, gives up his time to a new discovery, which is generally attended with a loss of property. The majority, so far from proposing to themselves the augmentation 
of the mass of arts and sciences, make no other use of an inquiry into the mass already before them, than is afforded by the conversion of it to some use in their lectures, or to gain, or to the acquirement of a name, and the like. But if one out of the multitude be found, who courts science from real zeal, and on his own account, even he will be seen rather to follow contemplation, and the variety of theories, than a severe and strict investigation of truth. Again, if there even be an unusually strict investigator of truth, yet will he propose to himself, as the test of truth, the satisfaction of his mind and understanding, as to the causes of things long since known, and not such a test as to lead to some new earnest of effects, and a new light in axioms. If, therefore, no one have laid down the real end of science, we cannot wonder that there should be error in points subordinate to that end.

LXXXII. But, in like manner, as the end and goal of science is ill defined, so, even were the case otherwise, men have chosen an erroneous and impassable direction. For it is sufficient to astonish any reflecting mind, that nobody should have cared or wished to open and complete a way for the understanding, setting off from the senses, and regular, well-conducted experiment; but that everything has been abandoned either to the mists of tradition, the whirl and con. fusion of argument, or the waves and mazes of chance, and desultory, ill-combined experiment. Now, let any one but consider soberly and diligently the nature of the path men have been accustomed to pursue in the investigation and discovery of any matter, and he will doubtless first observe the rude and inartificial manner of discovery most familiar to mankind: which is no other than this. When any one prepares himself for discovery, he first inquires and obtains 
a full account of all that has been said on the subject by others, then adds his own reflections, and stirs up and, as it were, invokes his own spirit, after much mental labor, to disclose its oracles. All which is a method without foundation, and merely turns on opinion.

Another, perhaps, calls in logic to assist him in discovery, which bears only a nominal relation to his purpose. For the discoveries of logic are not discoveries of principles and leading axioms, but only of what appears to accord with them. ${ }^{45}$ And when men become curious and importunate, and give trouble, interrupting her about her proofs, and the discovery of principles or first axioms, she puts them off with her usual answer, referring them to faith, and ordering them to swear allegiance to each art in its own department.

There remains but mere experience, which, when it offers itself, is called chance; when it is sought after, experiment. ${ }^{46}$ But this kind of experience is nothing but a loose fagot; and mere groping in the dark, as men at night try all means of liscovering the right road, while it would be better and more prudent either to wait for day, or procure a light, and then proceed. On the contrary, the real order of experience begins by setting up a light, and then shows the road by it, commencing with a regulated and digested, not a misplaced and vague course of experiment, and thence deducing axioms, and from those axioms new experiments: for not even the Divine Word proceeded to operate on the general mass of things without due order.

Let men, therefore, cease to wonder if the whole course

45 From the abuse of the scholasties, who mistook the $a$ priori method, the deductive syllogism, for the entire province of logic. $-E d$.

46 See Apliorism xcv. 
of science be not run, when all have wandered from the path; quitting it entirely, and deserting experience, or involving themselves in its mazes, and wandering about, while a regularly combined system would lead them in a sure track through its wilds to the open day of axioms.

LXXXIII. The evil, however, has been wonderfully increased by an opinion, or inveterate conceit, which is both vainglorious and prejudicial, namely, that the dignity of the human mind is lowered by long and frequent intercourse with experiments and particulars, which are the objects of sense, and confined to matter; especially since such matters generally require labor in investigation, are mean subjects for meditation, harsh in discourse, unproductive in practice, infinite in number, and delicate in their subtilty. Hence we have seen the true path not only deserted, but intercepted and blocked up, experience being rejected with disgust, and not merely neglected or improperly applied.

LXXXIV. Again, the reverence for antiquity, ${ }^{47}$ and the authority of men who have been esteemed great in philosophy, and general unanimity, have retarded men from advancing in science, and almost enchanted them. As to unanimity, we have spoken of it above.

The opinion which men cherish of antiquity is altogether idle, and scarcely accords with the term. For the old age and increasing years of the world should in reality be considered as antiquity, and this is rather the character of our own times than of the less advanced age of the world in those of the ancients; for the latter, with respect to our-

47 The incongruity to which Bacon alludes appears to spring from confounding two things, which are not only distinct, but affect human knowledge in inverse proportion, viz., the experience which terminates with life, with that experience which one century transmits to another.-Ed. 
selves, are ancient and elder, with respect to the world modern and younger. And as we expect a greater knowledge of human affairs, and more mature judgment from an old man than from a youth, on account of his experience, and the variety and number of things he has seen, heard, and meditated upon, so we have reason to expect much greater things of our own age (if it knew but its strength and would essay and exert it) than from antiquity, since the world has grown older, and its stock has been increased and accumulated with an infinite number of experiments and observations.

We must also take into our consideration that many ob. jects in nature fit to throw light upon philosophy have been exposed to our view, and discovered by means of long voyages and travels, in which our times have abounded. It would, indeed, be dishonorable to mankind, if the regions of the material globe, the earth, the sea, and stars, should be so prodigiously developed and illustrated in our age, and Jet the boundaries of the intellectual globe should be confined to the narrow discoveries of the ancients.

With regard to authority, it is the greatest weakness to attribute infinite credit to particular authors, and to refuse his own prerogative to time, the author of all authors, and, therefore, of all authority. For truth is rightly named the daughter of time, not of authority. It is not wonderful, therefore, if the bonds of antiquity, authority, and unanimity, have so enchained the power of man, that he is unable (as if bewitched) to become familiar with things themselves.

LXXXV. Nor is it only the admiration of antiquity, authority, and unanimity, that has forced man's indust:y to rest satisfied with present discoveries, but, also, the a.tmiration of the effects alrealy placed within his power. F.r. 
whoever passes in review the variety of subjects, and the beautiful apparatus collected and introduced by the mechanical arts for the service of mankind, will certainly be rather inclined to admire our wealth than to perceive our poverty: not considering that the observations of man and operations of nature (which are the souls and first movers of that variety) are few, and not of deep research; the rest must be attributed merely to man's patience, and the delicate and well-regulated motion of the hand or of instruments. To take an instance, the manufacture of clocks is delicate and accurate, and appears to imitate the heavenly bodies in its wheels, and the pulse of animals in its regular oscillation, yet it only depends upon one or two axioms of nature.

Again, if one consider the refinement of the liberal arts, or even that exhibited in the preparation of natural bodies in mechanical arts and the like, as the discovery of the heavenly motions in astronomy, of harmony in music, of the letters of the alphabet ${ }^{48}$ (still unadopted by the Chinese) in grammar; or, again, in mechanical operations, the productions of Bacchus and Ceres, that is, the preparation of wine and beer, the making of bread, or even the luxuries of the table, distillation, anc the like; if one reflect also, and consider for how long a period of ages (for all the above, except distillation, are ancient) these things have been brought to their present state of perfection, and (as we instanced in clocks) to how few observations and axioms of nature they may be referred, and how easily, and as it were, by obvious chance or contemplation, they might be discovered, one

48 The Chinese characters resemble, in many respects, the hieroglyphics of the Egyptians, being adapted to represent ideas, not sounds. 
would soon cease to admire and rather pity the human lot on account of its vast want and dearth of things and discov. eries for so many ages. Yet even the discoveries we have mentioned were more ancient than philosophy and the intellectual arts; so that (to say the truth) when contemplation. and doctrinal science began, the discovery of useful works ceased.

But if any one turn from the manufactories to libraries, and be inclined to admire the immerse variety of books offered to our view, let him but examine and diligently inspect the matter and contents of these books, and his astonishment will certainly change its object: for when he finds no end of repetitions, and how much men do and speak the same thing over again, he will pass from admiration of this variety to astonishment at the poverty and scarcity of matter, which has hitherto possessed and filled men's minds.

But if any one should condescend to consider such sci. ences as are deemed rather curious than sound, and take a full view of the operations of the alchemists or magii, he will perhaps hesitate whether he ought rather to laugh or to weep. For the alchemist cherishes eternal hope, and when his labors succeed not, accuses his own mistakes, deeming, in his self-accusation, that he has not properly understood the words of art or of his authors; upon which he listens to tradition and vague whispers, or imagines there is some slight unsteadiness in the minute letails of his practice, and then has recourse to an endless repetition of experiments: and in the meantime, when, in his casual experiments, he falls mpon something in appearance new, or of some degree of utility, he consoles himself with such an earnest, and ostentatiously publishes them, keeping up his hope of the final result. Nor can it be denied that the alche. 
mists have made several discoveries, and presented mankind with useful inventions. But we may well apply to them the fable of the old man, who bequeathed to his sons some gold buried in his garden, pretending not to know the exact spot, whereupon they worked diligently in digging the vineyard, and though they found no gold, the vintage was rendered more abundant by their labor.

The followers of natural magic, who explain everything by sympathy and antipathy, have assigned false powers and marvellous operations to things by gratuitous and idle con. jectures: and if they have ever produced any effects, they are rather wonderful and novel than of any real benefit or utility.

In superstitious magic (if we say anything at all about it) we must chiefly observe, that there are only some peculiar and definite objects with which the curious and superstitious arts have, in every nation and age, and even under every religion, been able to exercise and amuse themselves. Let us, therefore, pass them over. In the meantime we cannot wonder that the false notion of plenty should have occasioned want.

LXXXVI. The admiration of mankind with regard to the arts and sciences, which is of itself sufficiently simple and almost puerile, has been increased by the craft and artifices of those who have treated the sciences, and delivered them down to posterity. For they propose and produce them to our view so fashioned, and as it were masked, as to make them pass for perfect and complete. For if you consider their method and divisions, they appear to em. brace and comprise everything which can relate to the subject. And although this frame be badly filled up and resemble an empty bladder, yet it presents to the vul. 
gar understanding the form and appearance of a perfect science.

The first and most ancient investigators of truth were wont, on the contrary, with more honesty and success, to throw all the knowledge they wished to gather from contemplation, and to lay up for use, into aphorisms, or short scattered sentences unconnected by any method, and without pretending or professing to comprehend any entire art. But according to the present system, we cannot wonder that men seek nothing beyond that which is handed down to them as perfect, and already extended to its full complement.

LXXXVII. The ancient theories have received additional support and credit from the absurdity and levity of those who have promoted the new, especially in the active and practical part of natural philosophy. For there have been many silly and fantastical fellows who, from credulity or imposture, have loaded mankind with promises, announcing and boasting of the prolongation of life, the retarding of old age, the alleviation of pains, the remedying of natural defects, the deception of the senses, the restraint and excitement of the passions, the illumination and exaltation of the intellectual faculties, the transmutation of substances, the unlimited intensity and multiplication of motion, the impressions and changes of the air, the bringing into our power the management of celestial influences, the divination of future events, the representation of distant objects, the revelation of hidden objects, and the like. One would not be very wrong in observing with regard to such pretenders, that there is as much difference in philosophy, between their absurdity and real science, as there is in his. tory between the exploits of Cæsar or Alexander, and thos 
of Amadis de Gaul and Arthur of Britain. For those illustrious generals are found to have actually performed greater exploits than such fictitious heroes are even pretended to have accomplished, by the means, however, of real action, and not by any fabulous and portentous power. Yet it is not right to suffer our belief in true history to be diminished, because it is sometimes injured and violated by fables. In the meantime we cannot wonder that great prejudice has been excited against any new propositions (especially when coupled with any mention of effects to be produced), by the conduct of impostors who have made a similar attempt; for their extreme absurdity, and the disgust occasioned by it, has even to this day overpowered every spirited attempt of the kind.

LXXXVIII. Want of energy, and the littleness and futility of the tasks that human industry has undertaken, have produced much greater injury to the sciences: and yet (to make it still worse) that very want of energy manifests itself in conjunction with arrogance and disdain.

For, in the first place, one excuse, now from its repetition become familiar, is to be observed in every art, namely, that its promoters convert the weakness of the art itself into a calumny upon nature: and whatever it in their hands fails to effect, they pronounce to be physically impossible. But how can the art ever be condemned while it acts as judge in its own cause? Even the present system of philosophy cherishes in its bosom certain positions or dogmas, which (it will be found on diligent inquiry) are calculated to produce a full conviction that no difficult, commanding, and powerful operation upon nature ought to be anticipated through the means of art; we instanced ${ }^{49}$ above the alleged different 
quality of heat in the sun and fire, and composition and mixture. Upon an accurate observation the whole tendency of such positions is wilfully to circumscribe man's power, and to produce a despair of the means of invention and contrivance, which would not only confound the promises of hope, but cut the very springs and sinews of industry, and throw aside even the chances of experience. The only object of such philosophers is to acquire the reputation of perfection for their own art, and they are anxious to obtain the most silly and abandoned renown, by causing a belief that whatever has not yet been invented and understood can never be so hereafter. But if any one attempt to give himself ul to things, and to discover something new; yet he will only propose and destine for his object the investigation and discovery of some one invention, and nothing more; as the nature of the magnet, the tides, the heavenly system, and the like, which appear enveloped in some degree of mystery, and have hitherto been treated with but little success. Now it is the greatest proof of want of skill, to investigate the nature of any object in itself alone; for that same nature, which seems concealed and hidlen in some instances, is manifest and almost palpable in others, and excites wonder in the former, while it hardly attracts attention in the latter. ${ }^{50}$ Thus the nature of consistency is scarcely observed in wood or stone, but passed over by the term solid without any further inquiry about the repulsion of separation or the

5" The metholls hy which Newton carried the rule and compass to the boundaries of creation is a sufficient comment on the sugacity of the text. The same cunse which grobulizes a bubhle, has rounded the earth, and the same law which draws a stone to its surface, keeps the moon in her orhit. It was by calculating and ascertaining these principles upon substances entirely at his disposal that this great pliilosopher was enabled to give us a key to unlock the mysteries of the universe. $-E d$. 
solution of continuity. But in water-bubbles the same circumstance appears matter of delicate and ingenious research, for they form themselves into thin pellicles, curiously shaped into hemispheres, so as for an instant to avoid the solution of continuity.

In general those very things which are considered as secret are manifest and common in other objects, but will never be clearly seen if the experiments and contemplation of man be directed to themselves only. Yet it commonly happens, that if, in the mechanical arts, any one bring old discoveries to a finer polish, or more elegant height of ornament, or unite and compound them, or apply them more readily to practice, or exhibit them on a less heavy and voluminous scale, and the like, they will pass off as new.

We cannot, therefore, wonder that no magnificent discoveries, worthy of mankind, have been brought to light, while men are satisfied and delighted with such scanty and puerile tasks, nay, even think that they have pursued or attained some great object in their accomplishment.

LXXXIX. Nor should we neglect to observe that natural philosophy has, in every age, met with a troublesome and difficult opponent: I mean superstition, and a blind and immoderate zeal for religion. For we see that, among the Greeks, those who first disclosed the natural causes of thunder and storms to the yet untrained ears of man were condemned as guilty of impiety toward the gods. ${ }^{51}$ Nor did some of the old fathers of Christianity treat those much better who showed by the most positive proofs (such as no

51 See the "Clouds" of Aristophanes, where Socrates is represented as chasing Jupiter out of the sky, by resolving thunderstorms into aërial concussions and whirlwinds. $-E d$. 
one now disputes) that the earth is spherical, and thence asserted that there were antipodes. ${ }^{62}$

Even in the present state of things the condition of discussions on natural philosophy is rendered more difficult and dangerous by the summaries and methods of divines, who, after reducing divinity into such order as they could, and brought it into a scientific form, have proceeded to mingle an unclue proportion of the contentious and thorny philosophy of Aristotle with the substance of religion. ${ }^{53}$

The fictions of those who have not feared to deduce and confirm the truth of the Christian religion by the principles and authority of philosophers, tend to the same end, though in a clifferent manner. ${ }^{54}$ They celebrate the union of faith and the senses as though it were legitimate, with great pomp and solemnity, and gratify men's pleasing minds with a variety, but in the meantime confound most improperly things divine and human. Moreover, in these mixtures of divinity and philosophy the received doctrines of the latter are alone included, and any novelty, even though it

52 Robespierre was the latest victim of this bigotry. In his younger days he attempted to introduce Franklin's lightuing conductor into France, but was porsecuted by those whose lives he sought to protect, as one audaciously striving to avert the designs of Providence. $-E d$.

53 We can hardly agree with the text. The scholastics, in building up a system of divinity, certainly had recourse to the deductive syllogism, because the inductive was totally inapplicable, except as a verificatory process. With regard to the technical form in which they marshalled their arguments, which is what our author aims at in his censure, they owed nothing at all to Aristotle, the conducting a dispute in naked syllogistic fashion having originated entirely with themselves. - Ed.

54 Bacon cannot be supposed to allude to those divines who have attempted to show that the progress of pliysical science is confirmatory of revelation, but only to such as have built up a system of faith out of their own refinements on nature and revelation, as Patricius and Emanuel Swedenborg.-Ed. 
be an improvement, scarcely escapes banishment and extermination.

In short, you may find all access to any species of philosophy, however pure, intercepted by the ignorance of divines. Some in their simplicity are apprehensive that a too deep inquiry into nature may penetrate beyond the proper bounds of decorum, transferring and absurdly applying what is said of sacred mysteries in Holy Writ against those who pry into divine secrets, to the mysteries of nature, which are not forbidden by any prohibition. Others with more cunning imagine and consider, that if secondary causes be unknown, everything may more easily be referred to the Divine hand and wand, a matter, as they think, of the greatest consequence to religion, but which can only really mean that God wishes to be gratified by means of falsehood. Others fear, from past example, lest motion and change in philosophy should terminate in an attack upon religion. Lastly, there are others who appear anxious lest there should be something discovered in the investigation of nature to overthrow, or at least shake, religion, particularly among the unlearned. The last two apprehensions appear to resemble animal instinct, as if men were diffident, in the bottom of their minds and secret meditations, of the strength of religion and the empire of faith over the senses, and therefore feared that some danger awaited them from an inquiry into nature. But any one who properly considers the subject will find natural philosophy to be, after the Word of God, the surest remedy against superstition, and the most approved support of faith. She is, therefore, rightly bestowed upon religion as a most faithful attendant, for the one exhibits the will and the other the power of God. Nor was he wrong who observed, "Ye err, not knowing the 
Scriptures and the power of God," thus uniting in one bond the revelation of his will and the contemplation of his power. In the meanwhile, it is not wonderful that the progress of natural philosophy has been restrained, since religion, which has so much influence on men's minds, has been led and hurried to oppose her through the ignorance of some and the imprudent zeal of others.

XC. Again, in the habits and regulations of schools, universities, and the like assemblies, destined for the abode of learned men and the improvement of learning, everything is found to be opposed to the progress of the sciences; for the lectures and exercises are so ordered, that anything out of the common track can scarcely enter the thoughts and contemplations of the mind. If, however, one or two have perhaps dared to use their liberty, they can only impose the labor on themselves, without deriving any advantage from the association of others; and if they put up with this, they will find their industry and spirit of no slight disadvantage to them in making their fortune; for the pursuits of men in such situations are, as it were, chained down to the writings of particular authors, and if any one dare to dissent from them he is immediately attacked as a turbulent and revolutionary spirit. Yet how great is the difference between civil matters and the arts, for there is not the same danger from new activity and new light. In civil matters even a change for the better is suspected on account of the commotion it occasions, for civil government is supported by authority, unanimity, fame, and public opinion, and not by demonstration. In the arts and sciences, on the contrary, every department should resound, as in mines, with new works and advances. And this is the rational, though not the actual view of the case, for that administration and 
government of science we have spoken of is wont too rigorously to repress its growth.

XCI. And even should the odium I have alluded to be avoided, yet it is sufficient to repress the increase of science that such attempts and industry pass unrewarded; for the cultivation of science and its reward belong not to the same individual. The advancement of science is the work of a powerful genius, the prize and reward belong to the vulgar or to princes, who (with a few exceptions) are scarcely moderately well informed. Nay, such progress is not only deprived of the rewards and beneficence of individuals, but even of popular praise; for it is above the reach of the generality, and easily overwhelmed and extinguished by the winds of common opinions. It is not wonderful, therefore, that little success has attended that which has been little honored.

XCII. But by far the greatest obstacle to the advancement of the sciences, and the undertaking of any new attempt or department, is to be found in men's despair and the idea of impossibility; for men of a prudent and exact turn of thought are altogether diffident in matters of this nature, considering the obscurity of nature, the shortness of life, the deception of the senses, and weakness of the judgment. They think, therefore, that in the revolutions of ages and of the world there are certain floods and ebbs of the sciences, and that they grow and flourish at one time, and wither and fall off at another, that when they have attained a certain degree and condition they can proceed no further.

If, therefore, any one believe or promise greater things, they impute it to an uncurbed and immature mind, and imagine that such efforts begin pleasantly, then become 
laborious, and end in confusion. And since such thoughts easily enter the minds of men of clignity and excellent judg. ment, we must really take heed lest we should be captivated by our affection for an excellent and most beautiful object, and relax or diminish the severity of our judgment; and we must diligently examine what gleam of hope shines upon us, and in what direction it manifests itself, so that, banishing her lighter dreams, we may discuss and weigh whatever appears of more sound importance. We must consult the prudence of ordinary life, too, which is diffident upon principle, and in all human matters augurs the worst. Let us, then, speak of hope, especially as we are not vain promisers, nor are willing to enforce or insnare men's judgment, but would rather lead them willingly forward. And although we shall employ the most cogent means of enforcing hupe when we bring them to particulars, and especially those which are digested and arranged in our Tables of Invention (the sulject partly of the second, but principally of the fourth part of the Instauration), which are, indeed, rather the very object of our hopes than hope itself; yet to proceed more leniently we must treat of the preparation of men's minds, of which the manifestation of hope forms no slight part; for without it all that we have said tends rather to produce a glnom than to encourage activity or quicken the industry of experiment, by causing them to have a worse and more contemptuous opinion of things as they are than they now entertain, and to perceive and feel more thoroughly their unfortunate condition. We must, therefore, disclose and prefix our reasons for not thinking the hope of success irnprobable, as Columbus, before his wonderful voyage over the Atlantic, gave the reasons of his conviction that new lands and continents might be discovered besides those 
already known; and these reasons, though at first rejected, were yet proved by subsequent experience, and were the causes and beginnings of the greatest events.

XCIII. Let us begin from God, and show that our pursuit from its exceeding goodness clearly proceeds from him, the author of good and father of light. Now, in all divine works the smallest beginnings lead assuredly to some result, and the remark in spiritual matters that "the kingdom of God cometh without observation," is also found to be true in every great work of Divine Providence, so that everything glides quietly on without confusion or noise, and the matter is achieved before men either think or perceive that it is commenced. Nor should we neglect to mention the prophecy of Daniel, of the last days of the world, "Many shall run to and fro, and knowledge shall be increased," thus plainly hinting and suggesting that fate (which is Providence) would cause the complete circuit of the globe (now accomplished, or at least going forward by means of so many distant voyages), and the increase of learning to happen at the same epoch.

$\mathrm{XCIV}$. We will next give a most potent reason for hope deduced from the errors of the past, and the ways still unattempted; for well was an ill-governed state thus reproved, "That which is worst with regard to the past should appear most consolatory for the future; for if you had done all that your duty commanded, and your affairs proceeded no better, you could not even hope for their improvement; but since their present unhappy situation is not owing to the force of circumstances, but to your own errors, you have reason to hope that by banishing or correcting the latter

${ }_{55}$ Daniel xii. 4.

SCIENCE- Vol. $22-4$ 
you can produce a great change for the better in the former." So if men had, during the many years that have elapsed, adhered to the right way of discovering and cultivating the sciences without being able to advance, it would be assuredly bold and presumptuous to imagine it possible to improve; but if they have mistaken the way and wasted their labor on improper objects, it follows that the difficulty does not arise from things themselves, which are not in our power, but from the human understanding, its practice and application, which is susceptible of remedy and correction. Our best plan, therefore, is to expose these errors; for in proportion as they impeded the past, so do they afford reason to hope for the future. And although we have touched upon them above, yet we think it right to give a brief, bare, and simple enumeration of them in this place.

$\mathrm{XCV}$. Those who have treated of the sciences have been either empirics or dogmatical. ${ }^{66}$ The former like ants only heap up and use their store, the latter like spiders spin out their own webs. The bee, a mean between both, extracts matter from the flowers of the garden and the field, but works and fashions it by its own efforts. The true labor of philosophy resembles hers, for it neither relies entirely or principally on the powers of the mind, nor yet lays up in the memory the matter afforded by the experiments of natural history and mechanics in its raw state, but changes and works it in the understanding. We have good reason,

56 Bacon, in this Aphorism, appears to have entertained a fair idea of the use of the inductive and deductive methods in scientific inquiry, though his want of geometrical knowledge must have hindered him from accurately determining the precise functions of each, as it certainly led him in other parts of the Organon ( $\mathrm{V}$. Aph. 82), to undervalue the deductive, and, as he calls it, the dogmatic method, and to rely too much upon empiricism. - Ed. 
therefore, to derive hope from a closer and purer alliance of these faculties (the experimental and rational) than has yet been attempted.

XCVI. Natural philosophy is not yet to be found unadulterated, but is impure and corrupted-by logic in the school of Aristotle, by natural theology in that of Plato, ${ }^{\text {s7 }}$ by mathematics in the second school of Plato (that of Proclus and others) ${ }^{58}$ which ought rather to terminate natural philosophy than to generate or create it. We may, therefore, hope for better results from pure and unmixed natural philosophy.

XCVII. No one has yet been found possessed of sufficient firmness and severity to resolve upon and undertake the task of entirely abolishing common theories and notions, and applying the mind afresh, when thus cleared and levelled, to particular researches; hence our human reasoning is a mere farrago and crude mass made up of a great deal of credulity and accident, and the puerile notions it originally contracted.

${ }^{37}$ The reader may consult the note of the $23 \mathrm{~d}$ Aphorism for the fault which Bacon censures, and, if he wish to pursue the subject further, may read Plato's Timæus, where that philosopher explains his system in detail. Bacon, however, is hardly consistent in one part of his censure, for he also talks about the spirit and appetites of inanimate substances, and that so frequently, as to preclude the supposition that he is employing metaphor. $-E d$.

${ }_{58}$ Proclus flourished about the beginning of the fifth century, and was the successor of Plotinus, Porphyry and Iamblicus, who, in the two preceding centuries, had revived the doctrines of Plato, and assailed the Christian religion. The allusion in the text must be assigned to Iamblicus, who, in the fourth century, had republished the Pythagorean theology of numbers, and endeavored to construct the world out of arithmetic, thinking everything could be solved by the aid of proportions and geometry. Bacon must not be understood in the text to censure the use but the abuse of mathematics and physical investigations, as in the "De Augmentis" (lib. iv. c. 6), he enumerates the multiplicity of demon. stration scientific facts admit of, from this source. $-E d$. 
But if a man of mature age, unprejudiced senses, and clear mind, would betake himself anew to experience and particulars, we might hope much more from such a one; in which respect we promise ourselves the fortune of Alexander the Great, and let none accuse us of vanity till they have heard the tale, which is intended to check vanity.

For Aschines spoke thus of Alexander and his exploits: "We live not the life of mortals, but are born at such a period that posterity will relate and declare our prodigies"; as if he considered the exploits of Alexander to be miraculous.

But in succeeding ages ${ }^{59}$ Livy took a better view of the fact, and has made some such observation as this upon Alexander: "That he did no more than dare to despise insignificance." So in our opinion posterity will judge of us, that we have achieved no great matters, but only set less account upon what is considered important; for the meantime (as we have before observed) our only hope is in the regeneration of the sciences, by regularly raising them on the foundation of experience and building them anew, which I think none can venture to affirm to have been already done or even thought of.

XCVIII. The foundations of experience (our sole re. source) have hitherto failed completely or have been very weak; nor has a store and collection of particular facts, capable of informing the mind or in any way satisfactory, been either sought after or amassed. On the contrary, learned, but idle and indolent, men have received some

59 See Livy. lib. x. c. 17, where, in a digression on the probable effect of a contest between Rome and Alexander the Great, he says: "Non cum Dario rem esse dixisset: quem mulierum ac spadonum agmen trahentem inter purpuram atque aurum, oueratum fortune apparatibus, pradam veriùs quam hostem, nihil aliud quam ausus vana contemnere, incruentus devicit." 
mere reports of experience, traditions as it were of dreams, as establishing or confirming their philosophy, and have not hesitated to allow them the weight of legitimate evidence. So that a system has been pursued in philosophy with regard to experience resembling that of a kingdom or state wbich would direct its councils and affairs according to the gossip of city and street politicians, instead of the letters and reports of ambassadors and messengers worthy of credit. Nothing is rightly inquired into, or verified, noted, weighed, or measured, in natural history; indefinite and vague obser. vation produces fallacious and uncertain information. If this appear strange, or our complaint somewhat too unjust (because Aristotle himself, so distinguished a man and supported by the wealth of so great a king, has completed an accurate history of animals, to which others with greater diligence but less noise have made considerable additions, and others again have composed copious histories and notices of plants, metals, and fossils), it will arise from a want of sufficiently attending to and comprehending our present observations; for a natural history compiled on its own account, and one collected for the mind's information as a foundation for philosophy, are two different things. They differ in several respects, but principally in this-the former contains only the varieties of natural species without the experiments of mechanical arts; for as in ordinary life every person's disposition, and the concealed feelings of the mind and passions are most drawn out when they are disturbedso the secrets of nature betray themselves more readily when tormented by art than when left to their own course. We must begin, therefore, to entertain hopes of natural philosophy then only, when we have a better compilation of natural history, its real basis and support. 
XCIX. Again, even in the abundance of mechanical experiments, there is a very great scarcity of those which best inform and assist the understanding. For the mechanic, little solicitous about the investigation of truth, neither directs his attention, nor applies his hand to anything that is not of service to his business. But our hope of further progress in the sciences will then only be well founded, when numerous experiments shall be received and collected into natural history, which, though of no use in themselves, assist materially in the discovery of causes and axioms; which experiments we have termed enlightening, to distinguish them from those which are profitable. They possess this wonderful property and nature, that they never deceive or fail you; for being used only to discover the natural cause of some object, whatever be the result, they equally satisfy your aim by deciding the question.

C. We must not only search for, and procure a greater number of experiments, but also introduce a completely different method, order, and progress of continuing and promoting experience. For vague and arbitrary experience is (as we have observed), mere groping in the dark, and rather astonishes than instructs. But when experience shall proceed regularly and uninterruptedly by a determined rule, we may entertain better hopes of the sciences.

CI. But after having collected and prepared an abundance and store of natural history, and of the experience required for the operations of the understanding or philosophy, still the understanding is as incapable of acting on such materials of itself, with the aid of memory alone, as any person would be of retaining and achieving, by memory, the computation of an almanac. Yet meditation has hitherto done more for discovery than writing, and no 
experiments have been committed to paper. We cannot, however, approve of any mode of discovery without writing, and when that comes into more general use, we may have further hopes.

CII. Besides this, there is such a multitude and host, as it were, of particular objects, and lying so widely dispersed, as to distract and confuse the understanding; and we can, therefore, hope for no advantage from its skirmishing, and quick movements and incursions, unless we put its forces in due order and array, by means of proper and well arranged, and, as it were, living tables of discovery of these matters, which are the subject of investigation, and the mind then apply itself to the ready prepared and digested aid which such tables afford.

CIII. When we have thus properly and regularly placed before the eyes a collection of particulars, we must not im. mediately proceed to the investigation and discovery of new particulars or effects, or, at least, if we do so, must not rest satisfied therewith. For, though we do not deny that by transferring the experiments from one art to another (when all the experiments of each have been collected and arranged, and have been acquired by the knowledge, and subjected to the judgment of a single individual), many new experiments may be discovered tending to benefit society and mankind, by what we term literate experience; yet comparatively insignificant results are to be expected thence, while the more important are to be derived from the new light of axioms, deduced by certain method and rule from the above particulars, and pointing out and defining new particulars in their turn. Our road is not a long plain, but rises and falls, ascending to axioms, and descending to effects. 
CIV. Nor can we suffer the understanding to jump and fly from particulars to remote and most general axioms (such as are termed the principles of arts and things), and thus prove and make out their intermediate axioms according to the supposed unshaken truth of the former. This, however, has always been done to the present time from the natural bent of the understanding, educated too, and accustomed to this very method, by the syllogistic mode of demonstration. But we can then only augur well for the sciences, when the assent shall proceed by a true scale and successive steps, without interruption or breach, from particulars to the lesser axioms, thence to the intermediate (rising one above the other), and lastly, to the most general. For the lowest axioms differ but little from bare experiment; ${ }^{80}$ the highest and most general (as they are esteemed at present), are notional, abstract, and of no real weight. The intermediate are true, solid, full of life, and upon them depend the business and fortune of mankind; beyond these are the really general, but not abstract, axioms, which are truly limited by the intermediate.

60 The lowest axioms are such as spring from simple experience-such as in chemistry, that animal substances yield no fixed salt by calcination; in music, that concords intermixed with discords make harmony, etc. Intermediate axioms advance a step further, being the result of reflection, which, applied to our experimental knowledge, deduces laws from them, such as in optics of the first degree of generality, that the angle of incidence is equal to the angle of reflection; and in mechanics, Kepler's three laws of motion, while his general law, that all bodies attract each other with forces proportional to their masses, and inversely as the squares of their distances, may be taken as one of the highest axioms. Yet so far is this principle from being only notional or abstract, it has presented us with a key which fits into the intricate wards of the heavens, and has laid bare to our gaze the principal mechanism of the univêrse. But natural philosophy in Bacon's day had not advanced beyond intermediate axioms, and the term notional or abstract is applied to those general axioms then current, not founded on the solid principles of inductive inquiry, but based upon a prior reasoning and airy metaphysics. $-E d$. 
We must not then add wings, but rather lead and ballast to the understanding, to prevent its jumping or flying, which has not yet been done; but whenever this takes place, we may entertain greater hopes of the sciences.

CV. In forming axioms, we must invent a different form of induction from that hitherto in use; not only for the proof and discovery of principles (as they are called), but also of minor, intermediate, and, in short, every kind of axioms. The induction which proceeds by simple enumeration is puerile, leads to uncertain conclusions, and is exposed to danger from one contradictory instance, deciding generally from too small a number of facts, and those only the most obvious. But a really useful induction for the dis. covery and demonstration of the arts and sciences, should separate nature by proper rejections and exclusions, and then conclude for the affirmative, after collecting a sufficient number of negatives. Now this has not been done, nor even attempted, except perhaps by Plato, who certainly uses this form of induction in some measure, to sift definitions and ideas. But much of what has never yet entered the thoughts of man must necessarily be employed, in order to exhibit a good and legitimate mode of induction or demonstration, so as even to render it essential for us to bestow more pains upon it than have hitherto been bestowed on syllogisms. The assistance of induction is to serve us not only in the discovery of axioms, but also in defining our notions. Much indeed is to be hoped from such an induction as has been described.

CVI. In forming our axioms from induction, we must examine and try whether the axiom we derive be only fitted and calculated for the particular instances from which it is 
deduced, or whether it be more extensive and general. If it be the latter, we must observe, whether it confirm its own extent and generality by giving surety, as it were, in pointing out new particulars, so that we may neither stop at actual discoveries, nor with a careless grasp catch at shadows and abstract forms, instead of substances of a determinate nature: and as soon as we act thus, well authorized hope may with reason be said to beam upon us.

CVII. Here, too, we may again repeat what we have said above, concerning the extending of natural philosophy and reducing particular sciences to that one, so as to prevent any schism or dismembering of the sciences; without which we cannot hope to advance.

CVIII. Such are the observations we would make in order to remove despair and excite hope, by bidding farewell to the errors of past ages, or by their correction. Let us examine whether there be other grounds for hope. And, first, if many useful discoveries have occurred to mankind by chance or opportunity, without investigation or attention on their part, it must necessarily be acknowledged that much more may be brought to light by investigation and attention, if it be regular and orderly, not hasty and interrupted. For although it may now and then happen that one falls by chance upon something that had before escaped considerable efforts and laborious inquiries, yet undoubtedly the reverse is generally the case. We may, therefore, hope for further, better, and more frequent results from man's reason, indus. try, method, and application, than from chance and mere animal instinct, and the like, which have hitherto been the sources of invention.

CIX. We may also derive some reason for hope from the circumstance of several actual inventions being of such a 
nature, that scarcely any one could have formed a conjecture about them previously to their discovery, but would rather have ridiculed them as impossible. For men are wont to guess about new subjects from those they are already acquainted with, and the hasty and vitiated fancies they have thence formed: than which there cannot be a more fallacious mode of reasoning, because much of that which is derived from the sources of things does not flow in their usual channel.

If, for instance, before the discovery of cannon, one had described its effects in the following manner: There is a new invention by which walls and the greatest bulwarks can be shaken and overthrown from a considerable distance; men would have begun to contrive various means of multiplying the force of projectiles and machines by means of weights and wheels, and other modes of battering and projecting. But it is improbable that any imagination or fancy would have hit upon a fiery blast, expanding and developing itself so suddenly and violently, because none would have seen an instance at all resembling it, except perhaps in earthquakes or thunder, which they would have immediately rejected as the great operations of nature, not to be imitated by man.

So, if before the discovery of silk thread, any one had observed, That a species of thread had been discovered, fit for dresses and furniture, far surpassing the thread of worsted or flax in fineness, and at the same time in tenacity, beauty, and softness; men would have begun to imagine something about Chinese plants, or the fine hair of some animals, or the feathers or down of birds, but certainly would never have had an idea of its being spun by a small worm, in so copious a manner, and renewed annually. But if any one had ventured to suggest the silkworm, he would 
have been langhed at as if dreaming of some new manufacture from spiders.

So again, if before the discovery of the compass, any one had said, That an instrument had been invented, by which the quarters and points of the heavens could be exactly taken and distinguished, men would have entered into dis. quisitions on the refinement of astronomical instruments, and the like, from the excitement of their imaginations; but the thought of anything being discovered, which, not being a celestial body, but a mere mineral or metallic substance, should yet in its motion agree with that of such bodies, would have appeared absolutely incredible. Yet were these facts, and the like (unknown for so many ages) not discov. ered at last either by philosophy or reasoning, but by chance and opportunity; and (as we have observed), they are of a nature most heterogeneous, and remote from what was hitherto known, so that no previous knowledge could lead to them.

We may, therefore, well hope ${ }^{61}$ that many excellent and useful matters are yet treasured up in the bosom of nature, bearing no relation or analogy to our actual discoveries, but out of the common track of our imagination, and still undiscovered, and which will doubtless be brought to light in the course and lapse of years, as the others have been before them; but in the way we now point out, they may rapidly and at once be both represented and anticipated.

CX. There are, moreover, some inventions which render

61 This hope has been abundantly realized in the discovery of gravity and the decomposition of light, mainly by the inductive method. To a better philosophy we may also attribute the discovery of electricity, galvanism and their mutual connection with each other, and magnetism, the inventions of the airpump, steam-engine and the chronometer. 
it probable that men may pass and hurry over the most noble discoveries which lie immediately before them. For however the discovery of gunpowder, silk, the compass, sugar, paper, or the like, may appear to depend on peculiar properties of things and nature, printing at least involves no contrivance which is not clear and almost obvious. But from want of observing that although the arrangement of the types of letters required more trouble than writing with the hand, yet these types once arranged serve for innumerable impressions, while manuscript only affords one copy; and again, from want of observing that ink might be thickened so as to stain without running (which was necessary, seeing the letters face upward, and the impression is made from above), this most beautiful invention (which assists so materially the propagation of learning) remained unknown for so many ages.

The human mind is often so awkward and ill-regulated in the career of invention that it is at first diffident, and then despises itself. For it appears at first incredible that any such discovery should be made, and when it has been made, it appears incredible that it should so long have escaped men's research. All which affords good reason for the hope that a vast mass of inventions yet remains, which may be deduced not only from the investigation of new modes of operation, but also from transferring, comparing, and applying these already known, by the method of what we have termed literate experience.

CXI. Nor should we omit another ground of hope. Let men only consider (if they will) their infinite expenditure of talent, time, and fortune, in matters and studies of far inferior importance and value; a small portion of which applied to sound and solid learning would be sufficient to over- 
come every difficulty. And we have thought right to add this observation, because we candidly own that such a collection of natural and experimental history as we have traced in our own mind, and as is really necessary, is a great and as it were royal work, requiring much labor and expense.

CXII. In the meantime let no one be alarmed at the multitude of particulars, but rather inclined to hope on that very account. For the particular phenomena of the arts and nature are in reality but as a handful, when compared with the fictions of the imagination removed and separated from the evidence of facts. The termination of our method is clear, and I had almost said near at hand; the other admits of no termination, but only of infinite confusion. For men have hitherto dwelt but little, or rather only slightly touched upon experience, while they have wasted much time on theories and the fictions of the imagination. If we had but any one who could actually answer our interrogations of nature, the invention of all causes and sciences would be the labor of but a few years.

CXIII. We think some ground of hope is afforded by our own example, which is not mentioned for the sake of boasting, but as a useful remark. Let those who distrust their own powers observe myself, one who have among my contemporaries been the most engaged in public business, who am not very strong in health (which causes a great loss of time), and am the first explorer of this course, following the guidance of none, nor even communicating my thoughts to a single individual; yet having once firmly entered in the right way, and submitting the powers of my mind to things, I have somewhat advanced (as I make bold to think) the matter I now treat of. Then let others consider what may 
be hoped from men who enjoy abundant leisure, from united labors, and the succession of ages, after these suggestions on our part, especially in a course which is not confined, like theories, to individuals, but admits of the best distribution and union of labor and effect, particularly in collecting experiments. For men will then only begin to know their own power, when each performs a separate part, instead of undertaking in crowds the same work.

CXIV. Lastly, though a much more faint and uncertain breeze of hope were to spring up from our new continent, yet we consider it necessary to make the experiment, if we would not show a dastard spirit. For the risk attending want of success is not to be compared with that of neglecting the attempt; the former is attended with the loss of a little human labor, the latter with that of an immense benefit. For these and other reasons it appears to us that there is abundant ground to hope, and to induce not only those who are sanguine to make experiment, but even those who are cautious and sober to give their assent.

CXV. Such are the grounds for banishing despair, hitherto one of the most powerful causes of the delay and restraint to which the sciences have been subjected; in treating of which we have at the same time discussed the signs and causes of the errors, idleness, and ignorance that have prevailed; seeing especially that the more refined causes, which are not open to popular judgment and observation, may be referred to our remarks on the idols of the human mind.

Here, too, we should close the demolishing branch of our Instauration, which is comprised in three confutations: 1, the confutation of natural human reason left to itself; 2 , the confutation of demonstration; 3 , the confutation of theories, 
or received systems of philosophy and doctrines. Our confutation has followed such a course as was open to it, namely, the exposing of the signs of error, and the producing evidence of the causes of it: for we could adopt no other, differing as we do both in first principles and demonstrations from others.

It is time for us therefore to come to the art itself, and the rule for the interpretation of nature: there is, however, still something which must not be passed over. For the intent of this first book of aphorisms being to prepare the mind for understanding, as well as admitting, what follows, we must now, after having cleansed, polished, and levelled its surface, place it in a good position, and as it were a benevolent aspect toward our propositions; seeing that prej. udice in new matters may be produced not only by the strength of preconceived notions, but also by a false anticipation or expectation of the matter proposed. We shall therefore endeavor to induce good and correct opinions of what we offer, although this be only necessary for the moment, and as it were laid out at interest, until the matter itself be well understood.

CXVI. First, then, we must desire men not to suppose that we are ambitious of founding any philosophical sect, like the ancient Greeks, or some moderns, as Telesius, Pa. tricius, and Severinus. ${ }^{62}$ For neither is this our intention,

${ }^{62}$ As Bacon very frequently cites these authors, a slight notice of their labors may not be unacceptable to the reader. Bernardinus Telesius, born at Cosenza, in 1508, combated the Aristotelian system in a work entitled "De Rerum Natura juxta propria principia," i.e., according to principles of his own. The proem of the work announces his design was to show that "the construction of the world, the magnitude and nature of the bodies contained in it, are not to be investigated by reasoning, which was done by the ancients, but are to be apprehended by the senses, and collected from the things themselves." He 
nor do we think that peculiar abstract opinions on nature and the principles of things are of much importance to men's fortunes, since it were easy to revive many ancient theories, and to introduce many new ones; as, for instance, many hypotheses with regard to the heavens can be formed, differing in themselves, and yet sufficiently according with the phenomena.

We bestow not our labor on such theoretical and, at the same time, useless topics. On the contrary, our determination is that of trying, whether we can lay a firmer foundation, and extend to a greater distance the boundaries of human power and dignity. And although here and there, upon some particular points, we hold (in our own opinion) more true and certain, and I might even say, more advantageous tenets than those in general repute (which we have collected in the fifth part of our Instauration), yet we offer

had, however, no sooner laid down this principle than he departed from it in practice, and pursued the deductive method he so much condemned in his predecessors. His first step was an assumption of principles as arbitrary as any of the empirical notions of antiquity; at the outset of his book he very quietly takes it for granted that heat is the principle of motion, cold of immobility, matter being assumed as the corporeal substratum, in which these incorporeal and active agents carry on their operations. Out of these abstract and illdefined conceptions Telesius builds up a system quite as complete, symmetrical, and imaginative as any of the structures of antiquity.

Francis Patricius, born at Cherso, in Dalmatia, about 1529, was another physicist who rose up against Aristotle, and announced the dawn of a new philosophy. In 1593 appeared his "Nova de Universis Philosophia." He lays down a string of axioms, in which scholastic notions, physical discoveries, and theological dogmas, are strangely commingled, and erects upon them a system which represents all the grotesque features of theological empiricism.

Severinus, born in Jutland, in 1529, published an attack on Aristotle's natural history, but adopted fantasies which the Stagyrite ridiculed in his own day. He was a follower of Paracelsus, a Swiss enthusiast of the fifteenth century, who ignored the ancient doctrine of the four elements for salt, sulphur and mercury, and allied chemistry and medicine with mysticism. $-E \boldsymbol{d}$. 
no universal or complete theory. The time does not yet appear to us to be arrived, and we entertain no hope of our life being prolonged to the completion of the sixth part of the Instauration (which is destined for philosophy discovered by the interpretation of nature), but are content if we proceed quietly and usefully in our intermediate pursuit, scattering, in the meantime, the seeds of less adulterated truth for posterity, and, at least, commence the great work.

CXVII. And, as we pretend not to found a sect, so do we neither offer nor promise particular effects; which may occasion some to object to us, that since we so often speak of effects, and consider everything in its relation to that end, we ought also to give some earnest of producing them. Our course and method, however (as we have often said, and again repeat), is such as not to deduce effects from effects, nor experiments from experiments (as the empirics do), but in our capacity of legitimate interpreters of nature, to deduce causes and axioms from effects and experiments; and new effects and experiments from those causes and axioms.

And although any one of moderate intelligence and ability will observe the indications and sketches of many noble effects in our tables of inventions (which form the fourth part of the Instauration), and also in the examples of particular instances cited in the second part, as well as in our observations on history (which is the subject of the third part); yet we candidly confess that our present natural his. tory, whether compiled from books or our own inquiries, is not sufficiently copious and well ascertained to satisfy, or even assist, a proper interpretation.

If, therefore, there be any one who is more disposed and prepared for mechanical art, and ingenious in discovering effects, than in the mere management of experiment, we 
allow him to employ his industry in gathering many of the fruits of our history and tables in this way, and applying them to effects, receiving them as interest till he can obtain the principal. For our own part, having a greater object in view, we condemn all hasty and premature rest in such pursuits as we would Atalanta's apple (to use a common allu. sion of ours); for we are not childishly ambitious of golden fruit, but use all our efforts to make the course of art outstrip nature, and we hasten not to reap moss or the green blade, but wait for a ripe harvest.

CXVIII. There will be some, without doubt, who, on a perusal of our history and tables of invention, will meet with some uncertainty, or perhaps fallacy, in the experiments themselves, and will thence perhaps imagine that our discoveries are built on false foundations and principles. There is, however, really nothing in this, since it must needs happen in beginnings. ${ }^{83}$ For it is the same as if in writing or printing one or two letters were wrongly turned or misplaced, which is no great inconvenience to the reader, who can easily by his own eye correct the error; let men in the same way conclude, that many experiments in natural history may be erroneously believed and admitted, which are easily expunged $a^{2} d$ rejected afterward, by the discovery of causes and axioms. It is, however, true, that if these errors in natural history and experiments become great, frequent, and continued, they cannot be corrected and amended by

${ }^{63}$ Bacon's apology is sound, and completely answers those German and French critics, who have refused him a niche in the philosophical pantheon. One German commentator, too modest to reveal his name, accuses Bacon of ignorance of the calculus, though, in his day, Wallis had not yet stumbled upon the laws of continuous fractions; while Count de Maistre, in a coarse attack upon his genius, expresses his astonishment at finding Bacon unacquainted with discoveries which were not heard of till a century after his death.-Ed. 
any dexterity of wit or art. If then, even in our natura? history, well examined and compiled with such diligence, strictness, and (I might say) reverential scruples, there be now and then something false and erroneous in the details, what must we say of the common natural history, which is so negligent and careless when compared with ours? or of systems of philosophy and the sciences, based on such loose soil (or rather quicksand)? Let none then be alarmed by such observations.

CXIX. Again, our history and experiments will contain much that is light and common, mean and illiberal, too refined and merely speculative, and, as it were, of no use, and this perhaps may divert and alienate the attention of mankind.

With regard to what is common; let men reflect, that they have hitherto been used to do nothing but refer and adapt the causes of things of rare occurrence to those of things which more frequently happen, without any investigation of the causes of the latter, taking them for granted and admitted.

Hence, they do not inquire into the causes of gravity, the rotation of the heavenly bodies, heat, cold, light, hardness, softness, rarity, density, liquidity, solidity, animation, inanimation, similitude, difference, organic formation, but taking them to be self-evident, manifest, and admitted, they dispute and decide upon other matters of less frequent and familiar occurrence.

But we (who know that no judgment can be formed of that which is rare or remarkable, and much less anything new brought to light, without a previous regular examina. tion and discovery of the causes of that which is common, and the causes again of those causes) are necessarily com. 
pelled to admit the most common objects into our history. Besides, we have observed that nothing has been so injurious to philosophy as this circumstance, namely, that familiar and frequent objects do not arrest and detain men's contemplation, but are carelessly admitted, and their causes never inquired after; so that information on unknown subjects is not more often wanted than attention to those which are known.

CXX. With regard to the meanness, or even the filthiness of particulars, for which (as Pliny observes), an apology is requisite, such subjects are no less worthy of admission into natural history than the most magnificent and costly; nor do they at all pollute natural history, for the sun enters alike the palace and the privy, and is not thereby polluted. We neither dedicate nor raise a capitol or pyramid to the pride of man, but rear a holy temple in his mind, on the model of the universe, which model therefore we imitate. For that which is deserving of existence is deserving of knowledge, the image of existence. Now the mean and splendid alike exist. Nay, as the finest odors are sometimes produced from putrid matter (such as musk and civet), so does valuable light and information emanate from mean and sordid instances. But we have already said too much, for such fastidious feelings are childish and effemi. nate.

CXXI. The next point requires a more accurate consideration, namely, that many parts of our history will appear to the vulgar, or even any mind accustomed to the present state of things, fantastically and uselessly refined. Hence, we have in regard to this matter said from the first, and must again repeat, that we look for experiments that shall afford light rather than profit, imitating the divine creation, which, 
as we have often observed, only produced light on the first day, and assigned that whole day to its creation, without adding any material work.

If any one, then, imagine such matters to be of no use, he might equally suppose light to be of no use, because it is neither solid nor material. For, in fact, the knowledge of simple natures, when sufficiently investigated and defined, resembles light, which, though of no great use in itself, affords access to the general mysteries of effects, and with a peculiar power comprehends and draws with it whole bands and troops of effects, and the sources of the most valuable axioms. So also the elements of letters have of them. selves separately no meaning, and are of no use, yet are they, as it were, the original matter in the composition and preparation of speech. The seeds of substances, whose effect is powerful, are of no use except in their growth, and the scattered rays of light itself avail not unless collected.

But if speculative subtilties give offence, what must we say of the scholastic philosophers who indulged in them to such excess? And those subtilties were wasted on words, or, at least, common notions (which is the same thing), not on things or nature, and alike unproductive of benefit in their origin and their consequences: in no way resembling ours, which are at present useless, but in their consequences of infinite benefit. Let men be assured that all subtile disputes and discursive efforts of the mind are late and preposterous, when they are introduced subsequently to the discovery of axioms, and that their true, or, at any rate, chief opportunity is, when experiment is to be weighed and axioms to be derived from it. They otherwise catch and grasp at nature, but never seize or detain her: and we may well apply to nature that which has been said of opportunity 
or fortune, that she wears a lock in front, but is bald behind.

In short, we may reply decisively to those who despise any part of natural history as being vulgar, mean, or subtile, and useless in its origin, in the words of a poor woman to a haughty prince, ${ }^{64}$ who had rejected her petition as unworthy, and beneath the dignity of his majesty: "Then cease to reign"; for it is quite certain that the empire of nature can neither be obtained nor administered by one who refuses to pay attention to such matters as being poor and too minute.

CXXII. Again, it may be objected to us as being singular and harsh, that we should with one stroke and assault, as it were, banish all authorities and sciences, and that too by our own efforts, without requiring the assistance and support of any of the ancients.

Now we are aware, that had we been ready to act otherwise than sincerely, it was not difficult to refer our present method to remote ages, prior to those of the Greeks (since the sciences in all probability flourished more in their nat. ural state, though silently, than when they were paraded with the fifes and trumpets of the Greeks); or even (in parts, at least) to some of the Greeks themselves, and to derive authority and honor from thence; as men of no family labor to raise and form nobility for themselves in some ancient line, by the help of genealogies. Trusting, however, to the evidence of facts, we reject every kind of fiction and imposture; and think it of no more consequence to our subject, whether future discoveries were known to the ancients, and set or rose according to the vicissitudes of events and 
lapse of ages, than it would be of importance to mankind to know whether the new world be the island of Atlantis, ${ }^{\text {es }}$ and known to the ancients, or be now discovered for the first time.

With regard to the universal censure we have bestowed, it is quite clear, to any one who properly considers the matter, that it is both more probable and more modest than any partial one could have been. For if the errors bad not been rooted in the primary notions, some well conducted discoveries must have corrected others that were deficient. But since the errors were fundamental, and of such a nature, that men may be said rather to have neglected or passed over things, than to have formed a wrong or false judgment of them, it is little to be wondered at, that they did not obtain what they never aimed at, nor arrive at a goal which they had not determined, nor perform a course which they had neither entered upon nor adhered to.

With regard to our presumption, we allow that if we were to assume a power of drawing a more perfect straight line or circle than any one else, by superior steadiness of hand or acuteness of eye, it would lead to a comparison of talent; but if one merely assert that he can draw a more perfect line or circle with a ruler or compasses, than another can by his unassisted hand or eye, he surely cannot be said to boast of much. Now this applies not only to our first original attempt, but also to those who shall hereafter apply themselves to the pursuit. For our method of discovering the sciences merely levels men's wits, and leaves but little to their superiority, since it achieves everything by the most certain rules and demonstrations. Whence (as we have 
often observed), our attempt is to be attributed to fortune rather than talent, and is the offspring of time rather than of wit. For a certain sort of chance has no less effect upon our thoughts than on our acts and deeds.

CXXIII. We may, therefore, apply to ourselves the joke of him who said, that water and wine drinkers could not think alike, ${ }^{68}$ especially as it hits the matter so well. For others, both ancients and moderns, have in the sciences drank a crude liquor like water, either flowing of itself from the understanding, or drawn up by logic as the wheel draws up the bucket. But we drink and pledge others with a liquor made of many well-ripened grapes, collected and plucked from particular branches, squeezed in the press, and at last clarified and fermented in a vessel. It is not, therefore, wonderful that we should not agree with others.

CXXIV. Another objection will without doubt be made, namely, that we have not ourselves established a correct, or the best goal or aim of the sciences (the very defect we blame in others). For they will say that the contemplation of truth is more dignified and exalted than any utility or extent of effects; but that our dwelling so long and anxiously on experience and matter, and the fluctuating state of particulars, fastens the mind to earth, or rather casts it down into an abyss of confusion and disturbance, and separates and removes it from a much more divine state, the quiet and tranquillity of abstract wisdom. We willingly assent to their reasoning, and are most anxious to effect the very point they hint at and require. For we are founding a real model of the world in the understanding, such as it is found to be, not such as man's reason has distorted.

66 The saying of Philocrates when he differed from Demosthenes. $-E d$. 
Now this cannot be done without dissecting and anatomizing the world most diligently; but we declare it necessary to destroy completely the vain, little and, as it were, apish imitations of the world, which have been formed in various systems of philosophy by men's fancies. Let men learn (as we have said above) the difference that exists between the idols of the human mind and the ideas of the divine mind. The former are mere arbitrary abstractions; the latter the true marks of the Creator on his creatures, as they are imprinted on, and defined in matter, by true and exquisite touches. Truth, therefore, and utility, are here perfectly identical, and the effects are of more value as pledges of truth than from the benefit they confer on men.

CXXV. Others may object that we are only doing that which has already been done, and that the ancients followed the same course as ourselves. They may imagine, therefore, that, after all this stir and exertion, we shall at last arrive at some of those systems that prevailed among the ancients: for that they, too, when commencing their meditations, laid up a great store of instances and particulars, and digested them under topics and titles in their commonplace books, and so worked out their systems and arts, and then decirled upon what they discovered, and related now and then some examples to confirm and throw light upon their doctrine; but thought it superfluous and troublesome to publish their notes, minutes, and commonplaces, and therefore followed the example of builders who remove the scaffoluing and ladders when the building is finished. Nor can we indeed believe the case to have been otherwise. But to any one, not entirely forgetful of our previous observations, it will be easy to answer this objection or rather 
scruple; for we allow that the ancients had a particular form of investigation and discovery, and their writings show it. But it was of such a nature, that they immediately flew from a few instances and particulars (after adding some common notions, and a few generally received opinions most in vogue) to the most general conclusions or the prin. ciples of the sciences, and then by their intermediate propositions deduced their inferior conclusions, and tried them by the test of the immovable and settled truth of the first, and so constructed their art. Lastly, if some new particulars and instances were brought forward, which contradicted their dogmas, they either with great subtilty reduced them to one system, by distinctions or explanations of their own rules, or got rid of them clumsily as exceptions, laboring most pertinaciously in the meantime to accommodate the causes of such as were not contradictory to their own prin. ciples. Their natural history and their experience were both far from being what they ought to have been, and their flying off to generalities ruined everything.

CXXVI. Another objection will be made against us, that we prohibit decisions and the laying down of certain principles, till we arrive regularly at generalities by the intermediate steps, and thus keep the judgment in suspense and lead to uncertainty. But our object is not uncertainty but fitting certainty, for we derogate not from the senses but assist them, and despise not the understanding but direct it. It is better to know what is necessary, and not to imagine we are fully in possession of it, than to imagine that we are fully in possession of it, and yet in reality to know nothing which we ought.

CXXVII. Again, some may raise this question rather than objection, whether we talk of perfecting natural phi- 
losophy alone according to our method, or the other sciences also, such as logic, ethics, politics. We certainly intend to comprehend them all. And as common logic, which regulates matters by syllogisms, is applied not only to natural, but also to every other science, so our inductive method likewise comprehends them all. ${ }^{67}$ For we form a history and tables of invention for anger, fear, shame, and the like, and also for examples in civil life, and the mental operations of memory, composition, division, judgment, and the rest, as well as for heat and cold, light, vegetation, and the like. But since our method of interpretation, after preparing and arranging a history, does not content itself with examining the operations and disquisitions of the mind like common logic, but also inspects the nature of things, we so regulate the mind that it may be enabled to apply itself in every respect correctly to that nature. On that account we deliver numerous and various precopts in our doctrine of interpretation, so that they may apply in some

${ }^{67}$ The old error of placing the deductive syllogism in antagonism to the inductive, as if they were not both parts of one system or refused to cohere together. So far from there being any radical opposition between them, it would not be difficult to show that Bacon's method was syllogistic in his sense of the term. For the suppressed premise of every Baconian enthymeme, viz., the acknowledged uniformity of the laws of nature as stated in the axiom, whatever has once occurred will occur again, must be assumed as the basis of every conclusion which he draws before we can admit its legitimacy. The opposition, therefore, of Bacon's method could not be directed against the old logic, for it assumed and exemplified its principles, but rather to the abusive application which the ancients made of this science, in turning its powers to tive development of abstract principles which they imagined to be pregnant with the solution of the latent mysteries of the universe. Bacon justly overthrew these ideal notions, and accepted of no principle as a basis which was not guaranteed by actual experiment and observation; and so far he laid the foundations of a sound philosophy by turning the inductive logic to its proper acount in the interpretation of nature. 
measure to the method of discovering the quality and condition of the subject matter of investigation.

CXXVIII. Let none even doubt whether we are anxious to destroy and demolish the philosophy, arts, and sciences, which are now in use. On the contrary, we readily cherish their practice, cultivation, and honor; for we by no means interfere to prevent the prevalent system from encouraging discussion, adorning discourses, or being employed serviceably in the chair of the professor or the practice of common life, and being taken, in short, by general consent as current coin. Nay, we plainly declare, that the system we offer will not be very suitable for such purposes, not being easily adapted to vulgar apprehensions, except by effects and works. To show our sincerity in professing our regard and friendly disposition toward the received sciences, we can refer to the evidence of our published writings (especially our books on the Advancement of Learning). We will not, therefore, endeavor to evince it any further by words; but content ourselves with steadily and professedly premising, that no great progress can be made by the present methods in the theory or contemplation of science, and that they cannot be made to produce any very abundant effects.

CXXIX. It remains for us to say a few words on the excellence of our proposed end. If we had done so before, we might have appeared merely to express our wishes, but now that we have excited hope and removed prejudices, it will perhaps have greater weight. Had we prformed and completely accomplished the whole, without frequently calling in others to assist in our labors, we should then have refrained from saying any more, lest we should be thought to extol our own deserts. Since, however, the 
industry of others must be quickened, and their courage roused and inflamed, it is right to recall some points to their memory.

First, then, the introduction of great inventions appears one of the most distinguished of human actions, and the ancients so considered it; for they assigned divine honors to the authors of inventions, but only heroic honors to those who displayed civil merit (such as the founders of cities and empires, legislators, the deliverers of their country from lasting misfortunes, the quellers of tyrants, and the like). And if any one rightly compare them, he will find the judgment of antiquity to be correct; for the benefits derived from inventions may extend to mankind in general, but civil benefits to particular spots alone; the latter, moreover, last but for a time, the former forever. Civil reformation seldom is carried on without violence and confusion, while inventions are a blessing and a benefit without injuring or afflicting any.

Inventions are also, as it were, new creations and imitations of divine works, as was expressed by the poet: ${ }^{63}$

\footnotetext{
"Primum frugiferos fœetus mortalibus ægris Dididerant quondam præstanti nomine Athenæ Et recreaverunt vitam legesque rogarunt."
}

And it is worthy of remark in Solomon, that while he flourished in the possession of his empire, in wealth, in the

68 This is the opening of the Sixth Book of Lucretius. Bacon probably quoted from memory; the lines are-

"Primæ frugiferos fœetus mortalibus ægris

Dididerunt quondam præclaro nomine Athenæ

Et recreaverunt," etc.

The teeming corn, that feeble mortals crave,

First, and long since, renowned Athens gave,

And cheered their life-then taught to frame their laws. 
magnificence of his works, in his court, his household, his fleet, the splendor of his name, and the most unbounded admiration of mankind, he still placed his glory in none of these, but declared ${ }^{69}$ that it is the glory of God to conceal a thing, but the glory of a king to search it out.

Again, let any one but consider the immense difference between men's lives in the most polished countries of Europe, and in any wild and barbarous region of the new Indies, he will think it so great, that man may be said to be a god unto man, not only on account of mutual aid and benefits, but from their comparative states-the result of the arts, and not of the soil or climate.

Again, we should notice the force, effect, and consequences of inventions, which are nowhere more conspicuous than in those three which were unknown to the ancients; namely, printing, gunpowder, and the compass. For these three have changed the appearance and state of the whole world: first in literature, then in warfare, and lastly in navigation; and innumerable changes have been thence derived, so that no empire, sect, or star, appears to have exercised a greater power and influence on human affairs than these mechanical discoveries.

It will, perhaps, be as well to distinguish three species and degrees of ambition. First, that of men who are anx. ious to enlarge their own power in their country, which is a vulgar and degenerate kind; next, that of men who strive to enlarge the power and empire of their country over mankind, which is more dignified but not less covetous; but if one were to endeavor to renew and enlarge the power and empire of mankind in general over the universe, such ambi- 
tion (if it may be so termed) is both more sound and more noble than the other two. Now the empire of man over things is founded on the arts and sciences alone, for nature is only to be commanded by obeying her.

Besicles this, if the benefit of any particular invention has had such an eflect as to induce men to consider him greater than a man, who has thus obliged the whole race, how much more exalted will that discovery be, which leads to the easy discovery of everything else! Yet (to speak the truth) in the same manner as we are very thankful for light which enables us to enter on our way, to practice arts, to read, to distinguish each other, and yet sight is more excellent and beautiful than the various uses of light; so is the contemplation of things as they are, free from superstition or imposture, error or confusion, much more dignified in itself than all the advantage to be derived from discoveries.

Lastly, let none be alarmed at the objection of the arts and sciences becoming depraved to malevolent or luxurious jurposes and the like, for the same can be said of every worldly good; talent, courage, strength, beauty, riches, light itself, and the rest. Only let mankind regain their rights over nature, assigned to them by the gift of God, and obtain that power, whose exercise will be governed by right reason and true religion.

CXXX. But it is time for us to lay down the art of interpreting nature, to which we attribute no absolute ne. cessity (as if nothing could be done without it) nor perfection, although we think that our precepts are most useful and correct. For we are of opinion, that if men had at their command a proper history of nature and experience, and would apply themselves steadily to it, and could bind themselves to two things: 1 , to lay aside received 
opinions and notions; 2 , to restrain themselves, till the proper season, from generalization, they might, by the proper and genuine exertion of their minds, fall into our way of interpretation without the aid of any art. For interpretation is the true and natural act of the mind, when all obstacles are removed: certainly, however, everything will be more ready and better fixed by our precepts.

Yet do we not affirm that no addition can be made to them; on the contrary, considering the mind in its connection with things, and not merely relatively to its own powers, we ought to be persuaded that the art of invention can be made to grow with the inventions themselves. 


\section{APHORISMS-BOOK II}

\section{ON THE INTERPRETATION OF NATURE, OR THE REIGN OF MAN}

I. To GENERATE and superinduce a new nature or new natures, upon a given body, is the labor and aim of human power: while to discover the form or true difference of a given nature, or the nature ${ }^{1}$ to which such nature is owing, or source from which it emanates (for these terms approach nearest to an explanation of our meaning), is the labor and discovery of human knowledge; and subordinate to these primary labors are two others of a secondary nature and inferior stamp. Under the first must be ranked the transformation of concrete bodies from one to another, which is possible within certain limits; under the second, the discovery, in every species of generation and motion, of the latent and uninterrupted process from the manifest efficient and manifest subject matter up to the given form: and a like discovery of the latent conformation of bodies which are at rest instead of being in motion.

II. The unhappy state of man's actual knowledge is manifested even by the common assertions of the vulgar. It is rightly laid down that true knowledge is that which is deduced from causes. The division of four causes also is not amiss: matter, form, the efficient, and end or final

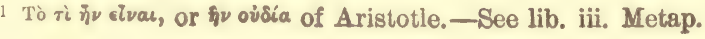
(108) 
cause. $^{2}$ Of these, however, the latter is so far from being beneficial, that it even corrupts the sciences, except in the intercourse of man with man. The discovery of form is considered desperate. As for the efficient cause and matter (according to the present system of inquiry and the received opinions concerning them, by which they are placed remote from, and without any latent process toward form), they are but desultory and superficial, and of scarcely any avail to real and active knowledge. Nor are we unmindful of our having pointed out and corrected above the error of the human mind, in assigning the first qualities of essence to forms. ${ }^{3}$ For although nothing exists in nature except individual bodies, ${ }^{4}$ exhibiting clear individual effects according to particular laws, yet in each branch of learning, that very law, its investigation, discovery, and development, are the foundation both of theory and practice. This law, therefore, and its parallel in each science, is what we undèrstand by the term form, ${ }^{5}$ adopting that word because it has grown into common use, and is of familiar occurrence.

2 These divisions are from Aristotle's Metaphysics, where they are termed,

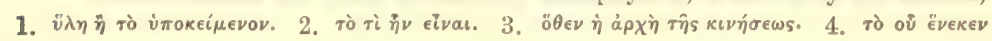

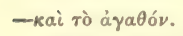

3 See Apliorism li. and second paragraph of Aphorisin lxv. in the first book.

4 Bacon means, that although there exist in nature only individualities, yet a certain number of these may have common properties, and be controlled by the same laws. Now, these homogeneous qualities which distinguish them from other individuals, lead us to class them under one expression, and sometimes under a single term. Yet these classes are only pure conceptions in Bacon's opinion, and cannot be taken for distinct substances. He evidently here aims a blow at the Realists, who concluded that the essence which united individualities in a class was the only real and immutable existence in nature, inasmuch as it entered into their ideas of individual substances as a distinct and essential property, and continued in the mind as the mold, type or pattern of the class, while its individual forms were undergoing perpetual renovation and decay. $-E d$.

5 Bacon's definition is obscure. All the idea we have of a law of nature 


\section{He who has learned the cause of a particular nature} (such as whiteness or heat), in particular subjects only, has acquired but an imperfect knowledge: as he who can induce a certain effect upon particular substances only, among those which are susceptible of it, has acquired but an imperfect power. But he who has only learned the efficient and material cause (which causes are variable and mere vehicles

consists in invariable sequence between certain classes of phenomena; but this cannot be the complete sense attached by Bacon to the term form, as be employs it in the fourth aphorism as convertible with the nature of any object; and again, in the first aphorism, as the natura naturans, or general law or condition in any substance or quality-nutura naturata-which is whatever its form is, or that particular combination of forces which impresses a certain nature upon matter subject to its influence. Thus, in the Newtonian sense, the form of whiteness would be that combination of the seven primitive rays of light which give rise to that color. In combination with this word, and affording a still further insight into its meaning, we have the phrases, latens processus ad formam, et latens schematismus corporum. Now, the latens schematismus signifies the internal texture, structure, or configuration of bodies, or the result of the respective situation of all the parts of a body; while the latens processus ad formam points out the gradation of movements which takes place among the molecula of bodies when they either conserve or change their figure. IIence we may consider the form of any quality in body as something convertible with that quality, i.e., when it exists the quality is present, and vice vers $\hat{A}_{\text {. }}$ In this sense, the form of a thing differs only from its efficient cause in being permanent, whereas we apply cause to that which exists in order of time. The latens processus and latens schematismus are subordinate to form, as concrete exemplifications of its essence. The former is the secret and invisible process by which change is effected, and involves the principle since called the law of continuity. Thus, the succession of events between the application of the match to the expulsion of the bullet is an instance of latent progress which we can now trace with some degree of accuracy. It also more directly refers to the operation by which one form or condition of being is induced upon another. For example, when the surface of iron becomes rusty, or when water is converted into steam, some change has taken place, or latent process from one form to another. Mechanics afford many exemplifications of the first latent process we have denoted, and chemistry of the second. The latens schematismus is that visible structure of bodies on which so many of their properties depend. When we inquire intu the constitution of erystals, and into the inter. nal structure of plants, we are examining into their latent schematism. $-E d$. 
conveying form to particular substances) may perhaps arrive at some new discoveries in matters of a similar nature, and prepared for the purpose, but does not stir the limits of things which are much more deeply rooted; while he who is acquainted with forms, comprehends the unity of nature in substances apparently most distinct from each other. $\mathrm{He}$ can disclose and bring forward, therefore (though it has never yet been done), things which neither the vicissitudes of nature, nor the industry of experiment, nor chance itself, would ever have brought about, and which would forever have escaped man's thoughts; from the discovery of forms, therefore, results genuine theory and free practice.

IV. Although there is a most intimate connection, and almost an identity between the ways of human power and human knowledge, yet, on account of the pernicious and inveterate habit of dwelling upon abstractions, it is by far the safest method to commence and build up the sciences from those foundations which bear a relation to the practical division, and to let them mark out and limit the theoretical. We must consider, therefore, what precepts, or what direction or guide, a person would most desire, in order to generate and superinduce any nature upon a given body: and this not in abstruse, but in the plainest language.

For instance, if a person should wish to superinduce the yellow color of gold upon silver, or an additional weight (observing always the laws of matter) or transparency on an opaque stone, or tenacity in glass, or vegetation on a substance which is not vegetable, we must (I say) consider what species of precept or guide this person would prefer. And, first, he will doubtless be anxious to be shown some method that will neither fail in effect, nor deceive him in the trial of 
it; secondly, he will be anxious that the prescribed method should not restrict him and tie him down to peculiar means, and certain particular methods of acting; for he will, perhaps, be at loss, and without the power or opportunity of collecting and procuring such means. Now if there be other means and methods (besides those prescribed) of creating such a nature, they will perhaps be of such a kind as are in his power, yet by the confined limits of the precept he will be deprived of reaping any advantage from them; thirdly, he will be anxious to be shown something not so difficult as the required effect itself, but approaching more nearly to practice.

We will lay this down, therefore, as the genuine and perfect rule of practice, that it should be certain, free and preparatory, or having relation to practice. And this is the same thing as the discovery of a true form; for the form of any nature is such, that when it is assigned the particular nature infallibly follows. It is, therefore, always present when that nature is present, and universally attests such presence, and is inherent in the whole of it. The same form is of such a character, that if it be removed the particular nature infallibly vanishes. It is, therefore, absent, whenever that nature is absent, and perpetually testifies such absence, and exists in no other nature. Lastly, the true form is such, that it deduces the particular nature from some source of essence existing in many subjects, and more known (as they term it) to nature, than the form itself. Such, then, is our determination and rule with regard to a genuine and perfect theoretical axiom, that a nature be found convertible with a given nature, and yet such as to limit the more known nature, in the manner of a real genus. But these two rules, the practical and theoretical, are in fact the 
same, and that which is most useful in practice is most correct in theory.

V. But the rule or axiom for the transformation of bodies is of two kinds. The first regards the body as an aggregate or combination of simple natures. Thus, in gold are united the following circumstances: it is yellow, heavy, of a certain weight, malleable and ductile to a certain extent; it is not volatile, loses part of its substance by fire, melts in a particular manner, is separated and dissolved by particular methods, and so of the other natures observable in gold. An axiom, therefore, of this kind deduces the subject from the forms of simple natures; for he who has acquired the forms and methods of superinducing yellowness, weight, ductility, stability, deliquescence, solution, and the like, and their degrees and modes, will consider and contrive how to unite them in any body, so as to transform ${ }^{6}$ it into gold. And this method of operating belongs to primary action; for it is the same thing to produce one or many simple natures, except that man is more confined and restricted in his operations, if many be required, on account of the difficulty of uniting many natures together. It must, however, be observed, that this method of operating (which considers natures as simple though in a concrete body) sets out from what is constant, eternal, and universal in nature, and opens such broad paths to human power, as the thoughts of man can in the present state of things scarcely comprehend or figure to itself.

The second kind of axiom (which depends on the discovery of the latent process) does not proceed by simple na-

${ }^{6}$ By the reccnt discoveries in electric magnetism, copper wires, or, indeed, wires of any metal, may be transformed into magnets; the magnetic law, or form, having been to that extent discovered. 
tures, but by concrete bodies, as they are found in nature and in its usual course. For instance, suppose the inquiry to be, from what beginnings, in what manner, and by what process gold or any metal or stone is generated from the original menstruum, or its elements, up to the perfect mincral: or, in like manner, by what process plants are generated, from the first concretion of juices in the earth, or from seeds, up to the perfect plant, with the whole successive motion, and varied and uninterrupted efforts of nature; and the same inquiry be made as to a regularly deduced system of the generation of animals from coition to birth, and so on of other bodies.

Nor is this species of inquiry confined to the mere generation of bodies, but it is applicable to other changes and labors of nature. For instance, where an inquiry is made into the whole series and continued operation of the nutri tive process, from the first reception of the food to its complete assimilation to the recipient; ${ }^{7}$ or into the voluntary motion of animals, from the first impression of the imagination, and the continuous effects of the spirits, up to the bending and motion of the joints; or into the free motion of the tongue and lips, and other accessories which give utterance to articulate sounds. For all these investigations relate to concrete or associated natures artificially brought together, and take into consideration certain particular and special habits of nature, and not those fundamental and general laws which constitute forms. It must, however, be plainly owned, that this method appears more prompt and easy, and of greater promise than the primary one.

7 Haller has pursued this investigation in his "Physiology," and has left - qsors little else to do than repeat his discoveries. $-E d$. 
In like manner the operative branch, which answers to this contemplative branch, extends and advances its operation from that which is usually observed in nature, to other subjects immediately connected with it, or not very remote from such immediate connection. But the higher and radical operations upon nature depend entirely on the primary axioms. Besides, even where man has not the means of acting, but only of acquiring knowledge, as in astronomy (for man cannot act upon, change, or transform the heavenly bodies), the investigation of facts or truth, as well as the knowledge of causes and coincidences, must be referred to those primary and universal axioms that regard simple natures; such as the nature of spontaneous rotation, attraction, or the magnetic force, and many others which are more com. mon than the heavenly bodies themselves. For let no one hope to determine the question whether the earth or heaven revolve in the diurnal motion, unless he have first comprehended the nature of spontaneous rotation.

VI. But the latent process of which we speak, is far from being obvious to men's minds, beset as they now are. For we mean not the measures, symptoms, or degrees of any process which can be exhibited in the bodies themselves, but simply a continued process, which, for the most part, escapes the observation of the senses.

For instance, in all generations and transformations of bodies, we must inquire, what is in the act of being lost and escaping, what remains, what is being added, what is being diluted, what is being contracted, what is being united, what is being separated, what is continuous, what is broken off, what is urging forward, what impedes, what predominates, what is subservient, and many other circumstances.

Nor are these inquiries again to be made in the mere 
generation and transformation of bodies only, but in all other alterations and fluctuations we must in like manner inquire; what precedes, what succeeds, what is quick, what is slow, what produces and what governs motion, and the like. All which matters are unknown and unattempted by the sciences, in their present heavy and inactive state. For, since every natural act is brought about by the smallest efforts, ${ }^{8}$ or at least such as are too small to strike our senses, let no one hope that he will be able to direct or change nature unless he have properly comprehended and observed these efforts.

VII. In like manner, the investigation and discovery of the latent conformation in bodies is no less new, than the discovery of the latent process and form. For we as yet are doubtless only admitted to the antechamber of nature, and do not prepare an entrance into her presence-room. But nobody can endue a given body with a new nature, or transform it successfully and appropriately into a new body, without possessing a complete knowledge of the body so to be changed or transformed. For he will run into vain, or, at least, into difficult and perverse methods, ill adapted to the nature of the body upon which he operates. A clear path, therefore, toward this object also must be thrown open, and well supported.

Labor is well and usefully bestowed upon the anatomy - of organized bodies, such as those of men and animals, which appears to be a subtile matter, and a useful examination of nature. The species of anatomy, however, is that of first sight, open to the senses, and takes place only in organ-

8 Bacon here first seems pregnant with the important development of the higher calculus, which, in the hands of Newton and Descartes, was to effect as great a revolution in philosophy as his method. - Ed. 
ized bodies. It is obvious, and of ready access, when compared with the real anatomy of latent conformation in bodies which are considered similar, particularly in specific objects and their parts; as those of iron, stone, and the similar parts of plants and animals, as the root, the leaf, the flower, the flesh, the blood, and bones, etc. Yet human industry has not completely neglected this species of anatomy; for we have an instance of it in the separation of similar bodies by distillation, and other solutions, which shows the dissimilarity of the compound by the union of the homogeneous parts. These methods are useful, and of importance to our inquiry, although attended generally with fallacy: for many natures are assigned and attributed to the separate bodies, as if they had previously existed in the compound, which, in reality, are recently bestowed and superinduced by fire and heat, and the other modes of separation. Besides, it is, after all, but a small part of the labor of discovering the real conformation in the compound, which is so subtile and nice, that it is rather confused and lost by the operation of the fire, than discovered and brought to light.

A separation and solution of bodies, therefore, is to be effected, not by fire indeed, but rather by reasoning and true induction, with the assistance of experiment, and by a comparison with other bodies, and a reduction to those simple natures and their forms which meet, and are combined in the compound; and we must assuredly pass from Vulcan to Minerva, if we wish to bring to light the real texture and conformation of bodies, upon which every occult and (as it is sometimes called) specific property and virtue of things depends, and whence also every rule of powerful change and transformation is deduced.

For instance, we must examine what spirit is in every 
body, ${ }^{\circ}$ what tangible essence; whether that spirit is copious and exuberant, or meagre and scarce, fine or coarse, aeriform or igniform, active or sluggish, weak or robust, progressive or retrograde, abrupt or continuous, agreeing with cxternal and surrounding objects, or differing from them, etc. In like manner must we treat tangible essence (which admits of as many distinctions as the spirit), and its hairs, fibres, and varied texture. Again, the situation of the spirit in the corporeal mass, its pores, passages, .veins, and cells, and the rudiments or first essays of the organic body, are subject to the same examination. In these, however, as in our former inquiries, and therefore in the whole investigation of latent conformation, the only genuine and clear light which completely dispels all darkness and subtile difficul. ties, is admitted by means of the primary axioms.

VIII. This method will not bring us to atoms, ${ }^{10}$ which takes for granted the vacuum, and immutability of matter (neither of which hypotheses is correct), but to the real particles such as we discover them to be. Nor is there any

9 By spirit, Bacon here plainly implies material fluid too tine to be grasped by the massisted sense, which rather operates than reasons. We sometimes adopt the same mode of expression, as in the words spirits of nitre, spirits of wine. Some such agency lias been assumed by nearly all the modern physicists, a few of whom, along wih Bacon, would leave us to gather from their expressions, that they believe such budies endowed with the sentient powers of pereeption. As another specimen of his sentiment on this subject, we may refer to a paragraph on the decomposition of compounds, in his essay on death, begiming-"The spirit which exists in all living bodies, keeps all the parts in due subjection; when it escapes, the body decomposes, or the similar parts unite." -Ed.

10 The theory of the Epicureans and others. The atoms are supposed to be invisible, unalterable particles, endued with all the properties of the given body, and forming that body by their union. They must be separated, of course, which either takes a vacuum for granted, or introduces a tertium quid into the composition of the body. 
ground for alarm at this refinement as if it were inexplicable, for, on the contrary, the more inquiry is directed to simple natures, the more will everything be placed in a plain and perspicuous light, since we transfer our attention from the complicated to the simple, from the incommensurable to the commensurable, from surds to rational quantities, from the indefinite and vague to the definite and certain; as when we arrive at the elements of letters, and the simple tones of concords. The investigation of nature is best conducted when mathematics are applied to physics. Again, let none be alarmed at vast numbers and fractions, for in calculation it is as easy to set down or to reflect upon a thousand as a unit, or the thousandth part of an integer as an integer itself.

IX." From the two kinds of axioms above specified, arise the two divisions of philosophy and the sciences, and we will use the commonly adopted terms which approach the nearest to our meaning, in our own sense, Let the investigation of forms, which (in reasoning at least, and after their own laws), are eternal and immutable, constitute metaphysics, ${ }^{12}$ and let the investigation of the efficient cause of

11 Compare the three following aphorisms with the last three chapters of the third book of the "De Augmentis Scientiarum."

12 Bacon gives this unfortunate term its proper signitication; $\mu \in \tau a$, in composition, with the Greeks signifying change or mutation. Most of our readers, no doubt, are aware that the obtrusion of this word into technical philosophy was purely capricious, and is of no older date than the publication of Aristotle's works by Andronicus of Rhodes, one of the learned men into whose hands the mauuscripts of that philosopher fell, after they were brought by Sylla from Athens to Rome. To fourteen books in these MSS. with no distinguishing title, Andronicus is said to have prefixed the words $\tau a \mu \in \tau \alpha \tau \alpha \phi v \sigma \kappa \alpha$, to denote the place which they ought to hold either in the order of Aristotle's arramgenent, or in that of study. These books treat first of those subjects which are common to matter and mind; secondly, of things separate from matter, i.e. of God, and of the subordinate spirits, which were supposed by the Peripatetics 


\section{matter, latent process, and latent conformation (which all} relate merely to the ordinary course of nature, and not to her fundamental and eternal laws), constitute physics. Parallel to these, let there be two practical divisions; to physics that of mechanics, and to metaphysics that of magic, in the purest sense of the term, as applied to its ample means, and its command over nature.

$\mathrm{X}$. The object of our philosophy being thus laid down, we proceed to precepts, in the most clear and regular order. The signs for the interpretation of nature comprehend two divisions; the first regards the eliciting or creating of axioms from experiment, the second the deducing or deriving of new experiments from axioms. The first admits of three subdirisions into ministrations. 1. To the senses. 2. To the memory. 3. To the mind or reason.

For we must first prepare as a foundation for the whole, a complete and accurate natural and experimental history. $T^{T}$ e must not imagine or invent, but discover the acts and properties of nature.

But natural and experimental history is so varied and diffuse, that it confounds and distracts the understanding unless it be fixed and exhibited in due order. We must, therefore, form tables and co-ordinations of instances, upon

to watch over particular portions of the universe. The followers of A ristotle accepted the whimsical title of Andronicus, and in their usual manner allowed a word to unite things into one science which were plainly heterogeneous. Their error was adopted by the Peripatetics of the Christian Church. The schoolmen addect to the notion of ontology, the science of the mind, or pneumatology, and as that genus of being has since become extinct with the schools, metaphysics thus in modern parlance comes to be synonymous with psychology. It were to be wished that Bacon's definition of the term had been accepted, and mental science delivered from one of the greatest monstrosities in its nomenclature, yet Bacon whimsically enough in his De Augmentis includes mathematics in metaphysics. - Ed. 
such a plan, and in such order that the understanding may be enabled to act upon them.

Even when this is done, the understanding, left to itself and to its own operation, is incompetent and unfit to construct its axioms without direction and support. Our third ministration, therefore, must be true and legitimate induction, the very key of interpretation. We must begin, however, at the end, and go back again to the others.

XI. The investigation of forms proceeds thus: a nature being given, we must first present to the understanding all the known instances which agree in the same nature, although the subject matter be considerably diversified. And this collection must be made as a mere history, and without any premature reflection, or too great degree of refinement. For instance; take the investigation of the form of heat.

\section{Instances agreeing in the Form of Heat}

1. The rays of the sun, particularly in summer, and at noon.

2. The same reflected and condensed, as between mountains, or along walls, and particularly in burning mirrors.

3. Ignited meteors.

4. Burning lightning.

5. Eruptions of flames from the cavities of mountains, etc.

6. Flame of every kind.

7. Ignited solids.

8. Natural warm baths.

9. Warm or heated liquids.

10. Warm vapors and smoke; and the air itself, which admits a most powerful and violent heat if confined, as in reverberating furnaces. 
11. Damp hot weather, arising from the constitution of the air, without any reference to the time of the year.

12. Confined and subterraneous air in some caverns, particularly in winter.

13. All shaggy substances, as wool, the skins of animals, and the plumage of birds, contain some heat.

14. All bodies, both solid and liquid, dense and rare (as the air itself), placed near fire for any time.

15. Sparks arising from the violent percussion of flint and steel.

16. All bodies rubbed violently, as stone, wood, cloth, etc., so that rudders, and axles of wheels, sometimes catch fire, and the West Indians obtain fire by attrition.

17. Green and moist vegetable matter confined and rubbed together, as roses, peas in baskets; so hay, if it be damp when stacked, often catches fire.

18. Quicklime sprinkled with water.

19. Iron, when first dissolved by acids in a glass, and without any application to fire; the same of tin, but not so intensely.

20. Animals, particularly internally; although the heat is not perceivable by the touch in insects, on account of their small size.

21. Horse dung, and the like excrement from other animals, when fresh.

22. Strong oil of sulphur and of vitriol exhibit the operation of heat in burning linen.

23. As does the oil of marjoram, and like substances, in burning the bony substance of the teeth.

24. Strong and well rectified spirits of wine exhibit the same effects; so that white of eggs when thrown into it grows hard and white, almost in the same manner as 
when boiled, and bread becomes burned and brown as if toasted.

25. Aromatic substances and warm plants, as the dracunculus [arum], old nasturtium, etc., which, though they be not warm to the touch (whether whole or pulverized), yet are discovered by the tongue and palate to be warm and almost burning when slightly masticated.

26. Strong vinegar and all acids, on any part of the body not clothed with the epidermis, as the eye, tongue, or any wounded part, or where the skin is removed, excite a pain differing but little from that produced by heat.

27. Even a severe and intense cold produces a sensation of burning. ${ }^{13}$

"Nec Boreæ penetrabile frigus adurit."

28. Other instances.

We are wont to call this a table of existence and presence.

XII. We must next present to the understanding instances which do not admit of the given nature, for form (as we have observed) ought no less to be absent where the given nature is absent, than to be present where it is pres. ent. If, however, we were to examine every instance, our labor would be infinite.

Negatives, therefore, must be classed under the affirmatives, and the want of the given nature must be inquired into more particularly in objects which have a very close connection with those others in which it is present and manifest. And this we are wont to term a table of deviation or of absence in proximity.

18 "Ne tenues pluviæ, rapidive potentia solis Acrior, aut Boreæ penetrabile frigus adurat.",

-Virg. Georg. i. 92, 93.

SCIENCE- Vol. $22-6$ 


\section{Proximate Instances wanting the Nature of Heat}

The rays of the moon, stars, and comets, are not found to be warm to the touch, nay, the severest cold has been observed to take place at the full of the moon. Yet the larger fixed stars are supposed to increase and render more intense the heat of the sun, as he approaches them, when ? the sun is in the sign of the Lion, for instance, and in the dog-days. ${ }^{14}$

The rays of the sun in what is called the middle region of the air give no heat, to account for which the commonly assigned reason is satisfactory; namely, that that region is neither sufficiently near to the body of the sun whence the rays emanate, nor to the earth whence they are reflected. And the fact is manifested by snow being perpetual on the tops of mountains, unless extremely lofty. But it is observed, on the other hand, by some, that at the Peak of Teneriffe, and also among the Andes of Peru, the tops of the mountains are free from snow, which only lies in the lower part as you ascend. Besides, the air on the summit of these mountains is found to be by no means cold, but only thin and sharp; so much so, that in the Andes it pricks and hurts the eyes from its extreme sharpness, and even excites the orifice of the stomach and produces vomiting. 'The ancients also observed, that the rarity of the air on the sum.

14 This notion, which he repeats again, and particularizes in the 18 th aph. of this book, is horrowed from the ancients, and we need not say is as wise as their other astronomical conjectures. The sum also approaches stars quite as large in other quarters of the zodiac, when it looks down upon the earth through the murky clouds of winter. When that luminary is in Leo, the heat of the earth is certainly greater than at any other period, but this arises from the accumulation of heat after the solstice, for the same reason that the maximum heat of the day is at two o'clock instead of noon. $-E d$. 
mit of Olympus was such, that those who ascended it were obliged to carry sponges moistened with vinegar and water, and to apply them now and then to their nostrils, as the air was not dense enough for their respiration; on the summit of which mountain it is also related, there reigned so great a serenity and calm, frce from rain, snow, or wind, that the letters traced upon the ashes of the sacrifices on the altar of Jupiter, by the fingers of those who had offered them, would remain undisturbed till the next year. Those even, who at this day go to the top of the Peak of 'Teneriffe, walk by night and not in the daytime, and are advised and pressed by their guides, as soon as the sun rises, to make haste in their descent, on account of the danger (apparently arising from the rarity of the atmosphere), lest their breathing should be relaxed and suffocated. ${ }^{15}$

The reflection of the solar rays in the polar regions is found to be weak and inefficient in producing heat, so that the Dutch, who wintered in Nova Zembla, and expected that their vessel would be freed about the beginning of July from the obstruction of the mass of ice which had blocked it up, were disappointed and obliged to embark in their boat. Hence the direct rays of the sun appear to have but little power even on the plain, and when reflected, unless they are multiplied and condensed, which takes place when the sun tends more to the perpendicular; for, then, the incidence of the rays occurs at more acute angles, so that the reflected rays are nearer to each other, while, on the contrary, when the sun is in a very oblique position,

15 Bouguer, employed by Louis XIV. in philosophical researches, ascended the Andes to discover the globular form of the earth, and published an account of his passage, which verifies the statement of Bacon. 
the angles of incidence are very obtuse, and the reflected rays at a greater distance. In the meantime it must be observed, that there may be many operations of the solar rays, relating, too, to the nature of heat, which are not proportioned to our touch, so that, with regard to us, they do not tend to produce warmth, but, with regard to some other bodies, have their due effect in producing it.

Let the following experiment be made. Take a lens the reverse of a burning-glass, and place it between the hand and the solar rays, and observe whether it diminish the heat of the sun as a burning-glass increases it. For it is clear, with regard to the visual rays, that in proportion as the lens is male of unequal thickness in the middle and at its sides, the images appear either more diffused or contracted. It should be seen, therefore, if the same be true with regard to heat.

Let the experiment be well tried, whether the lunar rays can be received and collected by the strongest and best burning-glasses, so as to produce even the least degree of heat. ${ }^{16} \quad$ But if that degree be, perhaps, so subtile and weak, as not to be perceived or ascertained by the touch, we must have recourse to those glasses which indicate the warm or cold state of the atmosphere, and let the lunar rays fall

16 Montanari asserts in his hook against the astrologers that he had satisfied limself by numerous and oft-repeited experiments, that the lumar rays gathered to a focus produced a sensible degree of heat. Muschenbröck, however, adopts the opposite opinion, and asserts that himself, De la Hire, Villet, and Tschirnliausen had tried with that view the strongest burning-glasses in vain. (Opera de Igne.) De la Lande makes a similar confession in his Astronomy (vol. ii. vii. $\$$ 1413). Bouguer, whom we have just quoted, demonstrated that the light of the moon was 300,000 decrees less than that of the sun; it would consequently be necesary to invent a glass with an alsorbing power 300,000 degrees greater than those ordinarily in use, to try the experiment Bacon speaks of.-Ed. 
through the burning-glass on the top of this thermometer, and then notice if the water be depressed by the heat. ${ }^{17}$

Let the burning-glass be tried on warm objects which emit no luminous rays, as heated but not ignited iron or stone, or hot water, or the like; and observe whether the heat become increased and condensed, as happens with the solar rays.

Let it be tried on common flame.

The effect of comets (if we can reckon them among meteors ${ }^{18}$ ) in augmenting the heat of the season is not found to be constant or clear, although droughts have generally been observed to follow them. However, luminous lines, and pillars, and openings, and the like, appear more often in winter than in summer, and especially with the most intense cold but joined with drought. Lightning, and coruscations, and thunder, however, rarely happen in winter, and

17 In this thermometer, mercury was not dilated by heat or contracted by cold, as the one now in use, but a mass of air employed instead, which filled the cavity of the bulb. This being placed in an inverted position to ours, that is to say, with the bulb uppermost, pressed down the liquor when the air became dilated by heat, as ours press it upward; and when the heat diminished, the liqour rose to occupy the place vacated by the air, as the one now in use descends. It consequently was liable to be affected by a change in the temperature, as by the weight of air, and could afford only a rude standard of accuracy in scientific investigations. This thermometer was not Bacon's own contrivance, as is commonly supposed, but that of Drebbel. $-E d$.

18 La Lande is indignant that the Chaldeans should have more correct notions of the nature of comets than the modern physicists, and charges Bacon with entertaining the idea that they were the mere effects of vapor and heat. This passage, with two others more positive, in the "De Aug." (cap. xl.) and the "Descript. Globi Intellect." (cap. vi.) certainly afford ground for the assertion; but if Bacon erred, he erred with Galileo, and with the foremost spirits of the times. It is true that Pythagoras and Seneca had asserted their belief in the solidity of these bodies, but the wide dominion which Aristotle subsequently exercised, threw their opinions into the shade, and made the opposite doctrine everywhere paramount.-Ed. 
generally at the time of the greatest heats. The appearances we term falling stars are generally supposed to consist of some shining and inflamed viscous substance, rather than of violently hot matter; but let this be further investigated.

Some coruscations emit light without burning, but are never accompanied by thunder.

Eructations and eruptions of flame are to be found in cold climates as well as in hot, as in Iceland and Greenland; just as the trees of cold countries are sometimes inflammable and more pitchy and resinous than in warm, as the fir, pine, and the like. But the position and nature of the soil, where such eruptions are wont to happen, is not yet sufficiently investigrated to enable us to subjoin a negative instance to the affirmative.

All flame is constantly more or less warm, and this instance is not altogether negative; yet it is said that the ignis fatuus (as it is called), and which sometimes is driven against walls, has but little heat; perhaps it resembles that of spirits of wine, which is mild and gentle. That flame, however, appears yet milder, which in some well authenticated and serious histories is said to have appeared round the head and hair of boys and virgins, and instead of burning their hair, merely to have played about it. And it is most certain that a sort of flash, without any evident heat, has sometimes been seen about a horse when sweating at night, or in damp weather. It is also a well known fact, ${ }^{19}$ and it was almost considered as a miracle, that a few years since a girl's apron sparkled when a little shaken or rubbed, which was, perhaps, occasioned by the alum or salts with which

19 Was it a silk apron which exhibited electric sparks? Silk was then scarce. 
the apron was imbued, and which, after having been stuck together and incrusted rather strongly, were broken by the friction. It is well known that all sugar, whether candied or plain, if it be hard, will sparkle when broken or scraped in the dark. In like manner sea and salt water is sometimes found to shine at night when struck violently by the oar. The foam of the sea when agitated by tempests also sparkles at night, and the Spaniards call this appearance the sea's lungs. It has not been sufficiently ascertained what degree of heat attends the flame which the ancient sailors called Castor and Pollux, and the moderns call St. Ermus' fire.

Every ignited body that is red-hot is always warm, although without flame, nor is any negative instance subjoined to this affirmative. Rotten wood, however, approaches nearly to it, for it shines at night, and yet is not found to be warm; and the putrefying scales of fish which shine in the same manner are not warm to the touch, nor the body of the glowworm, or of the fly called Lucciola. ${ }^{20}$

The situation and nature of the soil of natural warm baths has not been sufficiently investigated, and therefore a negative instance is not subjoined.

To the instances of warm liquids we may subjoin the negative one of the peculiar nature of liquids in general; for no tangible liquid is known that is at once warm in its nature and constantly continues warm; but their heat is only superinduced as an adventitious nature for a limited time, so that those which are extremely warm in their power and effect, as spirits of wine, chemical aromatic oils, the oils of vitriol and sulphur, and the litse, and which speedily burn, are yet cold at first to the touch, and the water of natural baths, poured into any vessel and separated from 
its source, cools down like water heated by the fire. It is, however, true that oily substances are rather less cold to the touch than those that are aqueous, oil for instance than water, silk than linen; but this belongs to the table of degrees of cold.

In like manner we may subjoin a negative instance to that of warm vapor, derived from the nature of vapor itself, as far as we are acquainted with it. For exhalations from oily substances, though easily inflammable, are yet never warm unless recently exhaled from some warm substance.

The same may be said of the instance of air; for wo never perceive that air is warm unless confined or pressed, or manilestly heated by the sun, by fire, or some other warm body.

$\Lambda$ negative instance is exhibited in weather by its coldness with an east or north wind, beyond what the season would lead us to expect, just as the contrary takes place with the south or west winds. An inclination to rain (especially in winter) attends warm weather, and to frost cold weather.

$\Lambda$ negative instance as to air confined in caverns may be observed in summer. Indeed, we should make a more diligent inquiry into the nature of confined air. For in the first place the qualities of air in its own nature with regard to heat and cold may reasonably be the subject of doubt; for air evidently derives its heat from the effects of celestial bodies, and possibly its cold from the exhalation of the earth, and in the mid region of air (as it is termed) from cold vapors and snow, so that no judgment can be formed of the nature of air by that which is out of doors and exposed, but a more correct one might be derived from confined air. It is necessary, however, that the air should be 
inclosed in a vessel of such materials as would not imbue it with heat or cold of themselves, nor easily admit the influence of the external atmosphere. The experiment should be made, therefore, with an earthen jar, covered with folds of leather to protect it from the external air, and the air should be kept three or four days in this vessel well closed. On opening the jar, the degree of heat may be ascertained either by the hand or a graduated glass tube.

There is a similar doubt as to whether the warmth of wool, skins, feathers, and the like, is devived from a slight inherent heat, since they are animal excretions, or from their being of a certain fat and oily nature that accords with heat, or merely from the confinement and separation of air which we spoke of in the preceding paragraph; $;^{21}$ for all air appears to possess a certain degree of warmth when separated from the external atmosphere. Let an experiment be made, therefore, with fibrous substances of linen, and not of wool, feathers, or silk, which are animal excretions. For it is to be observed that all powders (where air is manifestly inclosed) are less cold than the substances when whole, just as we imagine froth (which contains air) to be less cold than the liquid itself.

We have here no exactly negative instance, for we are not acquainted with any body tangible or spirituous which does not admit of heat when exposed to the fire. There is, however, this difference, that some admit it more rapidly, as air, oil, and water, others more slowly, as stone and metals. ${ }^{22}$ This, however, belongs to the table of degrees.

21 This last is found to be the real reason, air not being a good eonductor, and therefore not allowing the escape of heat. The confined air is disengiged when these substances are placed under an exhausted receiver.

22 This is erroneous. Air, in fact, is one of the worst, and metals are the best conductors of heat. 
No negative is here subjoined, except the remark that sparks are not kindled by flint and steel, or any other hard substance, unless some small particles of the stone or metal are struck off, and that the air never forms them by friction, as is commonly supposed; besides, the sparks from the weight of the ignited substance have a tendency to descend rather than to rise, and when extinguished become a sort of dark ash.

We are of opinion that here again there is no negative; for we are not acquainted with any tangible body which does not become decidedly warm by friction, so that the ancients feigned that the gods had no other means or power of creating heat than the friction of air, by rapid and violent rotation. On this point, however, further inquiry must be made, whether bodies projected by machines (as balls from cannon) do not derive some degree of heat from meeting the air, which renders them somewhat warm when they fall. The air in motion rather cools than heats, as in the winds, the bellows, or breath when the mouth is contracted. The motion, however, in such instances is not sufficiently rapid to excite heat, and is applied to a body of air, and not to its component parts, so that it is not surprising that heat should not be generated.

We must make a more diligent inquiry into this instance; for herbs and green and moist vegetables appear to possess a latent heat, so small, however, as not to be perceived by the touch in single specimens, but when they are united and confined, so that their spirit cannot exhale into the air, and they rather warm each other, their heat is at once manifested, and even flame occasionally in suitable substances.

Here, too, we must make a more diligent inquiry; for 
quicklime, when sprinkled with water, appears to conceive heat, either from its being collected into one point (as we observed of herbs when confined), or from the irritation and exasperation of the fiery spirit by water, which occasions a conflict and struggle. The true reason will more readily be shown if oil be used instead of water, for oil will equally tend to collect the confined spirit, but not to irritate. The experiment may be made more general, both by using the ashes and calcined products of different bodies and by pouring different liquids upon them.

A negative instance may be subjoined of other metals which are more soft and soluble; for leaf gold dissolved by aqua regia, or lead by aqua fortis, are not warm to the touch while dissolving, no more is quicksilver (as far as I remember), but silver excites a slight heat, and so does copper, and tin yet more plainly, and most of all iron and steel, which excite not only a powerful heat, but a violent bubbling. The heat, therefore, appears to be occasioned by the struggle which takes place when these strong dissolvents penetrate, dig into, and tear asunder the parts of those substances, while the substances themselves resist. When, however, the substances yield more easily, scarcely any heat is excited.

There is no negative instance with regard to the heat of animals, except in insects (as has been observed), owing to their small size; for in fishes, as compared with land animals, a lower degree rather than a deprivation of heat is observable. In plants and vegetables, both as to their exudations and pith when freshly exposed, there is no sensible degree of heat. But in animals there is a great difference in the degree, both in particular parts (for the heat varies near the heart, the brain, and the extremities) and in 
the circumstances in which they are placed, such as violent exercise and fevers.

Here, again, there is scarcely a negative instance. I might add that the excrements of animals, even when they are no longer fresh, possess evidently some effective heat, as is shown by their enriching the soil.

Such liquids (whether oily or watery) as are intensely acrid exhibit the effects of heat, by the separation and burning of bodies after some little action upon them, yet they are not at first warm to the touch, but they act according to their affinity and the pores of the substances to which they are applied; for aqua regia dissolves gold but not silveron the contrary, aqua fortis dissolves silver but not gold; neither of them dissolves glass, and so of the rest.

Let spirits of wine be tried on wood, or butter, wax, or pitch, to see if this will melt them at all by their beat; for the twenty-fourth instance shows that they possess properties resembling those of heat in causing incrustation. Let an experiment also be made with a graduated glass or calendar, ${ }^{23}$ concave at the top, by pouring well-rectified spirits of wine into the cavity, and covering it up in order that they may the better retain their heat, then observe whether their heat make the water descend.

Spices and acrid herbs are sensibly warm to the palate, and still more so when taken internally; one should see, therefore, on what other substances they exhibit the effects of heat. Now, sailors tell us that when large quantities of spices are suddenly opened, after having been shut up for some time, there is some danger of fever and inflammation to those who stir them or take them out. An experiment

${ }^{23}$ See No. 28 in the table of the degrees of heat. 
might, therefore, be made whether such spices and herbs, when produced, will, like smoke, dry fish and meat hung up over them.

There is an acrid effect and a degree of penetration in cold liquids, such as vinegar and oil of vitriol, as well as in warm, such as oil of marjoram and the like; they have, therefore, an equal effect in causing animated substances to smart, and separating and consuming inanimate parts. There is not any negative instance as to this, nor does there exist any animal pain unaccompanied by the sensation of heat.

There are many effects common to cold and heat, however different in their process; for snowballs appear to burn boys' hands after a little time, and cold no less than fire preserves bodies from putrefaction-besides both heat and cold contract bodies. But it is better to refer these instances and the like to the investigation of cold.

XIII. In the third place we must exhibit to the understanding the instances in which that nature, which is the object of our inquiries, is present in a greater or less degree, either by comparing its increase and decrease in the same object, or its degree in different objects; for since the form of a thing is its very essence, and the thing only differs from its form as the apparent from the actual object, or the exterior from the interior, or that which is considered with relation to man from that which is considered with relation to the universe; it necessarily follows that no nature can be considered a real form which does not uniformly diminish and increase with the given nature. We are wont to call this our Table of Degrees, or Comparative Instances. 


\section{Table of the Degrees or Comparative Instances of Heat}

We will first speak of those bodies which exhibit no degree of heat sensible to the touch, but appear rather to possess a potential heat, or disposition and preparation for it. We will then go on to others, which are actually warm to the touch, and observe the strength and degree of it.

1. There is no known solid or tangible body which is by its own nature originally warm; for neither stone, metal, sulphur, fossils, wood, water, nor dead animal carcasses are found warm. The warm springs in baths appear to be heated accidentally, by flame, subterraneous fire (such as is thrown up by Etna and many other mountains), or by the contact of certain bodies, as heat is exhibited in the dissolution of iron and tin. The degree of heat, therefore, in inanimate objects is not sensible to our touch; but they differ in their degrees of cold, for woor and metal are not equally cold. ${ }^{2+}$ This, however, belongs to the Table of Degrees of Cold.

2. But with regard to potential heat and predisposition to flame, we find many inanimate substances wonderfully adapted to it, as sulphur, naphtha, and saltpetre.

3. Bodies which have previously acquired heat, as horse dung from the animal, or lime, and perhaps ashes and soot from fire, retain some latent portion of it. Hence distillations and separations of substances are effected by burying

24 Bacon here mistakes sensation confined to ourselves for an internal property of distinct substances. Melals are denser than wood, and our bodies consequently coming into contact with more particles of matter when we touch them, lose a greater quantity of heat than in the case of lighter substances. - Ed. 
them in horse dung, and heat is excited in lime by sprinkling it with water (as has been before observed).

4. In the vegetable world we know of no plant, nor part of any plant (as the exudations or pith) that is warm to man's touch. Yet (as we have before observed) green weeds grow warm when confined, and some vegetables are warm and others cold to our internal touch, i.e., the palate and stomach, or even after a while to our external skin (as is shown in plasters and ointments).

5. We know of nothing in the various parts of animals, when dead or detached from the rest, that is warm to the touch; for horse dung itself does not retain its heat, unless it be confined and buried. All dung, however, appears to possess a potential heat, as in manuring fields; so also dead bodies are endued with this latent and potential heat to such a degree, that in cemeteries where people are interred daily the earth acquires a secret heat, which consumes any recently deposited body much sooner than pure earth; and they tell you that the people of the East are acquainted with a fine soft cloth, made of the down of birds, which can melt butter wrapped gently up in it by its own warmth.

6. Manures, such as every kind of dung, chalk, sea-sand, salt and the like, have some disposition toward heat.

7. All putrefaction exhibits some slight degree of heat, though not enough to be perceptible by the touch; for neither the substances which by putrefaction are converted into animalculæ, ${ }^{25}$ as flesh and cheese, nor rotten wood which shines in the dark, are warm to the touch. The heat,

25 This was the ancient opinion, but the moderns incline to the belief that these insects are produced by generation or fecundity from seeds deposited by their iribes in bodies on the verge of putrefaction. $-E d$. 
however, of putrid substances displays itself occasionally in a disgusting and strong scent.

8. The first degree of heat, therefore, in substances which are warm to the human touch appears to be that of animals, and this admits of a great variety of degrees, for the lowest (as in insects) is scarcely perceptible, the highest scarcely equals that of the sun's rays in warm climates and weather, and is not so acute as to be insufferable to the hand. It is said, however, of Constantius, and some others of a very dry constitution and habit of body, that when attacked with violent fevers, they became so warm as to appear almost to burn the hand applied to them.

9. Animals become more warm by motion and exercise, wine and feasting, venery, burning fevers, and grief.

10. In the paroxysm of intermittent fevers the patients are at first seized with cold and shivering, but soon afterward become more heated than at first-in burning and pestilential fevers they are hot from the beginning.

11. Let further inquiry be made into the comparative heat of different animals, as fishes, quadrupeds, serpents, birds, and also of the different species, as the lion, the kite, or man; for, according to the vulgar opinion, fishes are the least warm internally, and birds the most, particularly doves, hawks, and ostriches.

12. Let further incuiry be made as to the comparative heat in different parts and limbs of the same animal; for milk, blood, seed, and eggs are moderately warm, and less hot than the outward flesh of the animal when in motion or agitated. The degree of heat of the brain, stomach, heart, and the rest, has not yet been equally well investigated.

13. All animals are externally cold in winter and cold weather, but are thought to be internally warmer. 
14. The heat of the heavenly bodies, even in the warmest climates and seasons, never reaches such a pitch as to light or burn the driest wood or straw, or even tinder without the aid of burning-glasses. It can, however, raise vapor from moist substances.

15. Astronomers tell us that some stars are hotter than others. Mars is considered the warmest after the Sun, then Jupiter, then Venus. The Moon and, above all, Saturn, are considered to be cold. Among the fixed stars Sirius is thought the warmest, then Cor Leonis or Regulus, then the lesser Dog-star.

16. The sun gives out more heat as it approaches toward the perpendicular or zenith, which may be supposed to be the case with the other planets, according to their degree of heat; for instance, that Jupiter gives out more heat when situated beneath Cancer or Leo than when he is beneath Capricorn and Aquarius.

17. It is to be supposed that the sun and other planets give more heat in perigee, from their approximation to the earth, than when in apogee. But if in any country the sun should be both in its perigee and nearer to the perpendicular at the same time, it must necessarily give out more heat than in a country where it is also in perigee, but situated more obliquely; so that the comparative altitude of the planets should be observed, and their approach to or declination from the perpendicular in different countries.

18. The sun and other planets are thought also to give out more heat in proportion as they are nearer to the larger fixed stars, as when the sun is in Leo he is nearer Cor Leonis, Cauda Leonis, Spica Virginis, Sirius, and the lesser Dog-star, than when he is in Cancer, where, however, he approaches nearer to the perpendicular. It is probable, 
also, that the quarters of the heavens produce a greater heat (though not perceptibly), in proportion as they are actorned with a greater number of stars, particularly those of the first magnitude.

19. On the whole, the heat of the heavenly bodies is augmented in three ways: 1 . The approach to the perpen dicular; 2. Proximity or their perigee; 3. The conjunction or union of stars.

20. There is a very considerable difference between the degrce of heat in animals, and even in the rays of the heav. enly bodies (as they reach us), and the heat of the most gentle flame, and even of all ignited substances, nay, liquids, or the air itself when unusually heated by fire. For the flame of spirit of wine, though diffused and uncollected, is yet able to set straw, linen, or paper on fire, which animal heat, or that of the sun, will never accomplish without a burning-glass.

21. There are, however, many degrees of strength and weakness in flame and ignited bodies: but no diligent inquiry has been made in this respect, and we must, therefore, pass it hastily over. Of all flames, that of spirits of wine appears to be the most gentle, except perhaps the ignis fatums, or the flashes from the perspiration of animals. After this we should be inclined to place the flame of light and porous vegetables, such as straw, reeds, and dried leaves; from which the flame of hair or feathers differs but little. Then, perhaps, comes the flame of wood, particularly that which contains but little rosin or pitch; that of small wood, however (such as is usually tied up in fagots), is milder than that of the trunks or roots of trees. This can be easily tried in iron furnaces, where a fire of fagots or branches of trees is of little service. Next follows the flame 
of oil, tallow, wax, and the like oily and fat substances, which are not very violent. But a most powerful heat is found in pitch and rosin, and a still greater in sulphur, cam. phor, naphtha, saltpetre, and salts (after they have discharged their crude matter), and in their compounds; as in gunpowder, Greek fire (vulgarly called wild fire), and its varieties, which possess such a stubborn heat as scarcely to be extinguished by water.

22. We consider that the flame which results from some imperfect metals is very strong and active; but on all these points further inquiry should be made.

23. The flame of vivid lightning appears to cxceed all the above, so as sometimes to have melted even wrought iron into drops, which the other flames cannot accomplish.

2t. In ignited bodies there are different degrees of heat, concerning which, also, a diligent inquiry has not been made. TVe consider the faintest heat to he that of tinder, touchwood, and Ary rope match, such as is used for discharging cannon. Next follows that of ignited charcoal or cinders, and even bricks, and the like; but the most violent is that of ignited metals, as iron, copper, and the like. Further inquiry, however, must be made into this also.

25. Some ignited bodies are found to be much warmer than some flames; for instance, red hot iron is much warmer, and burns more than the flame of spirits of wine.

26. Some bodies even not ignited, but only heated by the fire, as boiling water, and the air confined in reverberatories, surpass in heat many flames and ignited substances.

27. Motion increases heat, ${ }^{26}$ as is shown in the bellows

26 The correct measure of the activity of flame may be obtained by multiplying its natural force into the square of its velocity. On this account the flame 
and the blowpipe; for the harder metals are not dissolved or melted by steady quiet fire, without the aid of the blowpipe.

28. Let an experiment be made with burning-glasses; in which respect I have observed, that if a glass be placed at the distance of ten inches, for instance, from the combustible object, it does not kindle or burn it so readily, as if the glass be placed at the distance of five inches (for instance), and be then gradually and slowly withdrawn to the distance of ten inches. The cone and focus of the rays, however, are the same, but the mere motion increases the effect of the heat.

29. Conflagrations, which take place with a high wind, are thought to make greater way against than with the wind, because when the wind slackens, the flame recoils more rapidly than it advances when the wind is favorable.

30. Flame does not burst out or arise unless it have some hollow space to move and exert itself in, except in the exploding flame of gunpowiler, and the like, where the compression and confinement of the flame increase its fury.

31. The anvil becomes so hot by the hammer, that if it were a thin plate it might probably grow red, like ignited iron by repeated strokes. Let the experiment be tried.

32. But in ignited bodies that are porous, so as to leave room for the fire to move itself, if its motion be prevented by strong compression, the fire is immediately extinguished; thus it is with tinder, or the burning snuff of a candle or lamp, or even hot charcoal or cinders; for when they are squeezed by surfters, or the foot, and the like, the effect of the fire instantly ceases.

of vivid lightning mentioned in No. 23 contains so much vigor, its velocity being greater than that arising from other heat. $-E d$. 
33. The approach toward a hot body increases heat in proportion to the approximation; a similar effect to that of light, for the nearer any object is placed toward the light, the more visible it becomes.

34. The $e^{27}$ union of different heats increases heat, unless the substances be mixed; for a large and small fire in the same spot tend mutually to increase each other's heat, but lukewarm water poured into boiling water cools it.

35. The continued neighborhood of a warm body increases heat. For the heat, which perpetually passes and emanates from it, being mixed with that which preceded it, multiplies the whole. A fire, for instance, does not warm a room in half an hour as much as the same fire would in an hour. This does not apply to light, for a lamp or candle placed in a spot gives no more light by remaining there, than it did at first.

36. The irritation of surrounding cold increases heat, as may be seen in fires during a sharp frost. We think that this is owing not merely to the confinement and compression of the heat (which forms a sort of union), but also by the exasperation of it, as when the air or a stick are violently compressed or hent, they recoil, not only to the point they first occupied, but still furtber back. Let an accurate experiment, therefore, be made with a stick, or ssmething of the kind, put into the flame, in order to see whether it be not sooner burned at the sides than in the middle of it. $^{28}$

27 The fires supply fresh heat, the water has only a certain quantity of heat, which being diffused over a fresh supply of cooler water, must be on the whole lowered.

$2 s$ If condensation were the cause of the greater heat, Bacon concludes the centre of the flame would be the hotter part, and vice versit. The fact is, neither of the causes assigned by Bacon is the true one; for the fire burns 
37. There are many degrees in the susceptibility of heat. And, first, it must be observed how much a low gentle heat changes and partially warms even the bodies least susceptible of it. For even the heat of the hand imparts a little warmth to a ball of lead or other metal held a short time in it; so easily is heat transmitted and excited, without any apparent change in the body.

38. Of all bodies that we are acquainted with, air admits and loses heat the most readily, which is admirably seen in weather-glasses, whose construction is as follows: Take a glass with a hollow belly, and a thin and long neck; turn it upside down, and place it with its mouth downward into another glass vessel containing water; the end of the tube touching the bottom of the vessel, and the tube itself leaning a little on the edge, so as to be fixed upright. In order to do this more readily, let a little wax be applied to the edge, not, however, so as to block up the orifice, lest, by preventing the air from escaping, the motion, which we shall presently speak of, and which is very gentle and delicate, should be impeded.

Before the first glass be inserted in the other, its upper part (the belly) should be warmed at the fire. Then upon placing $i^{t}$ as we have described, the air (which was dilated by the heat), after a sufficient time has been allowed for it to lose the additional temperature, will restore and contract itself to the same dimensions as that of the external or common atmosphere at the moment of immersion, and the water will be attracted upward in the tube to a proportionate extent. A long narrow slip of paper should be attached to air pressing rapidly into the heated room and toward the chimney.- $-E d$. 
the tube, divided into as many degrees as you please. You will then perceive, as the weather grows warmer or colder, that the air contracts itself into a narrower space in cold weather and dilates in the warm, which will be exhibited by the rising of the water as the air contracts itself, and its depression as the air dilates. The sensibility of the air with regard to heat or cold is so delicate and exquisite, that it far exceeds the human touch, so that a ray of sunshine, the heat of the breath, and much more, that of the hand placed on the top of the tube, immediately causes an evident depression of the water. We think, however, that the spirit of animals possesses a much more delicate susceptibility of heat and cold, only that it is impeded and blunted by the grossness of their bodies.

39. After air, we consider those bodies to be most sensible of heat, which have been recently changed and contracted by cold, as snow and ice; for they begin to be dissolved and melt with the first mild weather. Next, perhaps, follows quicksilver; then greasy substances, as oil, butter, and the like; then wood; then water; lastly, stones and metals, which do not easily grow hot, particularly toward their centre. ${ }^{29}$ When heated, however, they retain their temperature for a very long time; so that a brick or stone, or hot iron, plunged in a basin of cold water, and kept there

29 Bacon appears to have confounded combustibility and fusibility with susceptibility of heat; for though the metals will certainly neither dissolve as soon as ice or butter, nor be consumed as soon as wood, that only shows that different degrees of heat are required to produce similar effects on different bodies; but metals much more readily acquire and transmit the same degree of heat than any of the above substances. The rapid transmission renders them generally cold to the touch. The convenience of fixing wooden handles to vessels containing hot water illustrates these observations. 
for a quarter of an hour or thereabout, retains such a heat as not to admit of being touched.

40. The less massive the body is, the more readily it grows warm at the approach of a heated body, which shows that heat with us is somewhat averse to a tangible mass. ${ }^{30}$

41. Ileat with regard to the human senses and touch is various and relative, so that lukewarm water appears hot if the hand be cold, and cold if the hand be hot.

$\mathrm{XIV}$. Any one may readily see how poor we are in bistory, since in the above tables, besides occasionally inserting traditions and report instead of approved bistory and authentic instances (always, however, adcling some note if their credit or authority be doubtful), we are often forced to subjoin, "Let the experiment be tried-Let further inquiry be made."

XV. We are wont to term the office and use of these three tables the presenting a review of instances to the understanding; and when this has been done, induction itself is to be brought into action. For on an individual review of all the instances a nature is to be found, such as always to be present and absent with the given nature, to increase and decrease with it, and, as we have said, to form a more cormmon limit of the nature. If the mind attempt this affirmatively from the first (which it always will when left to itself), there will spring up phantoms, mere theories and ill-defined notions, with axioms requiring daily correction. These will, doubtless, be better or worse, according to the power and strength of the understanding which creates them. But it is only for God (the bestower and

30 Another singular error, the truth being, that solid bodies are the best conductors; but of course where heat is diffused over a large mass, it is less in each part, than if that part alone absorbed the whole quantum of heat. $-E d$. 
creator of forms), and perbaps for angels and intelligences, at once to recognize forms affirmatively at the first glance of contemplation: man, at lest, is unable to do so, and is only allowed to proceed first by negatives, and then to conclude with affirmatives, after every species of exclusion.

XVI. We must, therefore, effect a complete solution and separation of nature; not by fire, but by the mind, that divine fire. The first work of legitimate induction, in the discovery of forms, is rejection, or the exclusive instances of individual natures, which are not found in some one instance where the given nature is present, or are found in any one instance where it is absent, or are found to increase in any one instance where the given nature decreases, or the reverse. After an exclusion correctly effected, an affirmative form will remain as the residuum, solid, true, and well defined, while all volatile opinions go off in smoke. This is readily said; but we must arrive at it by a circuitous route. We shall perhaps, however, omit nothing that can facilitate our progress.

XVII. The first and almost perpetual precaution and warning which we consider necessary is this; that none should suppose from the great part assigned by us to forms, that we mean such forms as the meditations and thoughts of men have hitherto been accustomed to. In the first place, we do not at present mean the concrete forms, which (as we have observed) are in the common course of things compounded of simple natures, as those of a lion, an eagle, a rose, gold, or the like. The moment for discussing these will arrive when we come to treat of the latent process and latent conformation, and the discovery of them as they exist in what are called substances, or concrete natures.

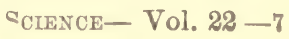


Nor again, would we be thought to mean (even when treating of simple natures) any abstract forms or ideas, either undefined or badly defined in matter. For when we speak of forms, we mean nothing else than those laws and regulations of simple action which arrange and constitute any simple nature, such as heat, light, weight, in every species of matter, and in a susceptible subject. The form of heat or form of light, therefore, means no more than the law of heat or the law of light. Nor do we ever abstract or withdraw ourselves from things, and the operative branch of philosophy. When, therefore, we say (for instance) in our investigation of the form of heat, Reject rarity, or, Rarity is not of the form of heat, it is the same as if we were to say, Man can superinduce heat on a dense body, or the reverse, Man can abstract or ward off heat from a rare body.

But if our forms appear to any one to be somewhat ab. stracted, from their mingling and uniting heterogeneous objects (the heat, for instance, of the heavenly bodies appears to be very different from that of fire; the fixed red of the rose and the like, from that which is apparent in the rainbow, or the radiation of opal or the diamond; ${ }^{31}$ death by drowning, from that by burning, the sword, apoplexy, or consumption; and yet they all agree in the common natures of heat, redness, and death), let him be assured that his understanding is inthralled by habit, by general appearances and hypotheses. For it is most certain that, however heterogencous and distinct, they agree in the form or law which regulates heat, redness, or death; and that human power cannot be emancipated and freed from the common

31 This general Jaw or form has been well illustraked by Newton's discovery of the decomposition of colors. 
course of nature, and expanded and exalted to new efficients and new modes of operation, except by the revelation and invention of forms of this nature. But after this ${ }^{32}$ union of nature, which is the principal point, we will afterward, in its proper place, treat of the divisions and ramifications of nature, whether ordinary or internal and more real.

XVIII. We must now offer an example of the exclusion or rejection of natures found by the tables of review, not to be of the form of heat; first premising that not only each table is sufficient for the rejection of any nature, but even each single instance contained in them. For it is clear from what has been said that every contradictory instance destroys a hypothesis as to the form. Still, however, for the sake of clearness, and in order to show more plainly the use of the tables, we redouble or repeat the exclusive.

\section{An Example of the Exclusive Table, or of the Rejection of Natures from the Form of Heat}

1. On account of the sun's rays, reject elementary (or terrestrial) nature.

2. On account of common fire, and particularly subterranean fires (which are the most remote and secluded from the rays of the heavenly bodies), reject celestial nature.

3. On account of the heat acquired by every description of substances (as minerals, vegetables, the external parts of animals, water, oil, air, etc.) by mere approximation to the fire or any warm body, reject all variety and delicate texture of bodies.

32 I.e., the common link or form which connects the various kinds of natures, such as the different hot or red natures enumerated above.-See Aphorism iii. part 2. 
4. On account of iron and ignited metals, which warm other bodies, and yet neither lose their weight nor substance, reject the imparting or mixing of the substance of the heating body.

5. On account of boiling water and air, and also those metals and other solid bodies which are heated, but not to ignition, or red heat, reject flame or light.

6. On account of the rays of the moon and other heavenly bodies (except the sun), again reject flame or light.

7. On account of the comparison between red-hot iron and the flame of spirits of wine (for the iron is more hot and less bright, while the flame of spirits of wine is more bright and less hot), again reject flame and light.

8. On account of gold and other ignited metals, which are of the greatest specific density, reject rarity.

9. On account of air, which is generally found to be cold and yet continues rare, reject rarity.

10. On account of ignited iron, ${ }^{33}$ which does not swell in bulk, but retains the same apparent dimension, reject the absolute expansive motion of the whole.

11. On account of the expansion of the air in thermometers and the like, which is absolutely moved and expanded to the eye, and yet acquires no manifest increase of heat, again reject absolute or expansive motion of the whole.

12. On account of the ready application of heat to all substances without any destruction or remarkable alteration of them, reject destructive nature or the violent communication of any new nature.

13. On account of the agreement and conformity of the effects produced by cold and heat, reject both expansive and contracting motion as regards the whole.

33 This is erroneous-all metals expand considerably when heated. 
14. On account of the heat excited by friction, reject principal nature, by which we mean that which exists positively, and is not caused by a preceding nature.

There are other natures to be rejected; but we are merely offering examples, and not perfect tables.

None of the above natures are of the form of heat; and man is freed from them all in his operation upon heat.

XIX. In the exclusive table are laid the foundations of true induction, which is not, however, completed until the affirmative be attained. Nor is the exclusive table perfect, nor can it be so at first. For it is clearly a rejection of simple natures; but if we have not as yet good and just notions of simple natures, how can the exclusive table be made correct? Some of the above, as the notion of elementary and celestial nature, and rarity, are vague and ill defined. We, therefore, who are neither ignorant nor forgetful of the great work which we attempt, in rendering the human understanding adequate to things and nature, by no means rest satisfied with what we have hitherto enforced, but push the matter further, and contrive and prepare more powerful aid for the use of the understanding, which we will next subjoin. And, indeed, in the interpretation of nature the mind is to be so prepared and formed, as to rest itself on proper degrees of certainty, and yet to remember (especially at first) that what is present depends much upon what remains behind.

XX. Since, however, truth emerges more readily from error than confusion, we consider it useful to leave the understanding at liberty to exert itself and attempt the interpretation of nature in the affirmative, after having constructed and weighed the three tables of preparation, such as we have laid them down, both from the instances there collected, and others occurring elsewhere. Which attempt 
we are wont to call the liberty of the understanding, or the commencement of interpretation, or the first vintage.

\section{The First Vintage of the Form of Heat}

It must be observed that the form of anything is inherent (as appears clearly from our premises) in each individual instance in which the thing itself is inherent, or it would not be a form. No cuntradictory instance, therefore, can be alleged. The form, however, is found to be much more conspicuous and evident in some instances than in others; in those (for example) where its nature is less restrained and embarrassed, and reduced to rule by other natures. Such instances we are wont to term coruscations, or conspicuous instances. We must proceed, then, to the first vintage of the form of heat.

From the instances taken collectively, as well as singly, the nature whose limit is heat appears to be motion. This is chiefly exhibited in flame, which is in constant motion, and in warm or boiling liquids, which are likewise in constant motion. It is also shown in the excitement or increase of heat by motion, as by bellows and draughts: for which see Inst. 29, Tab. 3, and by other species of motion, as in Inst. 28 and 31, Tab. 3. It is also shown by the extinction of fire and heat upon any strong pressure, which restrains and puts a stop to motion; for which see Inst. 30 and 32 , Tab. 3. It is further shown by this circumstance, namely, that every substance is destroyed, or at least materially changed, by strong and powerful fire and heat: whence it is clear that tumult and confusion are occasioned by heat, together with a violent motion in the internal parts of bodies; and this gradually tends to their dissolution.

What we have said with regard to motion must be thus 
understood, when taken as the genus of heat: it must not be thought that heat generates motion, or motion heat (though in some respects this be true), but that the very essence of heat, or the substantial self ${ }^{34}$ of heat, is motion and nothing else, limited, however, by certain differences which we will presently add, after giving some cautions for avoiding ambiguity.

Sensible heat is relative, and regards man, not universe; and is rightly held to be merely the effect of heat on animal spirit. It is even variable in itself, since the same body (in different states of sensation) excites the feeling of heat and of cold; this is shown by Inst. 41, Tab. 3.

Nor should we confound the communication of heat or its transitive nature, by which a body grows warm at the approach of a heated body, with the form of heat; for heat is one thing and heating another. Heat can be excited by friction without any previous heating body, and, therefore, heating is excluded from the form of heat. Even when heat is excited by the approach of a hot body, this depends not on the form of heat, but on another more profound and common nature; namely, that of assimilation and multiplication, about which a separate inquiry must be made.

The notion of fire is vulgar, and of no assistance; it is merely compounded of the conjunction of heat and light in any body, as in ordinary flame and red-hot substances.

Laying aside all ambiguity, therefore, we must lastly consider the true differences which limit motion and render it the form of heat.

I. The first difference is, that heat is an expansive motion, by which the body strives to dilate itself, and to

34 "Quid ipsum," the rỏ rì ᄁiv eivar of Aristotle. 
occupy a greater space than before. This difference is principally seen in flame, where the smoke or thick vapor is clearly dilated and bursts into flame.

It is also shown in all boiling liquids, which swell, rise, and boil up to the sight, and the process of expansion is urged forward till they are converted into a much more extended and dilated body than the liquid itself, such as steam, smoke, or air.

It is also shown in wood and combustibles where exudation sometimes takes place, and evaporation always.

It is also shown in the melting of metals, which, being very compact, do not easily swell and dilate, but yet their spirit, when dilated and desirous of further expansion, forces and urges its thicker parts into dissolution, and if the heat be pushed still further, reduces a considerable part of them into a volatile state.

It is also shown in iron or stones, which though not melter or dissolved, are however softened. The same circumstance takes place in sticks of wood, which become flexible when a little heated in warm ashes.

It is most readily observed in air, which instantly and manifestly expands with a small degree of heat, as in Inst. 38, Tab. 3.

It is also shown in the contrary nature of cold; for cold contracts and narrows every substance; ${ }^{35}$ so that in intense frosts nails fall out of the wall and brass cracks, and heated glass exposed suddenly to the cold cracks and breaks. So

${ }^{35}$ To show the error of the text, we need only mention the case of water, which, when confined in corked vases, and exposed to the action of a freezing atmosphere, is sure to swell ont and break those vessels which are not sufficiently large to contain its expanded volume. Megalotti narrates a hundred other instances of a similar character. $-E d$. 
the air, by a slight degree of cold, contracts itself, as in Inst. 38, Tab. 3. More will be said of this in the inquiry into cold.

Nor is it to be wondered at if cold and heat exhibit many common effects (for which see Inst. 32, Tab. 2), since two differences, of which we shall presently speak, belong to each nature: although in the present difference the effects be diametrically opposed to each other. For heat occasions an expansive and dilating motion, but cold a contracting and condensing motion.

II. The second difference is a modification of the preceding, namely, that heat is an expansive motion, tending toward the exterior, but at the same time bearing the body upward. For there is no doubt that there be many compound motions, as an arrow or dart, for instance, has both a rotatory and progressive motion. In the same way the motion of heat is both expansive and tending upward.

This difference is shown by putting the tongs or poker into the fire. If placed perpendicularly with the hand above, they soon burn it, but much less speedily if the hand hold them sloping or from below.

It is also conspicuous in distillations per descensum, which men are wont to employ with delicate flowers, whose scent easily evaporates. Their industry has devised placing the fire above instead of below, that it may scorch less; for not only flame but all heat has an upward tendency.

Let an experiment be made on the contrary nature of cold, whether its contraction be downward, as the expansion of heat is upward. Take, therefore, two iron rods or two glass tubes, alike in other respects, and warm them a little, and place a sponge, dipped in cold water, or some snow, below the one and above the other. We are of opinion that 
the extremities will grow cold in that rod first where it is placed beneath, as the contrary takes place with regard to heat.

III. The third difference is this; that heat is not a uniform expansive motion of the whole, but of the small par. ticles of the body; and this motion being at the same time restrained, repulsed, and reflected, becomes alternating, perpetually hurrying, striving, struggling, and irritated by the repercussion, which is the source of the violence of flame and heat.

But this difference is chiefly shown in flame and boiling liquids, which always hurry, swell, and subside again in detached parts.

It is also shown in bodies of such hard texture as not to swell or dilate in bulk, such as red-hot iron, in which the heat is most violent.

It is also shown by the fires burning most briskly in the coldest weather.

It is also shown by this, that when the air is dilated in the thermometer uniformly and equably, without any impediment or repulsion, the heat is not perceptible. In confined draughts also, although they break out very violently, no remarkable heat is pereeived, because the motion affects the whole, without any alternating motion in the particles; for which reason try whether flame do not burn more at the sides than in its centre.

It is also shown in this, that all burning proceeds by the minute pores of bodies - undermining, penetrating, piercing, and pricking them as if with an infinite number of needle-points. Hence all strong acids (if adapted to the body on which they act) exhibit the effects of fire, from their corroding and pungent nature. 
The difference of which we now speak is common also to the nature of cold, in which the contracting motion is restrained by the resistance of expansion, as in heat the expansive motion is restrained by the resistance of contraction.

Whether, therefore, the particles of matter penetrate inward or outward, the reasoning is the same, though the power be very different, because we have nothing on earth which is intensely cold.

IV. The fourth difference is a modification of the preceding, namely, that this stimulating or penetrating motion should be rapid and never sluggish, and should take place not in the very minutest particles, but rather in those of some tolerable dimensions.

It is shown by comparing the effects of fire with those of time. Time dries, consumes, undermines, and reduces to ashes as well as fire, and perhaps to a much finer degree; but as its motion is very slow, and attacks very minute particles, no heat is perceived.

It is also shown in a comparison of the dissolution of iron and gold; for gold is dissolved without the excitement of any heat, but iron with a vehement excitement of it, although most in the same time, because in the former the penetration of the separating acid is mild, and gently insinuates itself, and the particles of gold yield easily, but the penetration of iron is violent, and attended with some struggle, and its particles are more obstinate.

It is partially shown, also, in some gangrenes and mortifications of flesh, which do not excite great heat or pain, from the gentle nature of the putrefaction.

Let this suffice for a first vintage, or the commencement of the interpretation of the form of heat by the liberty of the understanding. 
From this first vintage the form or true definition of heat (considered relatively to the universe and not to the sense) is briefly thus-Heat is an expansive motion restrained, and striving to exert itself in the smaller particles. ${ }^{86}$ The expansion is modified by its tendency to rise, though expanding toward the exterior; and the effort is modified by its not being sluggish, but active and somewhat violent.

With regard to the operative definition, the matter is the same. If you are able to excite a dilating or expansive motion in any natural body, and so to repress that motion and fore it on itself as not to allow the expansion to proceed equally, but only to be partially exerted and partially repressed, you will beyond all doubt produce heat, without any consideration as to whether the body be of earth (or elementary, as they term it), or imbued with celestial influence, luminous or opaque, rare or dense, locally expanded

36 Bacon's inquisition into the nature of heat, as an example of the mode of interpreting nature, cannot be looked upon otherwise than as a complete failure. Thougl the exact nature of this phenomenon is still an obscure and controverted matter, the science of thermotics now consists of many important truths, and to none of these truths is there so much as an approximation in Bacon's process. The steps by which this scicnce really advanced were the discovery of it measure of a heat or temperature, the establishment of the laws of conduction and radiation, of the laws of specific heat, latent heat, and the like. Such advances have led to Ampère's hypothesis, that heat consists in the vibrations of an imponderable fluid; and to Laplace's theory, that temperature consists in the interual radiation of a similar medium. These hypotheses cannot Jet be satid to be even probable, but at least they are so modified as to include some of the preceling laws which are firmly established, whereas Bacon's "forn," or true detinition of leat, as stated in the text, includes no laws of phenomena, explains no process, and is indeed itself an example of illicit generalization.

In all tho details of his eximule of heat he is unfortunate. He includes in lis collection of instinces, the Tot tastes of aromatic plants, the caustic effects of acids, and many other facts which cannot be ascribed to heat without a studious laxity in the use of the word. $-E d$. 
or contained within the bounds of its first dimensions, verging to dissolution or remaining fixed, animal, vegetable, or mineral, water, or oil, or air, or any other substance whatever susceptible of such motion. Sensible heat is the same, but considered relatively to the senses. Let us now proceed to further helps.

XXI. After our tables of first review, our rejection or exclusive table, and the first vintage derived from them, we must advance to the remaining helps of the understanding with regard to the interpretation of nature, and a true and perfect induction, in offering which we will take the examples of cold and heat where tables are necessary, but where fewer instances are required we will go through a variety of others, so as neither to confound investigation nor to narrow our doctrine.

In the first place, therefore, we will treat of prerogative instances $;^{37} 2$. Of the supports of induction; 3 . Of the cor-

37 By this term Bacon understands general phenomena, taken in order from the great mass of indiscriminative facts, which, as they lie in nature, are apt to generate confusion by their number, indistinctness and complication. Such classes of phenomena, as being peculiarly suggestive of causation, he quaintly classes under the title of prerogative inquiries, either seduced by the fanciful analogy, which such instinces bore to the prerogativa centuria in the Roman Comitia, or justly considering them as Hersehel supposes to hold a kind of prerogative dignity from being peculiarly suggestive of causation.

Two high authorities in physical science (v. Herschel, Nit. Pliil., art. 192; Whewell's Philosophy of the Inductive Sciences, vol. ii. p. 243) pronounce these instances of little service in the task of induction, being for the most part classed not according to the ideas which they involve, or to any obvious circumstance in the fucts of which they consist, but according to the extent and manner of their influence upon the inquiry in which they are employed. Thus we !ave solitary instances, migrating instances, ostensive instances, clandestine instances, so termed according to the degree in which they exhibit, or scem to exhibit, the property, whose nature we would examine. We have guide-post instances, crucial instances, instances of the parted road, of the doorway, of the lamp, according to the guidance they supply to our advance. Whewell remarks 
rection of induction; 4 . Of varying the investigation according to the nature of the subject; 5 . Of the prerogative natures with respect to investigation, or of what should be the first or last objects of our research; 6. Of the limits of investigation, or a synopsis of all natures that exist in the universe; 7. Of the application to practical purposes, or of what relates to man; 8 . Of the preparations for investigation; 9. And lastly, of the ascending and descending scale of axioms. ${ }^{38}$

XXII. Among the prerogative instances we will first mention solitary instances. Solitary instances are those which exhibit the required nature in subjects that have nothing in common with any other subject than the nature in question, or which do not exbibit the required nature in subjects resembling others in every respect except that of the nature in question; for these instances manifestly remove prolixity, and accelerate and confirm exclusion, so, that a few of them are of as much avail as many.

For instance, let the inquiry be the nature of color. Prisms, crystalline gems, which yield colors not only internally but on the wall, dews, etc., are solitary instances; for

that such a classification is much of the same nature as if, having to teach the art of building, we were to describe tools with reference to the amount and place of the work which they must do, instead of pointing out their construction and use; as if we were to inform the pupil that we must have tools for lifting a stone up, tools for moving it sidewise, tools for laying it square, and tools for cementing it fimly. The means are thus lost in the end, and we reap the fruits of unmethodical arrangement in the confusion of cross division. In addition, all the instances are leavened with the error of confounding the laws with the causes of phenomenit, and we are urged to adopt the fundumental error of seeking therein the universal agents, or general cituses of phenomena, without ascending the gradual steps of intermediate laws. $-E d$.

${ }^{35}$ Of these nine general heads no more than the first is prosecuted by the author. 
they have nothing in common with the fixed colors in flowers and colored gems, metals, woods, etc., except the color itself. Hence we easily deduce that color is nothing but a modification of the image of the incident and absorbed light, occasioned in the former case by the different degrees of incidence, in the latter by the various textures and forms of bodies. ${ }^{39}$ These are solitary instances as regards similitude.

Again, in the same inquiry the distinct veins of white and black in marble, and the variegated colors of flowers of the same species, are solitary instances; for the black and white of marble, and the spots of white and purple in the flowers of the stock, agree in every respect but that of color. Thence we easily deduce that color has not much to do with the intrinsic natures of any body, but depends only on the coarser and as it were mechanical arrangement of the parts. These are solitary instances as regards difference. We call them both solitary or wild, to borrow a word from the astronomers.

XXIII. In the second rank of prerogative instances we will consider migrating instances. In these the required nature passes toward generation, having no previous existence, or toward corruption, having first existed. In each of these divisions, therefore, the instances are always two. fold, or rather it is one instance, first in motion or on its passage, and then brought to the opposite conclusion. These instances not only hasten and confirm exclusion, but also reduce affirmation, or the form itself, to a narrow compass; for the form must be something conferred by this

39 This very nearly approaches to Sir I. Newton's discovery of the decomposition of light by the prism. 
migration, or, on the contrary, removed and destroyed by it; and although all exclusion advances affirmation, yet this takes place more directly in the same than in different sub. jects; but if the form (as it is quite clear from what has been advanced) exhibit itself in one subject, it leads to all. The more simple the migration is, the more valuable is the instance. These migrating instances are, moreover, very useful in practice, for since they manifest the form, coupled with that which causes or destroys it, they point out the right practice in some subjects, and thence there is an easy transition to those with which they are most allied. There is, however, a degree of danger which demands caution, namely, lest they should refer the form too much to its efficient cause, and imbue, or at least tinge, the understanding with a false notion of the form from the appearance of such cause, which is never more than a vehicle or conveyance of the form. This may easily be remedied by a proper application of exclusion.

Let us then give an example of a migrating instance. Let whiteness be the required nature. An instance which passes toward generation is glass in its entire and in its powdered state, or water in its natural state, and when agitated to froth; for glass when entire, and water in its natural state, are transparent and not white, but powdered glass and the froth of water are white and not transparent. We must inquire, therefore, what has happened to the glass or water in the course of this migration; for it is manifest that the form of whiteness is conveyed and introduced by the bruising of the glass and the agitation of the water; but nothing is found to have been introduced but a diminishing of the parts of the glass and water and the insertion of air. Yet this is no slight progress toward discovering 
the form of whiteness, namely, that two bodies, in them. selves more or less transparent (as air and water, or air and glass), when brought into contact in minute portions, exhibit whiteness from the unequal refraction of the rays of light.

But here we must also give an example of the danger and caution of which we spoke; for instance, it will readily occur to an understanding perverted by efficients, that air is always necessary for producing the form of whiteness, or that whiteness is only generated by transparent bodies, which suppositions are both false, and proved to be so by many exclusions; nay, it will rather appear (without any particular regard to air or the like), that all bodies which are even in such of their parts as affect the sight exhibit transparency, those which are uneven and of simple texture whiteness, those which are uneven and of compound but regular texture all the other colors except black, but those which are uneven and of a compound irregular and confused texture exhibit blackness. An example has been given, therefore, of an instance migrating toward generation in the required nature of whiteness. An instance migrating toward corruption in the same nature is that of dissolving froth or snow, for they lose their whiteness and assume the transparency of water in its pure state without air.

Nor should we by any means omit to state, that under migrating instances we must comprehend not only those which pass toward generation and destruction, but also those which pass toward increase or decrease, for they, too, assist in the discovery of the form, as is clear from our definition of a form and the Table of Degrees. Hence paper, which is white when dry, is less white when moistened (from the exclusion of air and admission of water), and tends more to 
transparency. The reason is the same as in the above in. stances. ${ }^{40}$

XXIV. In the third rank of prerogative instances we will class conspicuous instances, of which we spoke in our first vintage of the form of heat, and which we are also wont to call coruscations, or free and predominant instances. They are such as show the required nature in its bare substantial shape, and at its height or greatest degree of power, emancipated and free from all impediments, or at least overcoming, suppressing, and restraining them by the strength of its qualities; for since every body is susceptible of many united forms of natures in the concrete, the consequence is that they mutually deaden, depress, break, and confine each other, and the individual forms are obscured. But there are some subjects in which the required nature exists in its full vigor rather than in others, either from the absence of any impediment, or the predominance of its quality. Such instances are eminently conspicuous. But even in these care must be taken, and the hastiness of the understanding checked, for whatever makes a show of the form, and forces it forward, is to be suspected, and recourse must be had to severe and diligent exclusion.

For example, let heat be the required nature. The thermometer is a conspicuous instance of the expansive motion, which (as has been observed) constitutes the chief part of the form of heat; for although flame clearly exhibits expansion, yet from its being extinguished every moment, it does not exhibit the progress of expansion. Boiling water again,

40 The mineral kingdom, as displaying the same nature in all its gradations, from the shells so perfect in structure in limestone to the finer marbles in which their nature gradually disappears, is the great theatre for instances of migration.-Ed. 
from its rapid conversion into vapor, does not so well exhibit the expansion of water in its own shape, while red-hot iron and the like are so far from showing this progress, that, on the contrary, the expansion itself is scarcely evident to the senses, on account of its spirit being repressed and weakened by the compact and coarse particles which subdue and restrain it. But the thermometer strikingly exhibits the expansion of the air as being evident and progressive, durable and not transitory. ${ }^{41}$

Take another example. Let the required nature be weight. Quicksilver is a conspicuous instance of weight; for it is far heavier than any otber substance except gold, which is not much heavier, and it is a better instance than gold for the purpose of indicating the form of weight; for gold is solid and consistent, which qualities must be referred to density, but quicksilver is liquid and teeming with spirit, yet much heavier than the diamond and other substances considered to be most solid; whence it is shown that the form of gravity or weight predominates only in the quantity of matter, and not in the close fitting of it. ${ }^{42}$

$\mathrm{XXV}$. In the fourth rank of prerogative instances we will class clandestine instances, which we are also wont to

41 Bacon was not aware of the fact since brought to light by Römer, that down to fourteen fathoms from the earth's mean level the thermometer remains fixed at the tenth degree, but that as the thermometer descends below that depth the heat increases in a ratio proportionate to the descent, which happens with little variation in all climates. Buffon considers this a proof of a central fire in our planet. $-E d$.

42 All the diversities of bodies depend upon two principles, i.e., the quantity and the position of the elements that enter into their composition. The primary difference is not that which depends on the greatest or least quantity of material elements, but that which depends on their position. It was the quick perception of this truth that made Leibnitz say that to complete mathematics it was necessary to join to the analysis of quantity the analysis of position. $-E d$. 
call twilight instances; they are as it were opposed to the conspicuous instances, for they show the required nature in its lowest state of efficacy, and as it were its cradle and first rudiments, making an effort and a sort of first attempt, but concealed and subdued by a contrary nature. Such in. stances are, however, of great importance in discovering forms, for as the conspicuous tend easily to differences, so do the clandestine best lead to genera, that is, to those com. mon natures of which the required natures are only the limits.

As an example, let consistency, or that which confines itself, be the required nature, the opposite of which is a liquid or flowing state. The clandestine instances are such as exhibit some weak and low degree of consistency in fluids, as a water bubble, which is a sort of consistent and bounded pellicle formed out of the substance of the water. So eaves' droplungs, if there be enough water to follow them, draw themselves out into a thin thread, not to break the continuity of the water, but if there be not enough to follow, the water forms itself into a round drop, which is the best form to prevent a breach of continuity; and at the moment the thread ceases, and the water begins to fall in drops, the thread of water recoils upward to avoid such a breach. Nay, in metals, which when melted are liquid but more tenacious, the melted drops often recoil and are suspended. There is something similar in the instance of the child's looking-glass, which little boys will sometimes form of spittle between rushes, and where the same pellicle of water is observable; and still more in that other amusement of children, when they take some water rendered a little more tenacious by soap, and inflate it with a pipe, forming the water into a sort of castle of bubbles, which assumes such consistency, 
by the interposition of the air, as to admit of being thrown some little distance without bursting. The best example is that of froth and snow, which assume such consistency as almost to admit of being cut, although composed of air and water, both liquids. All these circumstances clearly show that the terms liquid and consistent are merely vulgar notions adapted to the sense, and that in reality all bodies have a tendency to avoid a breach of continuity, faint and weak in bodies composed of homogeneous parts (as is the case with liquids), but more vivid and powerful in those composed of heterogeneous parts, because the approach of heterogeneous matter binds bodies together, while the insinuation of homogeneous matter loosens and relaxes them.

Again, to take another example, let the required nature be attraction or the cohesion of bodies. The most remarkable conspicuous instance with regard to its form is the magnet. The contrary nature to attraction is non-attraction, though in a similar substance. Thus iron does not attract iron, lead lead, wood wood, nor water water. But the clandestine instance is that of the magnet armed with iron, or rather that of iron in the magnet so armed. For its nature is such that the magnet when armed does not attract iron more powerfully at any given distance than when unarmed; but if the iron be brought in contact with the armed magnet, the latter will sustain a much greater weight than the simple magnet, from the resemblance of substance in the two portions of iron, a quality altogether clandestine and hidden in the iron until the magnet was introduced. It is manifest, therefore, that the form of cohesion is something which is vivid and robust in the magnet, and hidden and weak in the iron. It is to be observed, also, that small wooden arrows without an iron point, when discharged from large mortars, 
penetrate further into wooden substances (such as the ribs of ships or the like), than the same arrows pointed with iron, ${ }^{48}$ owing to the similarity of substance, though this quality was previously latent in the wood. Again, although in the mass air does not appear to attract air, nor water water, yet when one bubble is brought near another, they are both more readily dissolved, from the tendency to contact of the water with the water, and the air with the air. ${ }^{44}$ These clandes. tine instances (which are, as has been observed, of the most important service) are principally to be observed in small portions of bodies, for the larger masses observe more universal and general forms, as will be mentioned in its proper place. ${ }^{45}$

43 Query ?

4 The reil cause of this phenomenon is the attraction of the surface-water in the vessel by the sides of the bubbles. When the bubbles approach, the sides nearest each other both tend to raise the small space of water between them, and consequently less water is raised by each of these liearer sides than by the exterior part of the bubble, and the greater weight of the water raised on the exterior parts pushes the bubbles together. In the sime manner a bubble near the side of a vessel is pushed toward it; the vessel and bubble both drawing the water that is between them. The latter phenomenon cannot be explained on Bacon's hypothesis.

45 Modern discoveries appear to bear out the sagacity of Bitcon's remark, and the experiments of Baron Cagnard may be regarded as it first step toward its full demonstration. After the new facts elicited by that philosopher, there can he little doubt that the solid, liquid and aëriform state of bodies are merely staces in a progress of gradual transition from one extreme to the other, and that however strongly marked the distinctions between them may appear, they will ultimately turn out to be separated by no sudden or violent line of demarcation, hut slide into each other by imperceptible gradations. Bacon's suggestion, however, is as olu as Pythagoras, and perhaps simultaneous with the first dawn of philosophie reason. The doctrine of the reciprocal transmutation of the elements underlies all the physical systems of the ancients, and was adopted hy the Epicureans as well as the Stoics. Ovid opens his last book of the Metamorphoses with the poetry of the subject, where he expressly points to the hint of Bacon:- 
XXVI. In the fifth rank of prerogative instances we will class constitutive instances, which we are wont also to call collective instances. They constitute a species or lesser form, as it were, of the required nature. For since the real forms (which are always convertible with the given nature) lie at some depth, and are not easily discovered, the necessity of the case and the infirmity of the human understanding require that the particular forms, which collect certain groups of instances (but by no means all) into some common notion, should not be neglected, but most diligently observed. For whatever unites nature, even imperfectly, opens the way to the discovery of the form. The instances, therefore, which are serviceable in this respect are of no mean power, but endowed with some degree of prerogative.

Here, nevertheless, great care must be taken that, after the discovery of several of these particular forms, and the establishing of certain partitions or divisions of the required nature derived from them, the human understanding do not at once rest satisfied, without preparing for the investigation of the great or leading form, and taking it for granted that nature is compound and divided from its very root, despise and reject any further union as a point of superfluous refinement, and tending to mere abstraction.

For instance, let the required.nature be memory, or that

\author{
"Tenuatus in auras \\ Aëraque humor abit, etc., etc. \\ Inde retro redeunt, idemque retexitur ordo." $-\mathrm{xv} .246-249$.
}

and Seneca, in the third book of his Natural Philosophy, quest. iv., states the opinion in more precise language than either the ancient bard or the modern philosopher. $-E d$. 
which excites and assists memory. The constitutive instances are order or distribution, which manifestly assists memory: topics or commonplaces in artificial memory, which may be either places in their literal sense, as a gate, a corner, a window, and the like, or familiar persons and marks, or anything else (provided it be arranged in a determinate order), as animals, plants, and words, letters, characters, historical persons, and the like, of which, however, some are more convenient than others. All these commonplaces materially assist memory, and raise it far above its natural strength. Verse, too, is recollected and learned more easily than prose. From this group of three instances -order, the commonplaces of artificial memory, and ver'ses -is constituted one species of aid for the memory, ${ }^{46}$ which may be well termed a separation from infinity. For when a man strives to recollect or recall anything to memory, without a preconceived notion or perception of the object of his search, he inquires about, and labors, and turns from point to point, as if involved in infinity. But if he have any preconceived notion, this infinity is separated off, and the range of his memory is brought within closer limits. In the three instances given above, the preconceivel notion is clear and determined. In the first, it must be something that agrees with order; in the second, an image which has some relation or agreement with the fixed commonplaces; in the third, words which fall into a verse: and thus infinity is divider off. Other instances will offer another species, namely, that whatever brings the intellect into contact with

\$6 The author's own system of Memoria Technica may be found in the De Augmentis, chap. xv. We may add that, notwithstandiug Bacon's assertion that he intended lis method to apply to religion, polities, and morals, this is the only lengthy illustration he has adduced of any subject out of the domain of physical science.-Ed. 
something that strikes the sense (the principal point of artificial memory), assists the memory. Others again offer another species, namely, whatever excites an impression by any powerful passion, as fear, shame, wonder, delight, assists the memory. Other instances will afford another species: thus those impressions remain most fixed in the memory which are taken from the mind when clear and least occupied by preceding or succeeding notions, such as the things we learn in childhood, or imagine before sleep, and the first time of any circumstance happening. Other instances afford the following species: namely, that a multitude of circumstances or handles assist the memory, such as writing in paragraphs, reading aloud, or recitation. Lastly, other instances afford still another species: thus the things we anticipate, and which rouse our attention, are more easily remembered than transient events; as if you read any work twenty times over, you will not learn it by heart so readily as if you were to read it but ten times, trying each time to repeat it, and when your memory fails you looking into the book. There are, therefore, six lesser forms, as it were, of things which assist the memory: namely-1, the separation of infinity; 2 , the connection of the mind with the senses; 3, the impression in strong passion; 4, the impression on the mind when pure; 5 , the multitude of handles; 6 , anticipation.

Again, for example's sake, let the required nature be taste or the power of tasting. The following instances are constitutive: 1. Those who do not smell, but are deprived by nature of that sense, do not perceive or distinguish rancid or putrid food by their taste, nor garlic from roses, and the like. 2. Again, those whose nostrils are obstructed by accident (such as a cold) do not distinguish any putrid or SCIENCE- Vol. $22-8$ 
rancid matter from anything sprinkled with rose-water. 3. If those who suffer from a cold blow their noses violently at the very moment in which they have anything fetid or perfumed in their mouth, or on their palate, they instantly have a clear perception of the fetor or perfume. These instances afford and constitute this species or division of taste, namely, that it is in part nothing else than an internal smelling, passing and descending through the upper passages of the nostrils to the mouth and palate. But, on the other hand, those whose power of smelling is deficiont or obstructed, perceive what is salt, sweet, pungent, acid, rough, and bitter, and the like, as well as any one else: so that the taste is clearly something compounded of the internal smelling, and an exquisite species of touch which we will not here discuss.

Again, as another example, let the required nature be the communication of quality, without intermixture of substance. The instance of light will afford or constitute one species of communication, heat and the magnet another. For the communication of light is momentary and immediately arrested upon the removal of the original light. But heat, and the magnetic force, when once transmitted to or excited in another body, remain fixed for a considerable time after the removal of the source.

In fine, the prerogative of constitutive instances is considerable, for they materially assist the definitions (especially in detail) and the divisions or partitions of natures, concerning which Plato has well said, "He who can properly lefine and divide is to be considered a god." ${ }^{47}$

47 The collective instances here meant are no other than general facts or laws of some degree of generality, and are themselves the result of induction. For example, the system of Jupiter, or Saluru wilh its satellites, is a collective 
XXVII. In the sixth rank of prerogative instances we will place similar or proportionate instances, which we are also wont to call physical parallels, or resemblances. They are such as exhibit the resemblances and connection of things, not in minor forms (as the constitutive do), but at once in the concrete. They are, therefore, as it were, the first and lowest steps toward the union of nature; nor do they immediately establish any axiom, but merely indicate and observe a certain relation of bodies to each other. But

instance, and materially assisted in securing the admission of the Copernican system. We have here in miniature, and displayed at one view, a system anilogous to that of the planets about the sun, of which, from the circumstance of our being involved in it, and unfavorably situated for seeing it otherwise than in detail, we are incapacitated from forming a general idea, but by slow and progressive efforts of reason.

But there is a species of collective instance which Bacon does not seem to have contemplated, in which particular phenomena are presented iu such numbers at once, as to make the induction of their law a matter of ocular inspection. For example, the parabolic form assumed by a jet of water spouted out of a hole is a collective instance of the velocities and directions of the motions of all the particles which compose it seen together, and which thus leads us without trouble to recognize the law of the motion of a projectile. Again, the beautiful figures exhibited by sand strewed on regular plates of glass or metal set in vibration, are collective instances of an infinite number of points which remain at rest while the remainder of the plate vibrates, and in consequence afford us an insight into the law which regulates their arrangement and sequence throughout the whole surface. The richly colored lemniscates seen around the optic axis of crystals exposed to polarized light afford a striking instance of the same kind, pointing at once to the general mathematical expression of the law which regulates their production. Such collective instances as these lead us to a general law by an induction which offers itself spontaneously, and thus furnish advanced posts in philosophical exploration. The laws of Kepler, which Bacon ignored on account of his want of mathematical taste, may be cited as a collective instance. The first is, that the planets move in elliptical orbits, having the sun for their common focus. The second, that about this focus the radius vector of each planet describes equal areas in equal times. The third, that the squares of the periodic times of the planets are as the cubes of their mean distance from the sun. This collective instance "opened the way" to the discovery of the Newtonian law of gravitation. - Ed. 
although they be not of much assistance in discovering forms, yet they are of great advantage in disclosing the frame of parts of the universe, upon whose members they practice a species of anatomy, and thence occasionally lead us gently on to sublime and noble axioms, especially such as relate to the construction of the world, rather than to simple natures and forms.

As an example, take the following sinilar instances: a mirror and the eye; the formation of the ear, and places which return an echo. From such similarity, besicles ob. serving the resemblance (which is useful for many purposes), it is easy to collect and form this axiom. That the organs of the senses, and bodies which produce reflections to the senses, are of a similar nature. Again, the understanding once informed of this, rises easily to a higher and nobler axiom; namely, that the only distinction between sonsitive and inanimate bodies, in those points in which they agree and sympathize, is this: in the former, animal spirit is added to the arrangement of the body, in the latter it is wanting. So that there might be as many senses in animals as there are points of agreement with inanimate bodies, if the animated body were perforated, so as to allow the spirit to have access to the limb properly disposed for action, as a fit organ. And, on the other hand, there are, without doubt, as many motions in an inanimate as there are senses in the animated body, though the animal spirit be absent. There must, however, be many more motions in inanimate bodies than senses in the animated, from the small number of organs of sense. A very plain example of this is afforded by pains. For, as animals are liable to many kinds and various descriptions of pains (such as those of burning, of intense cold, of pricking, squeezing, stretch- 
ing, and the like), so is it most certain, that the same circumstances, as far as motion is concerned, happen to inanimate bodies, such as wood or stone when burned, frozen, pricked, cut, bent, bruised, and the like; although there be no sensation, owing to the absence of animal spirit.

Again, wonderful as it may appear, the roots and branches of trees are similar instances. For every vegetable swells and throws out its constituent parts toward the circumference, both upward and downward. And there is no difference between the roots and branches, except that the root is buried in the earth, and the branches are exposed to the air and sun. For if one take a young and vigorous shoot, and bend it down to a small portion of loose earth, although it be not fixed to the ground, yet will it immediately produce a root, and not a branch. And, vice versâ, if earth be placed above, and so forced down with a stone or any hard substance, as to confine the plant and prevent its branching upward, it will throw out branches into the air downward.

The gums of trees, and most rock gems, are similar instances; for both of them are exudations and filtered juices, derived in the former instance from trees, in the latter from stones; the brightness and clearness of both arising from a delicate and accurate filtering. For nearly the same reason, the hair of animals is less beautiful and vivid in its color than the plumage of most birds, because the juices are less delicately filtered through the skin than through the quills.

The scrotum of males and matrix of females are also similar instances; so that the noble formation which constitutes the difference of the sexes appears to differ only as to the one being internal and the other external; a greater degree of heat causing the genitals to protrude in the male, 
while the heat of the female being too weak to effect this, they are retained internally.

The fins of fishes and the feet of quadrupeds, or the feet and wings of hircls, are similar instances; to which Aristotle adds the four folds in the motion of serpents; ${ }^{48}$ so that in the formation of the universe, the motion of animals appears to be chiefly effected by four joints or bendings.

The teeth of land animals, and the bealis of birds, are similar instances, whence it is clear, that in all perfect animals there is a determination of some har substance toward the mouth.

Again, the resemblance and conformity of man to an inverted plant is not absurd. For the head is the root of the nerves and animal faculties, and the seminal parts are the lowest, not including the extremities of the legs and arms. But in the plant, the root (which resembles the head) is regularly placed in the lowest, and the seeds in the highest part. ${ }^{49}$

L:istly, we must particularly recommend and suggest, that man's present industry in the investigation and compilation of natural history be entirely changed, and directed to the reverse of the present system. For it has hitherto been active and curious in noting the variety of things, and explaining the accurate differences of animals, regetables, and minerals, most of which are the mere sport of nature, rather than of any real utility as concerns the sciences.

48 Is not this very hasty generalization? Do serpents move with four folds only ? Observe also the motion of centipedes and other insects.

49 Shaw states another point of difference between the objects cited in the text-animals having their roots within, while plants have theirs without; for their lacteals nearly correspond with the fibres of the roots in plants; so that animals seem nourished within themselves as plants are without.-Ed. 
Pursuits of this nature are certainly agreeable, and sometimes of practical advantage, but contribute little or nothing to the thorough investigation of nature. Our labor must therefore be directed toward inquiring into and observing resemblances and analogies, both in the whole and its parts, for they unite nature, and lay the foundation of the sciences.

Here, however, a severe and rigorous caution must be observed, that we only consider as similar and proportionate instances, those which (as we first observed) point out physical resemblances; that is, real and substantial resemblances, deeply founded in nature, and not casual and superficial, much less superstitious or curious; such as those which are constantly put forward by the writers on natural magic (the most idle of $m \in n$, and who are scarcely fit to be named in connection with such serious matters as we now treat of), who, with much vanity and folly, describe, and sometimes too, invent, unmeaning resemblances and sympathies.

But leaving such to themselves, similar instances are not to be neglected, in the greater portions of the world's conformation; such as Africa and the Peruvian continent, which reaches to the Straits of Magellan; both of which possess a similar isthmus and similar capes, a circumstance not to be attributed to mere accident.

Again, the New and Old World are both of them broad and expranded toward the north, and narrow and pointed toward the south.

Again, we have very remarkable similar instances in the intense cold, toward the middle regions (as it is termed) of the air, and the violent fires which are often found to burst from subterraneous spots, the similarity consisting in both being ends and extremes; the extreme of the nature of cold, 
for instance, is toward the boundary of heaven, and that of the nature of heat toward the centre of the earth, by a similar species of opposition or rejection of the contrary nature.

Lastly, in the axioms of the sciences, there is a similarity of instances worthy of observation. Thus the rhetorical trope which is called surprise, is similar to that of music termed the declining of a cadence. Again-the mathematical postulate, that things which are equal to the same are equal to one another, is similar to the form of the syl. logism in logic, which unites things agreeing in the middle term. ${ }^{50}$ Lastly, a certain degree of sagacity in collecting and searching for physical points of similarity, is very use. ful in many respects. ${ }^{61}$

$X X V I I I$. In the seventh rank of prerogative instances, we will place singular instances, which we are also wont to call irregular or heteroclite (to brorrow a term from the grammarians). They are such as exhibit bodies in the con.

50 Bacon falls into an error here in regarding the syllogism as something distinct from the reasoning faculty, and only one of its forms. It is not generally true that the syllocrism is only a form of reasoning by which we unite ideas which accord with the middle term. This agreenent is not even essential to accurate syllogisms; when the relation of the two things compared to the third is one of equality or similitude, it of course follows that the two things compared may be pronounced equal, or like to each other. But if the relation between these terms exist in a different form, then it is not true that the two extremes stand in the same relation to each other as to the middle term. For instance, if $\mathrm{A}$ is double of $\mathrm{B}$, and $\mathrm{B}$ double of $\mathrm{C}$, then $\mathrm{A}$ is quadruple of $\mathrm{O}$. But then the relation of $\mathrm{A}$ to $\mathrm{C}$ is different from that of $\mathrm{A}$ to $\mathrm{B}$ and of B to C.-Ed.

51 Compurative anatomy is full of analogies of this kind. Those between natural and artificial productions are well worthy of attention, and sometimes lead to important discoveries. By observing an analogy of this kind between the plan used in hydraulic engines for preventing the counter-current of a fluid, and a similar contrivance in the blood vessels, Harvey was led to the discovery of the circulation of the blood. $-E d$. 
crete, of an apparently extravagant and separate nature, agreeing but little with other things of the same species. For, while the similar instances resemble each other, those we now speak of are only like themselves. Their use is much the same with that of clandestine instances: they bring out and unite nature, and discover genera or common natures, which must afterward be limited by real differences. Nor should we desist from inquiry, until the properties and qualities of those things, which may be deemed miracles, as it were, of nature, be reduced to, and comprehended in, some form or certain law; so that all irregularity or singularity may be found to depend on some common form; and the miracle only consists in accurate differences, degree, and rare coincidence, not in the species itself. Man's meditation proceeds no further at present, than just to consider things of this kind as the secrets and rast efforts of nature, without an assigmable cause, and, as it were, exceptions to general rules.

As examples of singular instances, we have the sun and moon among the heavenly bodies; the magnet among minerals; quicksilver among metals; the elephant among quadrupeds; the venereal sensation among the different kinds of touch; the scent of sporting dogs among those of smell. The letter $\mathrm{S}$, too, is considered by the grammarians as sui generis, from its easily uniting with double or triple consonants, which no other letter will. These instances are of great value, because they excite and keep alive inquiry, and correct an understanding depraved by habit and the common course of things.

XXIX. In the eighth rank of prerogative instances, we will place deviacing instances, such as the errors of nature, or strange and monstrous objects, in which nature deviates 
and turns from hor ordinary course. For the errors of nature differ from singular instances, inasmuch as the latter are the miracles of species, the former of individuals. Their use is much the same, for they rectify the understanding in opposition to habit, and reveal common forms. For with regard to these, also, we must not desist from inquiry, till we liscern the cause of the deviation. The cause does not, however, in such cases rise to a regular form, but only to the latent process toward such a form. For he who is acquainted with the paths of nature, will more readily observe her deviations; and, vice versâ, he who has learned her deviations will be able more accurately to describe her paths.

They differ again from singular instances, by being much more apt for practice and the operative branch. For it would be very difficult to generate new species, but less so to vary known species, and thus produce many rare and unusual results. ${ }^{62}$ The passage from the miracles of nature to those of art is easy; for if nature be once seized in her variations, and the cause be manifest, it will be easy to lead her by art to such deviation as she was at first led to by chance; and not only to that but others, since deviations on the one side leat and open the way to others in every direction. Of this we do not require any examples, since they are so abundant. For a compilation, or particu. lir natural history, must be made of all monsters and prodigrious births of nature; of everything, in short, which is new, rare and unusual in nature. This should be done with a rigorous selection, so as to be worthy of credit.

52 This is well illustrated in plants, for the gardener can produce endless varieties of any known species, but can never produce a new species itself. 
Those are most to be suspected which depend upon superstition, as the prodigies of Livy, and those perhaps, but little less, which are found in the works of writers on natural magic, or even alchemy, and the like; for such men, as it were, are the very suitors and lovers of fables; but our instances should be derived from some grave and credible history, and faithful narration.

XXX. In the ninth rank of prerogative instances, we will place bordering instances, which we are also wont to term participants. They are such as exhibit those species of bodies which appear to be composed of two species, or to be the rudiments between the one and the other. They may well be classed with the singular or heteroclite instances; for in the whole system of things, they are rare and extraordinary. Yet from their dignity, they must be treated of and classed separately, for they point out admirably the order and constitution of things, anl suggest the causes of the number and quality of the more common species in the universe, leading the understanding from that which is, to that which is possible.

We have examples of them in moss, which is something between putrescence and a plant; ${ }^{53}$ in some comets, which hold a place between stars and ignited meteors; in flying fishes, between fishes and birds; and in bats, between birds and quadrupeds. ${ }^{54}$ Again,

Simia quam similis turpissima bestia nobis.

53 The discoveries of Tournefort have placed moss in the class of plants. The fish alluded to below are to be found only in the tropies.-Ed.

54 There is, however, no real approximation to birds in either the flying fish or bat, any more than a man approximates to a fish because ho can swim. The wings of the flying fish and bat are mere expansions of skin, bearing no resemblance whatever to those of birds. $-E d$. 
We have also biformed foetus, mingled species and the like.

XXXI. In the tenth rank of prerogative instances, we will place the instances of power, or the fasces (to borrow a term from the insignia of empire), which we are also wont to call the wit or hands of man. These are such works as are most noble and perfect, and, as it were, the masterpieces in every art. For since our principal object is to make nature subservient to the state and wants of man, it becomes us well to note and enumerate the works, which have long since been in the power of man, especially those which are most polished and perfect: because the passage from these to new and hitherto undiscovered works, is more easy and feasible. For if any one, after an attentive contemplation of such worlis as are extant, be willing to push forward in his design with alacrity and vigor, he will undoubtedly either advance them, or turn them to something within their immediate reach, or even apply and transfer them to some more noble purpose.

Nor is this all: for as the understanding is elevated and raised by rare and unusual works of nature, to investigate and discover the forms which include them also, so is the same effect frequently produced by the excellent and wonderful works of art; and even to a greater degree, because the mode of effecting and constructing the miracles of art is gencrally plain, while that of effecting the miracles of nature is more obscure. Great care, however, must be taken, that they lo not depress the understanding, and fix it, as it were, to earth.

For there is some danger, lest the understanding should be astonished and chained down, and as it were bewitched, by such works of art, as appear to be the very summit and 
pinnacle of human industry, so as not to become familiar with them, but rather to suppose that nothing of the kind can be accomplished, unless the same means be employed, with perhaps a little more diligence, and more accurate preparation.

Now, on the contrary, it may be stated as a fact, that the ways and means hitherto discovered and observed, of effecting any matter or work, are for the most part of little value, and that all really efficient power depends, and is really to be deduced from the sources of forms, none of which have yet been discovered.

Thus (as we have before observed), had any one meditated on ballistic machines, and battering rams, as they were used by the ancients, whatever application he might have exerted, and though he might have consumed a whole life in the pursuit, yet would he never have hit upon the invention of flaming engines, acting by means of gunpowder; nor would any person, who had made woollen manufactories and cotton the subject of his observation and reflection, have ever discovered thereby the nature of the silkworm or of silk.

Hence all the most noble discoveries have (if you obser:e) come to light, not by any gradual improvement and cxtension of the arts, but merely by chance; while nothing imitates or anticipates chance (which is wont to act at intervals of ages) but the invention of forms.

There is no necessity for adducing any particular examples of these instances, since they are abundant. The plan to be pursued is this: all the mechanical, and even the libcral arts (as far as they are practical), should be visited and thoroughly examined, and thence there should be formed a compilation or particular history of the great master- 
pieces, or most finished works in each, as well as of the mode of carrying them into effect.

$\mathrm{Nor}$ do we confine the diligence to be used in such a compilation to the leading works and secrets only of erery art, and such as excite wonder; for wonder is engendered by rarity, since that which is rare, although it be com. pounded of ordinary natures, always begets wonder.

On the contrary, that which is really wonderful, from some specific difference distinguishing it from other species, is carclessly observel, if it be but familiar. Yet the singular instances of art should be observed no less than those of nature, which we have before spoken of: and as in the lattor we have classed the sun, the moon, the magnet, and the like, all of them most familiar to us, but yet in their nature singular, so should we proceed with the singular instances of art.

For example: paper, a very common substance, is a singular instance of art; for if you consider the subject attentively, you will find that artificial substances are either woven by straight and transverse lines, as silk, woollen, or linen cloth, and the like; or coagulated from concrete juices, such as brick, earthenware, glass, enamel, porcelain and the like, which admit of a polish if they be compact, but if not, become hard without being polished; all which latter substances are brittle, and not adherent or tenacious. On the contrary, paper is a tenacious substance, which can be cut and torn, so as to resemble and almost rival the shin of any animal, or the leaf of vegetables, and the like works of nature; being neither brittle like glass, nor woven like cloth, but having fibres and not distinct threads, just as natural substances, so that scarcely anything similar can be found among artificial substances, and it is absolutely 
singular. And in artificial works we should certainly prefer those which approach the nearest to an imitation of nature, or, on the other hand, powerfully govern and change her course.

Again, in these instances which we term the wit and hands of man, charms and conjuring should not be altogether despised, for although mere amusements, and of little use, yet they may afford considerable information.

Lastly, superstition and magic (in its common acceptation) are not to be entirely omitted; for although they be overwhelmed by a mass of lies and fables, yet some investigation should be made, to see if there be really any latent natural operation in them; as in fascination, and the fortifying of the imagination, the sympathy of distant objects, the transmission of impressions from spirit to spirit no less than from body to body, and the like.

XXXII. From the foregoing remarks, it is clear that the last five species of instances (the similar, singular, deviating and bordering instances, and those of power) should not be reserved for the investigation of any given nature, as the preceding and many of the succeeding instances must, but a collection of them should be made at once, in the style of a particular history, so that they may arrange the matter which enters the understanding, and correct its depraved habit, for it is necessarily imbued, corrupted, perverted and distorted by daily and habitual impressions.

They are to be used, therefore, as a preparative, for the purpose of rectifying and purifying the understanding; for whatever withdraws it from habit, levels and planes down its surface for the reception of the dry and pure light of true notions.

These instances, moreover, level and prepare the way 
for the operative branch, as we will mention in its proper place when speaking of the practical decluctions.

XXXIII. In the eleventh rank of prerogative instances we will place accompanying and hostile instances. These are such as exhibit any body or concrete, where the required nature is constantly found, as an inseparable companion, or, on the contrary, where the required nature is constantly aroided, and excluded from attendance, as an enemy. From these instances may be formed certain and universal propositions, either affirmative or negative; the subject of which will be the concrete boly, and the predicate the required nature. For particular propositions are by no means fixed, when the required nature is found to fluctuate and change in the concrete, either approaching anc acquired, or receding and laid aside. Mence particular propositions have no great prerogative, except in the case of migration, of which we have spoken above. Yet such particular propositions are of great use, when compared with the universal, as will be mentioned in its proper place. Nor do we require absolute affirmation or negation, even in universal propositions, for if the exceptions be singular or rare, it is sufficient for our purpose.

The use of accompanying instances is to narrow the affirmative of form; for as it is narrowed by the migrating instances, where the form must necessarily be something communicated or destroyed by the act of migration, so it is narrowed by accompanying instances, where the form must necessarily be something which enters into the concretion of the body, or, on the contrary, is repugnant to it; and one who is well acquainted with the constitution or formation of the body, will not be far from bringing to light the form of the required nature. 
For example: let the required nature be heat. Flame is an accompanying instance; for in water, air, stone, metal, and many other substances, heat is variable, and can approach or retire; but all flame is hot, so that heat always accompanies the concretion of flame. We have no hostile instance of heat; for the senses are unacquainted with the interior of the earth, and there is no concretion of any known body which is not susceptible of heat.

Again, let solidity be the required nature. Air is a hostile instance; for metals may be liquid or solid, so may glass; even water may become solid by congelation, but air cannot become solid or lose its fluidity.

With regard to these instances of fixed propositions, there are two points to be observed, which are of importance. First, that if there be no universal affirmative or negative, it be carefully noted as not existing. Thus, in heat, we have observed that there exists no universal negative, in such substances, at least, as have come to our knowledge. Again, if the required nature be eternity or incorruptibility, we have no universal affirmative within our sphere, for these qualities cannot be predicated of any bodies below the heavens, or above the interior of the earth. Secondly, to our general propositions as to any conerete, whether affirmative or negative, we should subjoin the concretes which appear to approach nearest to the nonexisting substances; such as the most gentle or leastburning flames in heat, or gold in incorruptilility, since it approaches nearest to it. For they all serve to show the limit of existence and non-existence, and circumscribe forms, so that they cannot wander beyond the conditions of matter.

XXXIV. In the twelfth rank of prerogative instances, 
we will class those subjunctive instances, of which we spoke in the last aphorism, and which we are also wont to call instances of extremity or limits; for they are not only serviceable when subjoined to fixed propositions, but also of themselves and from their own nature. They indicate with sufficient precision the real divisions of nature, and measures of things, and the "how far" nature effects or allows of anything, and her passage thence to something else. Such are gold in weight, iron in haraness, the whale in the size of animals, the $\log$ in smell, the flame of gunpowder in rapid expansion, and others of a like nature. Nor are we to pass over the extremes in lefect, as well as in abundance, as spirits of wine in weight, the touchstone in softress, the worms upon the skin in the size of animals, and the like.

XXXV. In the thirtcenth rank of prerogative instances we will place those of alliance or union. They are such as mingle and unite natures held to be heterogeneous, and observed and marked as such in received classifications.

These instances show that the operation and effect, whichis consifered peculiar to some one of such heterogeneous natures, may also be attributed to another nature styled heterogeneous, so as to prove that the difference of the natures is not real nor essential, but a mere modification of a common nature. They are very serviceable, therefore, in elevating and carrying on the mind, from differences to genera, and in removing those phantoms and images of things, which meet it in disguise in concrete substances.

For example: let the required nature be heat. The classification of heat into three kincls, that of the celestial bodies, that of animals, and that of fire, appears to be set- 
tled and admitted; and these kinds of heat, especially one of them compared with the other two, are supposed to be different, and clearly heterogeneous in their essence and species, or specific nature, since the heat of the heavenly bodies and of animals generates and cherishes, while that of fire corrupts and destroys. We have an instance of alliance, then, in a very common experiment, that of a vine branch admitted into a building where there is a con. stant fire, by which the grapes ripen a whole month sooner than in the air; so that fruit upon the tree can be ripened by fire, although this appear the peculiar effect of the sun. From this leeginning, therefore, the understanding rejects all essential difference, and easily ascends to the investigation of the real differences between the heat of the sun and that of fire, by which their operation is rendered dissimilar, although they partake of a common nature.

These differences will be found to be four in number. 1. The heat of the sun is much milder and gentler in degree than that of fire. 2. It is much more moist in quality, especially as it is transmitted to us through the air. 3. Which is the chief point, it is very unequal, advancing and increased at one time, retiring and diminished at another, which mainly contributes to the generation of bodies. For Aristotle rightly asserted, that the principal cause of generation and corruption on the surface of the earth was the oblique path of the sun in the zodiac, whence its heat becomes very unequal, partly from the alternation of night and day, partly from the succession of summer and winter. Yet must he immediately corrupt and pervert his discovery, by dictating to nature according to his habit, and dogmatically assigning the cause of generation to the approach of 
the sun, and that of corruption to its retreat; while, in fact, each circumstance indifferently and not respectively contributes both to generation and corruption; for unequal heat tends to generate and corrupt, as equable beat does to preserve. 4. The fourth difference between the heat of the sun and fire is of great consequence; namely, that the sun, gradually, and for a length of time, insinuates its effects, while those of fire (urged by the impatience of man) are brought to a termination in a shorter space of time. But if any one were to pay attention to the tempering of fire, and reducing it to a more moderate and gentle degree (which may be done in various ways), and then were to sprinkle and mix a degree of humidity with it; and, above all, were to imitate the sun in its inequality; and, lastly, were patiently to suffer some delay (not such, how ever, as is proportioned to the effects of the sun, but more than men usually admit of in those of fire), he would soon banish the notion of any difference, and would attempt, or equal, or perhaps sometimes surpass the effect of the sun, by the heat of fire. A like instance of alliance is that of reviving butterflies, benumbed and nearly dead from cold, by the gentle warmth of fire; so that fire is no less able to revive animals than to ripen vegetables. We may also mention the celebrated invention of Fracastorius, of apply. ing a pan considerably heated to the head in desperate cases of apoplexy, which clearly expands the animal spirits, when compressed and almost extinguished by the humors and obstructions of the brain, and excites them to action, as the fire would operate on water or air, and in the result produces life. Eggs are sometimes hatched by the heat of fire, an exact imitation of animal heat; and there are many in. stances of the like nature, so that no one can doubt that the 
heat of fire, in many cases, can be modified till it resemble that of the heavenly bodies and of animals.

Again, let the required natures be motion and rest. There appears to be a settled classification, grounded on the deepest philosophy, that natural bodies either revolve, move in a straight line, or stand still and rest. For there is either motion without limit, or continuance within a certain limit, or a translation toward a certain limit. The eternal motion of revolution appears peculiar to the heavenly bodies, rest to this our globe, and the other bodies (heavy and light, as they are termed, that is to say, placed out of their natural position) are borne in a straight line to masses or aggregates which resemble them, the light toward the heaven, the heavy toward the earth; and all this is very fine language.

But we have an instance of alliance in low comets, which revolve, though far below the heavens; and the fiction of Aristotle, of the comet being fixed to, or necessarily following some star, has been long since exploded; not only because it is improbable in itself, but from the evident fact of the discursive and irregular motion of comets through various parts of the heavens. ${ }^{56}$

Another instance of alliance is that of the motion of air, which appears to revolve from east to west within the tropics, where the circles of revolution are the greatest.

The flow and ebh of the sea would perhaps be another instance, if the water were once found to have a motion of

55 Seneca was a sounder astronomer than Bacon. He ridiculed the idea of the motion of any heavenly bodies being irregular, and predicted that the day would come, when the laws which guided the revolution of these bodies would be proved to be identical with those which controlled the motions of the planets. The anticipation was realized by Newton. - Ed. 
revoluticn, though slow and hardly perceptible, from east to west, subject, however, to a reaction twice a day. If this be so, it is clear that the motion of revolution is not confined to the celestial bodies, but is shared, also, by air and water.

Again—the supposed peculiar disposition of light bodies to rise is rather shaken; and here we may find an instance of alliance in a water bubble. For if air be placed under water, it rises rapidly toward the surface by that striking motion (as Democritus terms it) with which the descending water strikes the air and raises it, not by any struggle or effort of the air itself; and when it has reached the surface of the water, it is prevented from ascending any further, by the slight resistance it meets with in the water, which does not allow an immediate separation of its parts, so that the tendency of the air to rise must be very slight.

A gain, let the required nature be weight. It is certainly a received classification, that dense and solid bodies are borne toward the centre of the earth, and rare and light borlies to the circumference of the heavens, as their appropriate places. As far as relates to places (though these things have much weight in the schools), the notion of there being any determinate place is absurd and puerile. Philosophers trifle, therefore, when they tell you, that if the earth were perforated, heavy bodies would stop on their arrival at the centre. This centre would indeed be an efficacious nothing, or mathematical point, could it affect bodies or be sought by them, for a body is not acted upon except by a body. ${ }^{56}$ In fact, this tendency to ascend and

${ }^{56}$ But see Bacon's uwn corollary at the end of the Instances of Divorce, Aphorism xxxvii. If Bacon's remark be accepted, the censure will fall upon 
descend is either in the conformation of the moving body, or in its harmony and sympathy with another body. But if any dense and solid body be found, which does not, however, tend toward the earth, the classification is at an end. Now, if we allow of Gilbert's opinion, that the magnetic power of the earth, in attracting heavy bodies, is not extended beyond the limit of its peculiar virtue (which operates always at a fixed distance and no further), ${ }^{j 7}$ and this be proved by some instance, such an instance will be one of alliance in our present subject. The nearest approach to it is that of waterspouts, frequently seen by persons navigating the Atlantic toward either of the Indies. For the force and mass of the water suddenly effused by waterspouts, appears to be so considerable, that the water must have been collected previously, and have remained fixed where it was formed, until it was afterward forced down by some violent cause, rather than made to fall by the natural motion of gravity: so that it may be conjectured that a dense and compact mass, at a great distance from the earth, may be suspended as the earth itself is, and would not fall, unless forced down. We do not, however, affirm this as certain. In the meanwhile, both in this respect and many others, it will readily be seen how deficient we are in nat-

Newton and the system so generally received at the present day. It is, however, unjust, as the centre of which Newton so often speaks is not a point with an active inherent force, but only the result of all the particular and reciprocal attractions of the different parts of the planet acting upon one spot. It is evident, that if all these forces were united in this centre, that the sum would be equal to all their partial effects. $-E d$.

${ }^{57}$ Since Newton's discovery of the law of gravitation, we find that the attractive force of the earth must extend to an infinite distance. Bacon himself alludes to the operation of this attractive force at great distances in the Instances of the Rod, Aphorism xlv. 
ural history, since we are forced to have recourse to suppositions for examples, instead of ascertained instances.

Again, let the required nature be the discursive power of the mind. The classification of human reason and animal instinct appears to be perfectly correct. Yet there are some instances of the actions of brutes which seem to show that they, too, can syllogize. Thus it is related, that a crow, which had nearly perished from thirst in a great drought, saw some water in the hollow trunk of a tree, but as it was too narrow for him to get into it, he continued to throw in pebbles, which made the water rise till he could drink; and it afterward became a proverb.

Again, let the required nature be vision. The classification appears real and certain, which considers light as that which is originally visible, and confers the power of seeing; and color, as being secondarily visible, and not capable of being seen without light, so as to appear a mere image or modification of light. Yet there are instances of alliance in each respect; as in snow when in great quantities, and in the flame of sulphur; the one being a color originally and in itself light, the other a light verging toward color. ${ }^{\text {B8 }}$

XXXVI. In the fourteenth rank of prerogative instances, we will place the instances of the cross, borrowing our metaplior from the crosses erected where two roads meet, to point out the different directions. We are wont also to call them decisive and judicial instances, and in some cases instances of the oracle and of command. Their nature is as follows: When in investigating any nature the understanding is, as it were, balanced, and uncertain to which of two or more natures the cause of the required

58 Snow reflects light, but is not a source of light. 
nature should be assigned, on account of the frequent and usual concurrence of several natures, the instances of the cross show that the union of one nature with the required nature is firm and indissoluble, while that of the other is unsteady and separable; by which means the question is decided, and the first is received as the cause, while the other is dismissed and rejected. Such instances, therefore, afford great light, and are of great weight, so that the course of interpretation sometimes terminates, and is completed in them. Sometimes, however, they are found among the instances already observed, but they are generally new, being expressly and purposely sought for and applied, and brought to light only by attentive and active diligence.

For example: let the required nature be the flow and ebb of the sea, which is repeated twice a day, at intervals of six hours between each advance and retreat, with some little difference, agreeing with the motion of the moon. We have here the following crossways:

This motion must be occasioned either by the advancing and the retiring of the sea, like water shaken in a basin, which leaves one side while it washes the other; or by the rising of the sea from the bottom, and its again subsiding, like boiling water. But a doubt arises, to which of these causes we should assign the flow and ebb. If the first assertion be admitted, it follows, that when there is a flood on one side, there must at the same time be an ebb on another, and the question therefore is reduced to this. Now Acosta, and some others, after a diligent inquiry, have observed that the flood tide takes place on the coast of Florida, and the opposite coasts of Spain and Africa, at the same time, as does also the ebb; and that there is not, on the contrary, a flood tide at Florida when there is an ebb on the coasts of 
Spain and Africa. Yet if one consider the subject attentively, this does not prove the necessity of a rising motion, nor refute the notion of a progressive motion. For the motion may be progressive, and yet inundate the opposite shores of a channel at the same time; as if the waters be forced and driven together from some other quarter, for instance, which takes place in rivers, for they flow and ebb toward each bank at the same time, yet their motion is clearly progressive, being that of the waters from the sea entering their mouths. So it may happen, that the waters coming in a vast body from the eastern Indian Ocean are driven together, and forced into the channel of the Atlantic, and therefore inundate both coasts at once. We must inquire, therefore, if there be any other channel by which the waters can at the same time sink and ebb; and the Southern Ocean at once suggests itself, which is not less than the Atlantic, but rather broader and more extensive than is requisite for this effect.

We at length arrive, then, at an instance of the cross, which is this. If it be positively discovered, that when the flood sets in toward the opposite coasts of Florida and Spain in the Atlantic, there is at the same time a flood tide on the coasts of Peru and the back part of China, in the Southern Ocean, then assuredly, from this decisive instance, we must reject the assertion, that the flood and ebb of the sea, about which we inquire, takes place by progressive motion; for no other sea or place is left where there can be an ebb. But this may most easily be learned, by inquiring of the inhabitants of Panama and Lima (where the two oceans are separated by a narrow isthmus), whether the flood and ebb takes place on the opposite sides of the isthmus at the same time, or the reverse. This decision or rejection appears certain, 
if it be granted that the earth is fixed; but if the earth revolves, it may perhaps happen, that from the unequal revolution (as regards velocity) of the earth and the waters of the sea, there may be a violent forcing of the waters into a mass, forming the flood, and a subsequent relaxation of them (when they can no longer bear the accumulation), forming the ebb. A separate inquiry must be made into this. Even with this hypothesis, however, it remains equally true, that there must be an ebb somewhere, at the same time that there is a flood in another quarter.

Again, let the required nature be the latter of the two motions we have supposed; namely, that of a rising and subsiding motion, if it should happen that upon diligent examination the progressive motion be rejected. We have, then, three ways before us, with regard to this nature. The motion, by which the waters raise themselves, and again fall back, in the floods and ebbs, without the addition of any other water rolled toward them, must take place in one of the three following ways: Either the supply of water emanates from the interior of the earth, and returns back again; or there is really no greater quantity of water, but the same water (without any augmentation of its quantity) is extended or rarefied, so as to occupy a greater space and dimension, and again contracts itself; or there is neither an additional supply nor any extension, but the same waters (with regard to quantity, density, or rarity) raise themselves and fall from sympathy, by some magnetic power attracting and calling them up, as it were, from above. Let us then (passing over the first two motions) reduce the investigation to the last, and inquire if there be any such elevation of the water by sympathy or a magnetic force; and it is evi-dent, in the first place, that the whole mass of water being 
placed in the trench or cavity of the sea, cannot be raised at once, because there would not be enough to cover the bottom, so that if there be any tendency of this kind in the water to raise itself, yet it would be interrupted and checked by the cohesion of things, or (as the common expression is) that there may be no vacuum. The water, therefore, must rise on one side, and for that reason be diminished and ebb on another. But it will again necessarily follow that the magnetic power not being able to operate on the whole, operates most intensely on the centre, so as to raise the waters there, which, when thus raised successively, desert and abandon the sides. ${ }^{59}$

We at length arrive, then, at an instance of the cross, which is this: if it be found that during the ebb the surface of the waters at sea is more curved and round, from the waters rising in the middle, and sinking at the sides or coast, and if, luring a flood, it be more even and level, from the waters returning to their former position, then assuredly, by this decisive instance, the raising of them by a magnetic force can be admitted; if otherwise, it must be entirely rejected. It is not difficult to make the experiment (by sounding in straits), whether the sea be deeper toward the middle in ebbs, than in floods. But it must be observed, if this be the case, that (contrary to common opinion) the waters rise in ebbs, and only return to their former position in floods, so as to bathe and inundate the coast.

Again, let the required nature be the spontaneous motion of revolution, and particularly, whether the diurnal motion, by which the sun and stars appear to us to rise and set, be

59 Bacon's sagacity here foreshadows Newton's theory of the tides. 
a real motion of revolution in the heavenly bodies, or only apparent in them, and real in the earth. There may be an instance of the cross of the following nature. If there be discovered any motion in the ocean from east to west, though very languid and weak, and if the same motion be discovered rather more swift in the air (particularly within the tropics, where it is more perceptible from the circles being greater). If it be discovered also in the low comets, and be already quick and powerful in them; if it be found also in the planets, but so tempered and regulated as to be slower in those nearest the earth, and quicker in those at the greatest distance, being quickest of all in the heavens, then the diurnal motion should certainly be considered as real in the heavens, and that of the earth must be rejected; for it will be evident that the motion from east to west is part of the system of the world and universal; since it is most rapid in the height of the heavens, and gradually grows weaker, till it stops and is extinguished in rest at the earth.

Again, let the required nature be that other motion of revolution, so celebrated among astronomers, which is contrary to the diurnal, namely, from west to east-and which the ancient astronomers assign to the planets, and even to the starry sphere, but Copernicus and his followers to the earth also-and let it be examined whether any such motion be found in nature, or it be rather a fiction and hypothesis for abridging and facilitating calculation, and for promoting that fine notion of effecting the heavenly motions by perfect circles; for there is nothing which proves such a motion in heavenly objects to be true and real, either in a planet's not returning in its diurnal motion to the same point of the starry sphere, or in the pole of the zodiac being different 
from that of the world, which two circumstances have occasioned this notion. For the first phenomenon is well accounted for by the spheres overtaking or falling behind each other, and the second by spiral lines; so that the in. accuracy of the return and declination to the tropics may be rather modifications of the one diurnal motion than contrary motions, or about different poles. And it is most certain, if we consider ourselves for a moment as part of the vulgar (setting aside the fictions of astronomers and the school, who are wont undeservedly to attack the senses in many respects, and to affect obscurity), that the apparent motion is such as we have said, a model of which we have sometimes caused to be represented by wires in a sort of a machine.

We may take the following instances of the cross upon this subject. If it be found in any history worthy of credit, that there has existed any comet, high or low, which has not revolved in manifest harmony (however irregularly) with the diurnal motion, then we may decicle so far as to allow such a motion to be possible in nature. But if nothing of the sort be found, it must be suspected, and recourse must be had to other instances of the cross.

Again, let the required nature be weight or gravity. Heary and ponderous bodies must, either of their own nature, tend toward the centre of the earth by their peculiar formation, or must be attracted and hurried by the corporeal mass of the earth itself, as being an assemblage of similar bodies, and be drawn to it by sympathy. But if the latter be the cause, it follows that the nearer bodies approach to the earth, the more powerfully and rapidly they must be borne toward it, and the further they are distant, the more faintly and slowly (as is the case in magnetic attractions), 
and that this must happen within a given distance; so that if they be separated at such a distance from the earth that the power of the earth cannot act upon them, they will remain suspended like the earth, and not fall at all. ${ }^{60}$ The following instance of the cross may be adopted. Take a clock moved by leaden weights, ${ }^{61}$ and another by

60 The error in the text arose from Bacon's impression that the earth was immovable. It is evident, since gravitation acts at an infinite distance, that no such point could be found; and even supposing the impossible point of equilibrium discovered, the body could not maintain its position an instant, but would be hurried, at the first movement of the heavenly bodies, in the direction of the dominant gravitating power. $-E d$.

61 Fly clocks are referred to in the text, rot pendulum clocks, which were not known in England till 1662. The former, though clumsy and rude in their construction, still embodied sound mechanical principles. The comparison of the effect of a spring with that of a weight in producing certain motions in certain times on altitudes and in mines, has recently been tried by Professors Airy and Whewell in Dalcoath mine, by means of a pendulum, which is only a weight moved by gravity, and a chronometer balance moved and regulated by a spring. In his thirty-seventh Aphorism, Bacon also speaks of gravity as an incorporeal power, acting at a distance, and requiring time for its trans. mission; a consideration which occurred at a later period to Laplace in one of his most delicate investigations.

Crucial instances, as Herschel remarks, afford the readiest and securest means of eliminating extraneous causes, and deciding between the claims of rival hypotheses; especially when these, running parallel to each other, in the explanation of great classes of phenomena, at length come to be placed at issue upon a single fact. A curious example is given by M. Fresnel, as decisive in his mind of the question between the two great theories on the nature of light, which, since the time of Newton and Hujghens, have divided philosophers. When two very clean glasses are laid one on the other, if they be not perfectly flat, but one or both, in an almost impereeptible degree, convex or prominent, beautiful and vivid colors will be seen between them; and if these be viewed through a red glass, their appearance will be that of alternate dark and bright stripes. These stripes are formed between the two surfitces in apparent contact, and being applicable on both theories, are appealed to by their respective supporters as strong confirmatory facts; but there is a difterence in one circumstance, according as one or other theory is employed to explain them. In the case of the Huyghenian theory, the intervals between the bright stripes ought to appear absolutely black, when a prism is used for the upper glass, in the other hulf bright. This curious case of difference was tried, as soon as the op- 
a spring, and let them be set well together, so that one be neither quicker nor slower than the other; then let the clock moved by weights be placed on the top of a very high church, and the other be kept below, and let it be well observed, if the former move slower than it did, from the diminished power of the weights. Let the same experiment be made at the bottom of mines worked to a considerable depth, in order to see whether the clock move more quickly from the increased power of the weights. But if this power be found to diminish at a height, and to increase in subterraneous places, the attraction of the corporeal mass of the earth may be taken as the cause of weight.

Again, let the required nature be the polarity of the steel needle when touched with the magnet. We have these two ways with regard to this nature-Either the touch of the magnet must communicate polarity to the steel toward the north and south, or else it may only excite and prepare it, while the actual motion is occasioned by the presence of the earth, which Gilbert considers to be the case, and endeavors to prove with so much labor. The particulars he has inquired into with such ingenious zeal amount to this -1. An iron bolt placed for a long time toward the north and south aequires polarity from this habit, without the touch of the magnet, as if the earth itself operating but weakly from its distance (for the surface or outer crust of the earth does not, in his opinion, possess the magnetic power), yet, by long continued motion, could supply the place of the magnet, excite the iron, and convert and change it when excited. 2. Iron, at a red or white heat, when

posing consequences of the two theories were noted by M. Fresnel, and tho result is stated by him to be decisive in favor of that theory which makes light to consist in the vibrations of an elastic medium. $-E d$. 
quenched in a direction parallel to the north and south, also acquires polarity without the touch of the magnet, as if the parts of iron being put in motion by ignition, and afterward recovering themselves, were, at the moment of being quenched, more susceptible and sensitive of the power emanating from the earth, than at other times, and therefore as it were excited. But these points, though well observed, do not completely prove his assertion.

An instance of the cross on this point might be as follows: Let a small magnetic globe be taken, and its poles marked, and placed toward the east and west, not toward the north and south, and let it continue thus. Then let an untouched needle be placed over it, and suffered to remain so for six or seven days. Now, the needle (for this is not disputed), while it remains over the magnet, will leave the poles of the world and turn to those of the magnet, and therefore, as long as it remains in the above position, will turn to the east and west. But if the needle, when removed from the magnet and placed upon a pivot, be found immediately to turn to the north and south, or even by degrees to return thither, then the presence of the earth must be considered as the cause, but if it remains turned as at first, towarl the east and west, or lose its polarity, then that cause must be suspected, and further inquiry made.

Again, let the required nature be the corporeal substance of the moon, whether it be rare, fiery, and aërial (as most of the ancient philosophers have thought), or solid and dense (as Gilbert and many of the moderns, with some of the ancients, hold). ${ }^{62}$ The reasons for this latter opinion

62 Bacon plainly, from this passage, was inclined to believe that the moon, like the comets, was nothing more than illuminated vapor. The Newtonian 
are grounded chiefly upon this, that the moon reflects the sun's rays, and that light does not appear capable of being reflected except by solids. The instances of the cross will therefore (if any) be such as to exhibit reflection by a rare body, such as flame, if it be but sufficietly dense. Now, certainly, one of the reasons of twilight is the reflection ${ }^{e s}$ of the rays of the sun by the upper part of the atmosphere. We see the sun's rays also reflected on fine evenings by streaks of moist clouds, with a splendor not less, but perhaps more bright and glorious than that reflected from the body of the moon, and yet it is not clear that those clouds have formed into a dense body of water. We sse, also, that the dark air behind the windows at night reflects the light of a candle in the same manner as a dense body would do. ${ }^{64}$ The experiment should also be made of causing the sun's rays to fall through a hole upon some dark and bluish flame. The unconfined rays of the sun, when falling on faint flames, do certainly appear to deaden them, and render them more like white smoke than flames. These are the only instances which occur at present of the nature of those of the cross, and better perhaps can be found. But it must always be observed that reflection is not to be expected from flame, unless it be of some depth, for otherwise it be-

law, however, has not only established its solidity, but its density and weight. A sufficient proof of the former is afforded by the attraction of the sea, and the moon's motion round the earth. $-E d$.

${ }^{6} 3$ Rather the refraction; the sky or air, however, reflects the blue rays of light.

${ }^{64}$ The polished surface of the glass causes the reflection in this case, and not the air; and a lat or other black surface put behind the window in the daytime will enable the glass to reflect distinctly for the same reason, namely. that the reflected rays are not mixed and confused with those transmitted from the other side of the window. 
comes nearly transparent. This at least may be considered certain, that light is always either received and transmitted or reflected by an even surface.

Again, let the required nature be the motion of projectiles (such as darts, arrows, and balls) through the air. The school, in its usual manner, treats this very carelessly, considering it enough to distinguish it by the name of violent motion, from that which they term natural, and as far as regards the first percussion or impulse, satisfies itself by its axiom, that two bodies cannot exist in one place, or there would be a penetration of dimensions. With regard to this nature we have these two crossways-The motion must arise either from the air carrying the projected body, and collecting behind it, like a stream behind boats, or the wind behind straws; or from the parts of the body itself not supporting the impression, but pushing themselves forward in succession to ease it. Fracastorius, and nearly all those who have entered into any refined inquiry upon the subject, adopt the first. Nor can it be doubted that the air has some effect, yet the other motion is without doubt real, as is clear from a vast number of experiments. Among others we may take this instance of the cross, namely, that a thin plate or wire of iron rather stiff, or even a reed or pen split in two, when drawn up and bent between the finger and thumb, will leap forward; for it is clear that this cannot be attributed to the air's being collected behind the body, because the source of motion is in the centre of the plate or pen, and not in its extremities.

Again, let the required nature be the rapid and powerful motion of the explosion of gunpowder, by which such vast masses are upheaved, and such weights discharged as we observe in large mines and mortars, there are two cross- 
ways before us with regard to this nature. This motion is excited either by the mere effort of the body expanding itself when inflamed, or by the assisting effort of the crude spirit, which escapes rapialy from fire, and bursts violently from the surrounding flame as from a prison. The school, however, and common opinion only consider the first effort; for men think that they are great philosophers when they assert that flame, from the form of the element, is endowed with a kind of necessity of occupying a greater space than the same body had occupied when in the form of powder, and that thence proceeds the motion in question. In the meantime they do not observe, that although this may be true, on the supposition of flame being generated, yet the generation may be impeded by a weight of sufficient force to compress and suffocate it, so that no such necessity exists as they assert. They are right, indeed, in imagining that the expansion and the consequent emission or removal of the opposing body, is necessary if flame be once generated, but such a necessity is avoided if the solid opposing mass suppress the flame before it be generated; and we in fact see that flame, especially at the moment of its generation, is mild and gentle, and requires a hollow space where it can play and try its force. The great violence of the effect, therefore, cannot be attributed to this cause; but the truth is, that the generation of these exploding flames and fiery blasts arises from the conflict of two bodies of a decidedly opposite nature-the one very inflammable, as is the sulphur, the other having an antipathy to flame, namely, the crude spirit of the nitre; so that an extraordinary conflict takes place while the sulphur is becoming inflamed as far as it can (for the third body, the willow charcoal, merely incorporates and conveniently unites the two others), and 
the spirit of nitre is escaping, as far also as it can, and at the same time expanding itself (for air, and all crude substances, and water are expanded by heat), fanning thus, in every direction, the flame of the sulphur by its escape and violence, just as if by invisible bellows.

Two kinds of instances of the cross might here be used -the one of very inflammable substances, such as sulphur and camphor, naphtha and the like, and their compounds, which take fire more readily and easily than gunpowder if left to themselves (and this shows that the effort to catch fire does not of itself produce such a prodigious effect); the other of substances which avoid and repel flame, such as all salts; for we see that when they are cast into the fire, the aqueous spirit escapes with a crackling noise before flame is produced, which also happens in a less degree in stiff lesves, from the escape of the aqueous part refore the oily part has caught fire. This is more particularly observed in quicksilver, which is not improperly called mineral water, and which, without any inflammation, nearly equals the force of gunpowder by simple explosion and expansion, and is said, when mixed with gunpowder, to increase its force.

Again, let the required nature be the transitory nature of flame and its momentaneous extinction; for to us the nature of flame does not appear to be fixed or settled, but to be generated from moment to moment, and to be every instant extinguished; it being clear that those flames which continue and last, do not owe their continuance to the same mass of flame, but to a continued succession of new flame regularly generated, and that the same identical flame does not continue. This is easily shown by removing the food or source of the flame, when it at once goes out. We 
have the two following crossways with regard to this nature:

This momentary nature either arises from the cessation of the cause which first produced it, as in light, sounds, and violent motions, as they are termed, or flame may be capa. ble, by its own nature, of duration, but is subjected to some violence from the contrary natures which surround it, and is destroyed.

We may therefore adopt the following instance of the cross. We see to what a height the flames rise in great conflagrations; for as the base of the flame becomes more extensive, its vertex is more lofty. It appears, then, that the commencement of the extinction takes place at the sides, where the flame is compressed by the air, and is ill at ease; but the centre of the flame, which is untouched by the air and surrounded by flame, continues the same, and is not extinguished until compressed by degrees by the air attacking it from the sides. All flame, therefore, is pyramidal, having its base near the source, and its vertex pointed from its being resisted by the air, and not supplied from the source. On the contrary, the smoke, which is narrow at the base, expands in its ascent, and resembles an inverted pyramid, because the air admits the smoke, but compresses the flame; for let no one dream that the lighted flame is air, since they are clearly heterogeneous.

The instance of the cross will be more accurate, if the experiment can be made by flames of different colors. Take, therefore, a small metal sconce, and place a lighted taper in it, then put it in a basin, and pour a small quantity of spirits of wine round the sconce, so as not to reach its edge, and light the spirit. Now the flame of the spirit will be blue, and that of the taper yellow; observe, therefore, 
whether the latter (which can easily be distinguished from the former by its color, for flames do not mix immediately, as liquids do) continue pyramidal, or tend more to a globular figure, since there is nothing to destroy or compress it. If the latter result be observed, it must be considered as settled, that flame continues positively the same, while inclosed within another flame, and not exposed to the resisting force of the air.

Let this suffice for the instances of the cross. We have $\mathrm{d}$ welt the longer upon them in order gradually to teach and accustom mankind to judge of nature by these instances, and enlightening experiments, and not by probable reasons. ${ }^{65}$

65 These instances, which Bacon seems to consider as a great discovery, are nothing more than disjunctive propositions combined with dilemmas. In proposing to explain an effect, we commence with the enumeration of the different causes which seem connected with its production; then with the aid of one or more dilemmas, we eliminate each of the phenomena accidental io its composition, and conclude with attributing the effect to the residue. For instance, a certain phenomenon $(a)$ is produced either by phenomenon (B) or phenomenon (C); but C cannot be the cause of $a$, for it is found in D, E, F, neither of which are connected with $a$. Then the true cause of phenomenon $(a)$ must be phenomenon (B).

This species of reasoning is liable to several paralogisms, against which Bacon has not guarded his readers, from the very fact that he stumbled into them unwittingly himself. The two principal ones are false exclusions and defective enumerations. Bacon, in his survey of the causes which are able to concur in producing the phenomena of the tides, takes no account of the periodic melting of the Polar ice, or the expansion of water by the solar heat; nor does he fare better in his exclusions. For the attraction of the planets and the progression and retrograde motion communicated by the earth's diurnal revolution, can plainly affect the sea together, and have a simultaneous influence on its surface.

Bacon is hardly just or consistent in his censure of Ramus; the end of whose dichotomy was only to render reasoning by dilemma, and crucial instances, more certain in their results, by reducing the divisions which composed their parts to two sets of contradictory propositions. The affirmative or negative of one would then necessarily have led to the acceptance or rejection of the other. $-E d$. 
XXXVII. We will treat of the instances of divorce as the fifteenth of our prerogative instances. They indicate the separation of natures of the most common occurrence. They differ, however, from those subjoined to the accompanying instances; for the instances of divorce point out the separation of a particular nature from some concrete substance with which it is usually found in conjunction, while the hostile instances point out the total separation of one nature from another. They difter, also, from the instances of the cross, because they decide nothing, but only inform us that the one nature is capable of being separated from the other. They are of use in exposing false forms, and dissipating hasty theories derived from obvious facts; so that they add ballast and weight, as it were, to the understanding.

For instance, let the acquired natures be those four which Telesius terms associates, and of the same family, namely, heat, light, rarity, and mobility, or promptitude to motion; yet many instances of divorce can be discovered between them. Air is rare and easily moved, but neither hot nor light; the moon is light but not hot; boiling water is warm but not light; the motion of the needle in the com. pass is swift and active, and yet its substance is cold, dense, and opaque; and there are many similar examples.

Again, let the required natures be corporeal nature and natural action. The latter appears incapable of subsisting without some body, yet may we, perhaps, even here find an instance of divorce, as in the magnetic motion, which draws the iron to the magnet, and heavy bodies to the globe of the earth; to which we may add other actions which operate at a distance. For such action takes place in time, by distinct moments, not in an instant; and in space, by regular de- 
grees and distances. There is, therefore, some one moment of time and some interval of space, in which the power or action is suspended between the two bodies creating the motion. Our consideration, then, is reduced to this, whether the bodies which are the extremes of motion prepare or alter the intermediate bodies, so that the power advances from one extreme to the other by succession and actual contact, and in the meantime exists in some intermediate body; or whether there exists in reality nothing but the bodies, the power, and the space? In the case of the rays of light, sounds, and heat, and some other objects which operate at a distance, it is indeed probable that the intermediate bodies are prepared and altered, the more so because a qualified medium is required for their operation. But the magnetic or attractive power admits of an indifferent medium, and it is not impeder in any. But if that power or action is independent of the intermediate body, it follows that it is a natural power or action existing in a certain time and space without any body, since it exists neither in the extreme nor in the intermediate bodies. Hence the magnetic action may be taken as an instance of divorce of corporeal nature and natural action; to which we may add, as a corollary and an advantage not to be neglected, that it may be taken as a proof of essence and substance being separate and incorporeal, even by those who philosophize according to the senses. For if natural power and action emanating from a body can exist at any time and place entirely without any body, it is nearly a proof that it can also emanate originally from an incorporeal substance; for a corporeal nature appears to be no less necessary for supporting and conveying, than for exciting or generating natural action. 
XXXVIII. Next follow five classes of instances which we are wont to call by the general term of instances of the lamp, or of immediate information. They are such as assist the senses; for since every interpretation of nature sets out from the senses, and leads, by a regular fixed and wellestablished road, from the perceptions of the senses to those of the understanding (which are true notions and axioms), it necessarily follows, that in proportion as the representatives or ministerings of the senses are more abundant and accurate, everything else must be more easy and successful.

The first of these five sets of instances of the lamp, strengthen, enlarge, and correct the immediate operations of the senses; the sccond reduce to the sphere of the senses such matters as are beyond it; the third indicate the continued process or series of such things and motions, as for the most part are only observed in their termination, or in periods; the fourth supply the absolute wants of the senses; the fifth excite their attention and observation, and at the same time limit the subtilty of things. We will now proceed to speak of them singly.

XXXIX. In the sixteenth rank, then, of prerogative instances, we will place the instances of the door or gate, by which name we designate such as assist the immediate action of the senses. It is obvious, that sight holds the first rank among the senses, with regard to information, for which reason we must seek principally helps for that sense. These helps appear to be threefold, either to enable it to perceive objects not naturally scen, or to see them from a greater distance, or to see them more accurately and distinctly.

We have an example of the first (not to speak of spectacles and the like, which only correct and remove the in- 
firmity of a deficient sight, and therefore give no further information) in the lately invented microscopes, which exhibit the latent and invisible minutiæ of substances, and their hidden formation and motion, by wonderfully increasing their apparent magnitude. By their assistance we behold with astonishment the accurate form and outline of a flea, moss, and animalculæ, as well as their previously invisible color and motion. It is said, also, that an apparently straight line, drawn with a pen or pencil, is discovered by such a microscope to be very uneven and curved, because neither the motion of the hand, when assisted by a ruler, nor the impression of ink or color, are really regular, although the irregularities are so minute as not to be perceptible without the assistance of the microscope. Men have (as is usual in new and wonderful discoveries) added a superstitious remark, that the microscope sheds a lustre on the works of nature, and dishonor on those of art, which only means that the tissue of nature is much more delicate than that of art. For the microscope is only of use for minute objects, and Democritus, perhaps, if he had seen it, would have exulted in the thought of a means being discovered for seeing his atom, which he affirmed to be entirely invisible. But the inadequacy of these microscopes, for the observation of any but the most minute bodies, and even of those if parts of a larger body, destroys their utility; for if the invention could be extended to greater bodies, or the minute parts of greater bodies, so that a piece of cloth would appear like a net, and the latent minutiæ and irregularities of gems, liquids, urine, blood, wounds, and many other things could be rendered visible, the greatest advantage would, without doubt, be derived. 
We have an instance of the second kind in the telescope, discovered by the wonderful exertions of Galileo; by the assistance of which a nearer intercourse may be opened (as by boats or vessels) between ourselves and the heavenly objects. For by its aid we are assured that the Milky Way is but a knot or constellation of small stars, clearly defined and separate, which the ancients only conjectured to be the case; whence it appears to be capable of demonstration, that the spaces of the planetary orbits (as they are termed) are not quite destitute of other stars, but that the heaven begins to glitter with stars before we arrive at the starry sphere, although they may be too small to be visible without the telescope. By the telescope, also, we can behold the revolutions of smaller stars round Jupiter, whence it may be conjectured that there are several centres of motion among the stars. By its assistance, also, the irregularity of light and shade on the moon's surface is more clearly observed and determined, so as to allow of a sort of selenography. ${ }^{66} \mathrm{By}$ the telescope we see the spots in the sun, and other similar phenomena; all of which are most noble discoveries, as far as credit can be safely given to demonstrations of this nature, which are on this account very suspicious, namely, that experiment stops at these few, and nothing further has yet been discovered by the same method, among objects equally worthy of consideration.

We have instances of the third kind in measuring-rods, astrolabes, and the like, which do not enlarge, but correct and guide the sight. If there be other instances which assist

66 Pìre Shenier first pointed out the spots on the sun's disk, and by the marks which they afforded him, computed its revolution to be performed in twenty-five days and some hours. $-E d$. 
the other senses in their immediate and individual action, yet if they add nothing further to their information they are not apposite to our present purpose, and we have therefore said nothing of them.

XL. In the seventeenth rank of prerogative instances we will place citing instances (to borrow a term from the tribunals), because they cite those things to appear, which have not yet appeared. We are wont also to call them in. voking instances, and their property is that of reducing to the sphere of the senses objects which do not immediately fall within it.

Objects escape the senses either from their distance, or the intervention of other bodies, or because they are not calculated to make an impression upon the senses, or because they are not in sufficient quantity to strike the senses, or because there is not sufficient time for their acting upon the senses, or because the impression is too violent, or because the senses are previously filled and possessed by the object, so as to leave no room for any new motion. These remarks apply principally to sight, and next to touch, which two senses act extensively in giving information, and that too upon general objects, while the remaining three inform us only, as it were, by their immediate action, and as to specific objects.

There can be no reduction to the sphere of the senses in the first case, unless in the place of the object, which cannot be perceived on account of the distance, there be added or substituted some other object, which can excite and strike the sense from a greater distance, as in the communication of intelligence by fires, bells, and the like.

In the second case we effect this reduction by rendering those things which are concealed by the interposition of 
other bodies, and which cannot easily be laid onen, evident to the senses by means of that which lies at the surface, or proceeds from the interior; thus the state of the body is judged of by the pulse, urine, etc.

The third and fourth cases apply to many subjects, and the reduction to the sphere of tho senses must be obtained from every quarter in the investigation of things. There are many examples. It is obvious that air, and spirit, and the like, whose whole substance is extremely rare and delicate, can neither be seen nor touched-a reduction, therefore, to the senses becomes necessary in every investigation relating to such bodies.

Let the required nature, therefore, be the action and motion of the spirit inclosed in tangible bodies; for every tangible body with which we are acquainted contains an invisible and intangible spirit, over which it is drawn, and which it seems to clothe. This spirit being emitted from a tangible substance, leaves the body contracted and dry; when retained, it softens and melts it; when neither wholly enitted nor retained, it models it, endows it with limbs, assimilates, manifests, organizes it, and the like. All these points are reduced to the sphere of the senses by manifest effects.

For in every tangible and inanimate body the inclosed spirit at first increases, and as it were feeds on the tangible parts which are most open and prepared for it; and when it has digested and modified them, and turned them into spirit, it escapes with them. This formation and increase of spirit is rendered sensible by the diminution of weight; for in every desiccation somsthing is lost in quantity, not only of the spirit previously existing in the body, but of the body itself, which was previously tangible, and has 
been recently changed, for the spirit itself has no weight. The departure or emission of spirit is rendered sensible in the rust of metals, and other putrefactions of a like nature, which stop before they arrive at the rudiments of life, which belong to the third species of process. ${ }^{67}$ In compact bodies the spirit does not find pores and passages for its escape, and is therefore obliged to force out, and drive before it, the tangible parts also, which consequently protrude, whence arises rust and the like. The contraction of the tangible parts, occasioned by the emission of part of the spirit (whence arises desiccation), is rendered sensible by the increased hardness of the substance, and still more by the fissures, contractions, shrivelling, and folds of the bodies thus produced. For the parts of wood split and contract, skins become shrivelled, and not only that, but, if the spirit be emitted suddenly by the heat of the fire, become so hastily contracted as to twist and roll themselves up.

On the contrary, when the spirit is retained, and yet expanded and excited by heat or the like (which happens in solid and tenacious bodies), then the bodies are softened, as in hot iron; or flow, as in metals; or melt, as in gums, wax, and the like. The contrary effects of heat, therefore (hardening some substances and melting others), are easily reconciled, ${ }^{68}$ because the spirit is emitted in the former, and

67 Rust is now well known to be a chemical combination of oxygen with the metal, and the metal when rusty acquires additional weight. His theory as to the generation of animals, is deduced from the erroncons notion of the possibility of spontaneous generation (as it was termed). See the next para. graph but one.

68 "Limus ut hic durescit, et hæc ut cera liquescit

Uno eodemque igni."'-Virg. Ecl. viii. 
agitated and retained in the latter; the latter action is that of heat and the spirit, the former that of the tangible parts themselves, after the spirit's emission.

But when the spirit is neither entirely retained nor emitted, but only strives and exercises itself, within its limits, and meets with tangible parts, which obey and readily follow it wherever it leads them, then follows the formation of an organic body, and of limbs, and the other vital actions of vegetables and animals. These are rendered sensible chiefly by diligent observation of the first beginnings, and rudiments or effects of life in animalculæ sprung from putrefaction, as in the eggs of ants, worms, mosses, frogs after rain, etc. Both a mild heat and a pliant sub. stance, however, are necessary for the production of life, in order that the spirit may neither hastily escape, nor be restrained by the obstinacy of the parts, so as not to be able to bend and model them like wax.

Again, the difference of spirit which is important and of effect in many points (as unconnected spirit, branching spirit, branching and cellular spirit, the first of which is that of all inanimate substances, the second of vegetables, and the third of animals), is placed, as it were, before the eyes by many reducing instances.

Again, it is clear that the more refined tissue and conformation of things (though forming the whole body of visible or tangible objects) are neither visible nor tangible. Our information, therefore, must here also be derived from reduction to the sphere of the senses. But the most radical and primary difference of formation depends on the abundance or scarcity of matter within the same space or dimensions. For the other formations which regard the dissimilarity of the parts contained in the same body, and their 
collocation and position, are secondary in comparison with the former.

Let the required nature then be the expansion or cohe. rence of matter in different bodies, or the quantity of matter relative to the dimensions of each. For there is nothing in nature more true than the twofold proposition-that nothing proceeds from nothing and that nothing is reduced to nothing, but that the quantum, or sum total of matter, is constant, and is neither increased nor diminished. Nor is it less true, that out of this given quantity of matter, there is a greater or less quantity, contained within the same space or dimensions according to the difference of bodies; as, for instance, water contains more than air. So that if any one were to assert that a given content of water can be changed into an equal content of air, it is the same as if he were to assert that something can be reduced into nothing. On the contrary, if any one were to assert that a given content of air can be changed into an equal content of water, it is the same as if he were to assert that something can proceed from notbing. From this abundance or scarcity of matter are properly derived the notions of density and rarity, which are taken in various and promiscuous senses.

This third assertion may be considered as being also sufficiently certain; namely, that the greater or less quantity of matter in this or that body, may, by comparison, be reduced to calculation, and exact, or nearly cxact, proportion. Thus, if one should say that there is such an accumulation of matter in a griven quanity of gold, that it would require twenty-one times the quantity in dimension of spirits of wine, to make up the same quantity of matter, it would not be far from the truth. 
The accumulation of matter, however, and its relative quantity, are rendered sensible by weight; for weight is proportionate to the quantity of matter, as regards the parts of a tangible substance, but spirit and its quantity of matter are not to be computed by weight, which spirit rather diminishes than augments.

We have made a tolerably accurate table of weight, in which we have selected the weights and size of all the metals, the principal minerals, stones, liquids, oils, and many other natural and artificial bodies: a very useful proceeding both as regards theory and practice, and which is capable of revealing many unexpected results. Nor is this of little consequence, that it serves to demonstrate that the whole range of the variety of tangible bodies with which we are acquainted (we mean tolerably close, and not spongy, hollow bodies, which are for a considerable part filled with air), does not exceed the ratio of one to twentyone. So limited is nature, or at least that part of it to which we are most habituated.

$W^{\top}$ e have also thought it deserving our industry, to try if we could arrive at the ratio of intangible or pneumatic bodies to tangible bolies, which we attempted by the following contrivance. We took a vial capable of containing about an ounce, using a small vessel in order to effect the subsequent evaporation with less heat. We filled this vial, almost to the neck, with spirits of wine, selecting it as the tangible body which, by our table, was the rarest, and contained a less quantity of matter in a given space than all other tangible bodies which are compact and not hollow. Then we noted exactly the weight of the liquid and vial. We next took a bladier, containing about two pints, and squeezed all the air out of it, as completely as possible, and 
until the sides of the bladuer met. We first, however, rubbed the bladder gently with oil, so as to make it airtight, by closing its pores with the oil. We tied the bladder tightly round the mouth of the vial, which we had inserted in it, and with a piece of waxed thread to make it fit better and more tightly, and then placed the vial on some hot coals in a brazier. The vapo: or steam of the spirit, dilated and become aëriform by the heat, gradually swelled out the bladder, and stretched it in every direction like a sail. As soon as that was accomplished, we removed the vial from the fire and placed it on a carpet, that it might not be cracked by the cold; we also pricked the bladder immediately, that the steam might not return to a liquid state by the cessation of heat, and confound the proportions. We then removed the bladder, and again took the weight of the spirit which remained; and so calculated the quantity which had been converted into vapor, or an aëriform shape, and then examined how much space had been occupied by the body in its form of spirits of wine in the vial, and how much, on the other hand, had been occupied by it in its aëriform shape in the bladder, and subtracted the results; from which it was clear that the body, thus converted and changed, acquired an expansion of one hundred times beyond its former bulk.

Again, let the required nature be heat or cold, of such a degree as not to be sensible from its weakness. They are rendered sensible by the thermometer, as we described it above $;^{69}$ for the cold and heat are not actually perceived by the touch, but heat expands and cold contracts the air. Nor, again, is that expansion or contraction of the air in

69 See Table of Degrees, No. 38. 
itself visible, but the air when expanded depresses the water, and when contracted raises it, which is the first reduction to sight.

Again, let the required nature be the mixture of bodies; namely, how much aqueous, oleaginous or spirituous, ashy or salt parts they contain; or, as a particular example, how much butter, cheese, and whey there is in milk, and the like. These things are rendered sensible by artificial and skilful separations in tangible substances; and the nature of the spirit in them, though not immediately perceptible, is nevertheless discovered by the various motions and efforts of bodies. And, indeed, in this branch men have labored hard in distillations and artificial separations, but with little more success than in their other experiments now in use; their methods being mere guesses and blind attempts, and more industrious than intelligent; and what is worst of all, without any imitation or rivalry of nature, but rather by violent heats and too energetic agents, to the destruction of any delicate conformation, in which principally consist the hidden virtues and sympathies. Nor do men in these separations ever attend to or observe what we have before pointed out; namely, that in attacking bodies by fire, or other methods, many qualities are superinduced by the fire itself, and the other bodies used to effect the separation, which were not originally in the compound. Hence arise most extraordinary fallacies; for the mass of vapor which is emitted from water by fire, for instance, did not exist as vapor or air in the water, but is chiefly created by the expansion of the water by the heat of the fire.

So, in general, all delicate experiments on natural or artificial bodies, by which the genuine are distinguished from the adulterated, and the better from the more com- 
mon, should be referred to this division; for they bring that which is not the object of the senses within their sphere. They are therefore to be everywhere diligently sought after.

With regard to the fifth cause of objects escaping our senses, it is clear that the action of the sense takes place by motion, and this motion is time. If, therefore, the motion of any body be either so slow or so swift as not to be proportioned to the necessary momentum which operates on the senses, the object is not perceived at all; as in the motion of the hour hand, and that, again, of a musket-ball. The motion which is imperceptible by the senses from its slowness, is readily and usually rendered sensible by the accumulation of motion; that which is imperceptible from its velocity, has not as yet been well measured; it is necessary, however, that this should be done in some cases, with a view to a proper investigation of nature.

The sixth case, where the sense is impeded by the power of the object, admits of a reduction to the sensible sphere, either by removing the object to a greater distance, or by deadening its effects by the interposition of a medium, which may weaken and not destroy the object; or by the admission of its reflection where the direct impression is too strong, as that of the sun in a basin of water.

The seventh case, where the senses are so overcharged with the object as to leave no further room, scarcely occurs except in the smell or taste, and is not of much consequence as regards our present subject. Let what we have said, therefore, suffice with regard to the reduction to the sensible sphere of objects not naturally within its compass.

Sometimes, however, this reduction is not extended to the senses of man, but to those of some other animal, whose scnses, in some points, exceed those of man; as (with regard 
to some scents) to that of the dog, and with regard to light existing imperceptibly in the air, when not illuminated from any extraneous source, to the sense of the cat, the owl, and other animals which see by night. For Telesius has well observed, that there appears to be an original portion of light even in the air itself, ${ }^{70}$ although but slight and meagre, and of no use for the most part to the eyes of men, and those of the generality of animals; because those animals to whose senses this light is proportioned can see by night, which does not, in all probability, proceed from their seeing either without light or by any internal light.

Here, too, we would observe, that we at present discuss only the wants of the senses, and their remedies; for their deceptions must be referred to the inquiries appropriated to the senses, and sensible objects; except that important deception, which makes them define objects in their relation to man, and not in their relation to the universe, and which is only corrected by universal reasoning and philosophy. ${ }^{n 1}$

XLI. In the eighteenth rank of prerogative instances we will class the instances of the road, which we are also wont to call itinerant and jointed instances. They are such as indicate the gradually continued motions of nature. This

70 Riccati, and all modern plyysicists, discover some portion of light in every body, which seems to confirm the passuge in Genesis that assigns to this substance priority in creation.- $-E d$.

7 As instances of this kind, which the progress of science since the time of Bacon affords, we may cite the air-pump and the barometer, for manifesting the weight and elasticity of air: the measurement of the velocity of light, by means of the occultation of Jupiter's sutellites and the aberration of the fixed stars: the experiments in electricity and galvanisin, and in the greater part of pneumatic chemistry. In all these cases scientific facts are elicited, which sense could never have revealed to us. $-E d$. 
species of instances escapes rather our observation than our senses; for men are wonderfully indolent upon this subject, consulting nature in a desultory manner, and at periodic intervals, when bodies have been regularly finished and completed, and not during her work. But if any one were desirous of examining and contemplating the talents and industry of an artificer, he would not merely wish to see the rude materials of his art, and then his work when finished, but rather to be present while he is at labor, and proceeding with his work. Something of the same kind should be done with regard to nature. For instance, if any one investigate the vegetation of plants, he should observe from the first sowing of any seed (which can easily be done, by pulling up every day seeds which have been two, three, or four days in the ground, and examining them diligently), how and when the seed begins to swell and break, and be filled, as it were, with spirit; then how it begins to burst the bark and push out fibres, raising itself a little at the same time, unless the ground be very stiff; then how it pushes out these fibres, some downward for roots, others upward for the stem, sometimes also creeping laterally, if it find the earth open and more yielding on one side, and the like. The same should be done in observing the hatching of eggs, where we may easily see the process of animation and organization, and what parts are formed of the yolk, and what of the white of the egry, and the like. The same may be said of the inquiry into the formation of animals from putrefaction; for it would not be so humane to inquire into perfect and terrestrial animals, by eutting the foctus from the womb; but opportunities may lerhaps be offererl of abortions, animals killed in hunting; and the like. Nature, therefore, must, as it were, be watched, as being 
more easily observed by night than by day: for contempla. tions of this kind may be considered as carried on by night, from the minuteness and perpetual burning of our watch-light.

The same must be attempted with inanimate objects, which we have ourselves done by inquiring into the opening of liquils by fire. For the mode in which water expands is different from that observed in wine, vinegar, or verjuice, and very different, again, from that observed in milk and oil, and the like; and this was easily seen by boiling them with slow heat, in a glass vessel, through which the whole may be clearly perceived. But we merely mention this, intending to treat of it more at large and more closely when we come to the discovery of the latent process; for it should always be remembered that we do not here treat of things themselves, but merely propose examples. ${ }^{72}$

XLII. In the nineteenth rank of prerogative instances we will class supplementary or substitutive instances, which we are also wont to call instances of refuge. They are such as supply information, where the senses are entirely deficient, and we therefore have recourse to them when appropriate instances cannot be obtained. This substitution is

72 The itinerant instances, as well as frontier instances, are cases in which we are enabled to trace the geteral law of continuity which seems to pervade all nature, and which has been aptly embodied in the sentence, "natura non agrit per saltum." The pursuit of this law into phenomena where its application is not at first sight obvious, has opened a mine of physical discovery, and led us to perecive an intimate commection between facts which at first seemed liostile to each other. For example, the transparency of gold-leaf, which permits a bluish-green light to pass through it, is a frontier instance betweèn transparent and opaque bodies, by exhibiting a body of the glass generally regirded the most opaque in nature, as still possessed of some slight degree of transparency. It thus proves that the quality of opacity is not a contrary or antagonistic quality to that of transparency, but only its extreme lowcs: degree. 
twofold, either by approximation or by analogy. For instance, there is no known medium which entirely prevents the effect of the magnet in attracting iron-neither gold, nor silver, nor stone, nor glass, wood, water, oil, cloth, or fibrous bodies, air, flame, or the like. Yet by accurate experiment, a medium may perhaps be found which would deaden its effect, more than another comparatively and in degree; as, for instance, the magnet would not perhaps attract iron through the same thickness of gold as of air, or the same quantity of ignited as of cold silver, and so on; for we have not ourselves made the experiment, but it will suffice as an example. Again, there is no known body which is not susceptible of heat, when brought near the fire; yet air becomes warm much sooner than stone. These are examples of substitution by approximation.

Substitution by analogy is useful, but less sure, and therefore to be adopted with some judgment. It serves to reduce that which is not the object of the senses to their sphere, not by the perceptible operations of the imperceptible body, but by the consideration of some similar perceptible body. For instance, let the subject for inquiry be the mixture of spirits, which are invisible bodies. There appears to be some relation between bodies and their sources or support. Now, the source of flame seems to be oil and fat; that of air, water, and watery sulstances; for flame increases over the exhalation of oil, and air over that of water. One must therefore consicler the mixture of oil and water, which is manifest to the senses, since that of air and flame in general escapes the senses. But oil and water mix very imperfectly by composition or stirring, while they are exactly and nicely mixed in herbs, blood, and the parts of animals. Something similar, therefore, may take place in 
the mixture of flame and air in spirituous substances, not bearing mixture very well by simple collision, while they appear, however, to be well mixed in the spirits of plants and animals.

Again, if the inquiry do not relate to perfect mixtures of spirits, but merely to their composition, as whether they easily incorporate with each other, or there be rather (as an example) certain winds and exhalations, or other spiritual bodies, which do not mix with common air, but only adhere to and float in it in globules and drops, and are rather broken and pounded by the air, than received into, and incorporated with it; this cannot be perceived in common air, and other aëriform substances, on account of the rarity of the bodies, but an image, as it were, of this process may be conceived in such liquids as quicksilver, oil, water, and even air, when broken and dissipated it ascends in small portions through water, and also in the thicker kinds of smoke; lastly, in dust, raised and remaining in the air, in all of which there is no incorporation: and the above repre. sentation in this respect is not a bad one, if it be first diligently investigated, whether there can be such a difference of nature between spirituous substances, as between liquids, for then these images might conveniently be substituted by analogy.

And although we have observed of these supplementary instances, that information is to be derived from them, when appropriate instances are wanting, by way of refuge, yet we would have it understood, that they are also of great use, when the appropriate instances are at hand, in order to confirm the information afforded by them; of which we will spuik more at lengrth, when our subject leads us, in due course, to the support of induction. 
XLIII. In the twentieth rank of prerogative instances we will place lancing instances, which we are also wont (but for a different reason) to call twitching instances. We adopt the latter name, because they twitch the understand. ing, and the former because they pierce nature, whence we style them occasionally the instances of Democritus. ${ }^{73}$ Thev are such as warn the understanding of the admirable and exquisite subtilty of nature, so that it becomes roused and awakened to attention, observation, and proper inquiry; as, for instance, that a little drop of ink should be drawn out into so many letters; that silver merely gilt on its surface should be stretched to such a length of gilt wire; that a little worm, such as you may find on the skin, should possess both a spirit and a varied conformation of its parts; that a little saffron should imbue a whole tub of water with its color; that a little musk or aroma should imbue a much greater extent of air with its perfume; that a cloud of smoke should be raised by a little incense; that such accurate differences of sounds as articulate words should be conveyed in all directions through the air, and even penetrate the pores of wood and water (though they become much weakened), that they should be, moreover, reflected, and that with such distinctness and velocity; that light and color should for such an extent and so rapidly pass through solid bodies, such as glass and water, with so great and so exquisite a variety of images, and should be refracted and reflected; that the magnet should attract through every deseription of body, even the most compact; but (what is still more wonderful) that in all these cases the action of one should not impede that of another in a common

ข Alluding to his theory of atoms. 
medium, such as air; and that there should be borne through the air, at the same time, so many images of visible objects, so many impulses of articulation, so many different perfumes, as of the violet, rose, etc., besicles cold and heat, and magnetic attractions; all of them, I say, at once, without any impediment from each other, as if each had its paths and peculiar passage set apart for it, without infringing against or meeting each other.

To these lancing instances, however, we are wont, not without some advantage, to add those which we call the limits of such instances. Thus, in the cases we have pointed out, one action does not disturb or impede another of a different nature, yet those of a similar nature subrlue and extinguish each other; as the light of the sun does that of the candle, the sound of a cannon that of the voice, a strong perfume a more delicate one, a powerful heat a more gentle one, a plate of iron between the magnet and other iron the effect of the magnet. But the proper place for mentioning these will be also among the supports of induction.

XIIV. We have now spoken of the instances which assist the senses, and which are principally of service as regards information; for information begins from the senses. But our whole labor terminates in practice, and as the former is the beginning, so is the latter the end of our subject. The following instances, therefore, will be those which are chiefly useful in practice. They are compre. hended in two classes, and are seven in number. We call them all by the general name of practical instances. Now there are two defects in practice, and as many divisions of important instances. Practice is either deceptive or too laborious. It is generally deceptive (especially after a dili. 
gent examination of natures), on account of the power and actions of bodies being ill defined and determined. Now the powers and actions of bodies are defined and determined either by space or by time, or by the quantity at a given period, or by the predominance of energy; and if these four circumstances be not well and diligently considered, the sciences may indeed be beautiful in theory, but are of no effect in practice. We call the four instances referred to this class, mathematical instances and instances of measure.

Practice is laborious either from the multitude of instruments, or the bulk of matter and substances requisite for any given work. Those instances, therefore, are valuable, which either direct practice to that which is of most consequence to mankind, or lessen the number of instruments or of matter to be worked upon. We assign to the three instances relating to this class, the common name of propitious or benevolent instances. We will now separately discuss these seven instances, and conclude with them that part of our work which relates to the prerogative or illustrious instances.

XLV. In the twenty-first rank of prerogative instances we will place the instances of the rod or rule, which we are also wont to call the instances of completion or non ultrd. For the powers and motions of bodies do not act and take effect through indefinite and accidental, but through limited and certain siatces; and it is of great importance to practice that these should be understood and noted in every nature which is investigated, not only to prevent deception, but to render practice more extensive and efficient. For it is sometimes possible to extend these powers, and bring the Aistance, as it were, nearer, as in the example of telescopes. Many powers act and take effect only by actual touch, as 
in the percussion of bodies, where the one does not remove the other, unless the impelling touch the impelled body. External applications in medicine, as ointment and plasters, do not exercise their efficacy except when in contact with the body. Lastly, the objects of touch and taste only strike those senses when in contact with their organs.

Other powers act at a distance, though it be very small, of which but few have as yet been noted, although there be more than men suspect; this happens (to take everyday instances) when amber or jet attracts straws, bubbles dissolve bubbles, some purgative medicines draw humors from above, and the like. The magnetic power by which iron and the magnet, or two magnets, are attracted together, acts within a definite and narrow sphere, but if there be any magnetic power emanating from the earth a little below its surface, and affecting the needle in its polarity, it must act at a great distance.

Again, if there be any magnetic force which acts by sympathy between the globe of the earth and heavy bodies, or between that of the moon and the waters of the sea (as seems most probable from the particular floods and ebbs which occur twice in the month), or between the starry sphere and the planets, by which they are summoned and raised to their apogees, these must all operate at very great dis. tances. ${ }^{74}$

7* Observe the approximation to Newton's theory. The same notion repeated still more clearly in the nintl motion. Newton believed that the planets might so conspire as to deringe the earth's annual revolution, and to elougate the line of the apsides and ellipsis that the earth describes in its annual revolution round the sun. In the supposition that all the planets meet on the same straight line, Venus and Mercury on one side of the sun, and the earth, moon, Mars, Jupiter and Siturn on the side diametrically opposite; then Saturn would attract Jupiter, Jupiter Mars, Mars the moon, which must in its 
Again, some conflagrations and the kindling of flames take place at very considerable distances with particular substances, as they report of the naphtha of Babylon. Heat, too, insinuates itself at wide distances, as does also cold, so that the masses of ice which are broken off and float upon the Northern Ocean, and are borne through the Atlantic to the coast of Canada, become perceptible by the inhabitants, and strike them with cold from a distance. Perfumes also (though here there appears to be always some corporeal emission) act at remarkable distances, as is experienced by persons sailing by the coast of Florida, or parts of Spain, where there are whole woods of lemons, oranges, and other odoriferous plants, or rosemary and marjoram bushes, and the like. Lastly, the rays of light and the impressions of sound act at extensive distances.

Yet all these powers, whether acting at a small or great distance, certainly act within definite distances, which are well ascertained by nature, so that there is a limit depending either on the mass or quantity of the bodies, the vigor or faintness of the powers, or the favorable or impeding nature of the medium, all of which should be taken into

turn attract the earth in proportion to the force with which it was drawn out of its orbit. The result of this combined action on our planet would elongate its ecliptic orbit, and so far draw it from the source of heat, as to produce an intensity of cold destructive to animal life. But this movement would inmediately cease with the planetary concurrence which produced it, and the earth, like a cornpressed spring, bound almost as near to the sun as she had been drawn from it, the reaction of the heat on its surface being about as intense as the cold caused by the first removal was severe. The earth, until it gained its regular track, would thus alternately vibrate between each side of its orbit, with successive changes in its atmosphere, proportional to the square of the variation of its distance from the sull. In no place is Bacon's genius more conspicuous than in these repeated guesses at truth. He would have been a strong Copernican, had not Gilbert defended the system.-Ed. 
account and observed. We must also note the boundaries of violent motions, such as missiles, projectiles, wheels and the like, since they are also manifestly confined to certain limits.

Some motions and virtues are to be found of a directly contrary nature to these, which act in contact but not at a distance; namely, such as operate at a distance and not in contact, and again act with less force at a less distance, and the reverse. Sight, for instance, is not easily effective in contact, but requires a medium and distance; although I remember having heard from a person deserving of credit, that in being cured of a cataract (which was done by putting a small silver needle within the first coat of the eye, to remove the thin pellicle of the cataract, and force it in to a corner of the eye), he had distinctly seen the needle moving across the pupil. Still, though this may be true, it is clear that large bodies cannot be seen well or distinctly, unless at the vertex of a cone, where the rays from the object meet at some distance from the eye. In old persons the eye sees better if the object be moved a little further, and not nearer. Again, it is certain that in projectiles the impact is not so violent at too short a distance as a little afterward. ${ }^{75}$ Such are the observations to be made on the measure of motions as regards distance.

There is another measure of motion in space which must

75 This is not true except when the projectile acquires greater velocity at every successive instant of its course, which is never the case except with falling bodies. Bacon appears to liave been led into the opinion from observing that gunishots pierce many objects at a distance from which they rebound when brought within a certain proximity of contact. This apparent inconsistency, however, arises from the resistance of the parts of the object, which velocity combined with force is necessary to overcome. $-E d$. 
not be passed over, not relating to progressive but spherical motion-that is, the expansion of bodies into a greater, or their contraction into a lesser sphere. For in our measure of this motion we must inquire what degree of compression or extension bodies easily and readily admit of, according to their nature, and at what point they begin to resist it, so as at last to bear it no further-as when an inflated bladder is compressed, it allows a certain compression of the air, but if this be increased, the air does not suffer it, and the bladder is burst.

We have proved this by a more delicate experiment. We took a metal bell, of a light and thin sort, such as is used for salt-cellars, and immersed it in a basin of water, so as to carry the air contained in its interior down with it to the bottom of the basin. We had first, however, placed a small globe at the bottom of the basin, over which we placed the bell. The result was, that if the globe were small compared with the interior of the bell, the air would contract itself, and be compressed without being forced out, but if it were too large for the air readily to yield to it, the latter became impatient of the pressure, raised the bell partly up, and ascended in bubbles.

To prove, also, the extension (as well as the compression) which air admits of, we adopted the following method: -We took a glass egg, with a small hole at one end; we drew out the air by violent suction at this hole, and then closed the hole with the finger, immersed the egg in water, and then removed the finger. The air being constrained by the effort made in suction, and dilated beyond its natural state, and therefore striving to recover and contract itself (so that if the egg had not been immersed in water, it would have drawn in the air with a hissing souncl), now drew in 
a sufficient quantity of water to allow the air to recover its former dimensions. ${ }^{70}$

It is well ascertained that rare bodies (such as air) admit of considerable contraction, as has been before observed; but tangible bodies (such as water) admit of it much less readily, and to a less extent. We investigated the latter point by the following experiment:

We had a leaden globe made, capable of containing about two pints, wine measure, and of tolerable thickness, so as to support considerable pressure. We poured water into it through an aperture, which we afterward closed with melted lead, as soon as the globe was filled with water, so that the whole became perfectly solicl. We next flattened the two opposite sides with a heavy hammer, which necessarily caused the water to occupy a less space, since the sphere is the solid of greatest content; and when hammering failed from the resistance of the water, we made use of a mill or press, till at last the water, refusing to submit to a greater pressure, exuded like a fine dew through the solid lead. We then computed the extent to which the original space had been reduced, and concluded that water admitted such a degree of compression when constrained by great violence.

The more solid, dry or compact bodies, such as stones, wood and metals, admit of much less, and indeed scarcely any perceptible compression or expansion, but escape by breaking, slipping forward, or other efforts; as appears in bending wood, or steel for watch-springs, in projectiles, hammering and many other motions, all of which, together

76 This passage shows that the pressure of the external atmosphere, which forces the water into the egg, was not in Bacon's time understood. $-E d$. 
with their degrees, are to be observed and examined in the investigation of nature, either to a certainty, or by estimation, or comparison, as opportunity permits.

XLVI. In the twenty-second rank of prerogative instances we will place the instances of the course, which we are also wont to call water instances, borrowing our expression from the water hour-glasses employed by the ancients instead of those with sand. They are such as measure nature by the moments of time, as the last instances do by the degrees of space. For all motion or natural action takes place in time, more or less rapidly, but still in determined moments well ascertained by nature. Even those actions which appear to take effect suddenly, and in the twinkling of an eye (as we express it), are found to admit of greater or less rapidity.

In the first place, then, we see that the return of the heavenly bodies to the same place takes place in regular times, as does the flood and ebb of the sea. The descent of heavy bodies toward the earth, and the ascent of light bodies toward the heavenly sphere, take place in definite times, ${ }^{77}$ according to the nature of the body, and of the medium through which it moves. The sailing of ships, the motions of animals, the transmission of projectiles, all

77 We have already alluded, in a note prefixed to the same aphorism of the first book, to Newton's error of the absolute lightness of bodies. In speaking again of the volatile or spiritual substances (Aph. xl. b. ii.), which he supposed with the Platonists and some of the schoolmen to enter into the composition of every body, he ascribes to them a power of lessening the weight of the material coating in which he supposes them inclosed. It would appear from these passages and the text that Bacon had no idea of the relative density of bodies, and the capability which some havo to diminish the spectic gravity of the heavier substances by the dilation of their parts; or if he had, the reveries in which Aristotle indulged in treating of the soul, about the appetency of bodies to fly to kindred substances-flame and spirit to the sky, and solid opaque substances to the earth, must have vitiated his mind.-Ed. 
take place in times the sums of which can be computed. With regard to heat, we see that boys in winter bathe their hands in the flame without being burned; and conjurers, by quick and regular movements, overturn vessels filled with wine or water, and replace them without spilling the liquid, with several similar instances. The compres. sion, expansion and eruption of several bodies, take place more or less rapidly, according to the nature of the body and its motion, but still in definite moments.

In the explosion of several cannon at once (which are sometimes heard at the distance of thirty miles), the sound of those nearest to the spot is heard before that of the most distant. Even in sight (whose action is most rapid), it is clear that a definite time is necessary for its exertion, which is proved by certain objects being invisible from the velocity of their motion, such as a musket-ball; for the flight of the ball is too swift to allow an impression of its figure to be conveyed to the sight.

This last instance, and others of a like nature, have sometimes excited in us a most marvellous doubt, no less than whether the image of the sky and stars is perceived as at the actual moment of its existence, or rather a little after, and whether there is not (with regard to the visible appearance of the heavenly bodies) a true and apparent time, as well as a true and apparent place, which is observed by astronomers in parallaxes. It appeared so incredible to us, that the images or radiations of heavenly bodies could suddenly be conveyed through such immense spaces to the sight, and it seemed that they ought rather to be transmitted in a definite time. ${ }^{78}$ That doubt, however

38 Römer, a I)anish astronomer, was the tirst to demonstrate, by connecting the irregularities of the eclipses of Jupiter's satellites with their distances from 
(as far as regards any great difference between the true and apparent time), was subsequently completely set at rest, when we considered the infinite loss and diminution of size as regards the real and apparent magnitude of a star, occasioned by its distance, and at the same time observed at how great a distance (at least sixty miles) bodies which are merely white can be suddenly seen by us. For there is no doubt, that the light of the heavenly bodies not only far surpasses the vivid appearance of white, but even the light of any flame (with which we are acquainted) in the vigor of its radiation. The immense velocity of the bodies themselves, which is perceived in their diurnal motion, and has so astonished thinking men, that they have been more ready to believe in the motion of the earth, renders the motion of radiation from them (marvellous as it is in its rapidity) more worthy of belief. That which has weighed most with us, however, is, that if there were any considerable interval of time between the reality and the appearance, the images would often be interrupted and confused by clouds formed in the meantime, and similar disturbances of the medium. Let this suffice with regard to the simple measures of time.

It is not merely the absolute, but still more the relative measure of motions and actions which must be inquired into, for this latter is of great use and application. We perceive that the flame of firearmis is seen sooner than the sound is heard, although the ball must have struck the air before the flame, which was behind it, could escape: the reason of which is, that light moves with greater velocity

the earth, the necessity of time for the propagation of light. The idea occurred to Mominic Cassini as well as Bacon, but both allowed the discovery to slip out of their hands. $-E d$. 
than sound. We perceive, also, that visible images are received by the sight with greater rapidity than they are dismissed, and for this reason, a violin string touched with the finger aplears double or triple, because the new image is received before the former one is dismissed. Hence, also, rings when spinning appear globular, and a lighted torch, borne rapidly along at night, appears to have a tail. Upon the principle of the inequality of motion, also, Galileo attempted an explanation of the flood and ebb of the sea, supposing the earth to move rapidly, and the water slowly, by which means the water, after accumulating, would at intervals fall back, as is shown in a vessel of water made to move rapidly. He has, however, imagined this on data which cannot be granted (namely, the earth's motion), and besides, does not satisfactorily account for the tide taking place every six hours.

An example of our present point (the relative measure of motion), and, at the same time, of its remarkable use of which we have spoken, is conspicuous in mines filled with gunpowder, where immense weights of earth, buildings, and the like, are overthrown and prostrated by a small quantity of powder; the reason of which is decidedly this, that the rnotion of the expansion of the gunpowder is much more rapid than that of gravity, ${ }^{79}$ which would resist it, so that the former has terminated before the latter has commenced. Hence, also, in missiles, a strong blow will not carry them so far as a sharp and rapid one. Nor could a small portion of animal spirit in animals, especially in such

79 The author in the text confounds inertness, which is a simple indifference of bodies to action, with gravity, which is a force acting always in proportion to their density. He falls into the same error further on.-Ed. 
vast bodies as those of the whale and elephant, have ever bent or directed such a mass of body, were it not owing to the velocity of the former, and the slowness of the latter in resisting its motion.

In short, this point is one of the principal foundations of the magic experiments (of which we shall presently speak), where a small mass of matter overcomes and regulates a much larger, if there but be an anticipation of motion, by the velocity of one before the other is prepared to act.

Finally, the point of the first and last should be observed in all natural actions. Thus, in an infusion of rhubarb the purgative property is first extracted, and then the astringent; we have experienced something of the same kind in steeping violets in vinegar, which first extracts the sweet and delicate odor of the flower, and then the more earthy part, which disturbs the perfume; so that if the violets be steeped a whole day, a much fainter perfume is extracted than if they were steeped for a quarter of an hour only, and then taken out; and since the odoriferous spirit in the violet is not abundant, let other and fresh violets be steeped in the vinegar every quarter of an hour, as many as six times, when the infusion becomes so strengthened, that although the violets have not altogether remained there for more than one hour and a half, there remains a most pleasing perfume, not inferior to the flower itself, for a whole year. It must be observed, however, that the perfume does not acquire its full strength till about a month after the infusion. In the distillation of aromatic plants macerated in spirits of wine, it is well known that an aqueous and useless phlegm rises first, then water containing more of the spirit, and, lastly, water containing more of the 
aroma; and many observations of the like kind, well worthy of notice, are to be made in distillations. But let these suffice as examples. ${ }^{80}$

s" The experiments of the last two classes of instances are considered only in relation to practice, and Bacon does not so much as mention their infinitely greater importance in the theoretical part of induction. The important law of gravitation in physical astronomy could never have been demonstrated but by such observations and experiments as assigned accurate geometrical measures to the quantities compared. It was necessary to determine with precision the demi-diameter of the earth, the velocity of falling bodies at its surface, the distance of the moon, and the speed with which she describes her orbit, before the relation could be discovered between the force which draws a stone to the ground and that which retains the moon in her sphere.

In many cases the result of a number of particular facts, or the collective instances rising out of them, can only be discovered by geometry, which so far becomes necessary to complete the work of induction. For instance, in the case of optics, when light passes from one transparent medium to another, it is refracted, and the angle which the ray of incidence makes with the superficies which bounds the two media determines that which the refracted ray makes with the same superficies. Now, all experimeut can do for us in this case is, to determine for any particular angle of incidence the corresponding angle of refraction. But with respect to the general rule which in every possible case deduces one of these angles from the other, or expresses the constant and invariable relation which subsists between them, experiment gives no direct information. Geometry must, consequently, be called in, which, wheu a constant though unknown relation subsists between two angles, or two variable qualities of any kind, and when an indefinite number of values of those quantities are assigned, furnishes infallible means of discovering that unknown relation either accurately or by approximation. In this way it has been found, when the two media remain the same, the cosines of the above-mentioned angles have a constant ratio to each other. Hence, when the relations of the simple elements of phenomena are discovered to afford a general rule which will apply to any concrete case, the deductive method must be applied, and the elementary principles made through its agency to account for the laws of their more complex combinations. The reflection and refraction of light by the rain falling from a cloud opposite to the sun was thought, even before Newton's day, to contain the form of the rainbow. This philosopher transformed a probable conjecture into a certain fact when he deduced from the known laws of reflection and refraction the breadth of the colored arch, the diameter of the circle of which it is a part, and the relation of the latter to the place of the spectator and the sun. Doubt was at once silenced when there came out of his calculus a combination of the same laws of the simple elements of optics arswering to the phenomena in nature.-Ed. 
XLVII. In the twenty-third rank of prerogative instances we will place instances of quantity, which we are also wont to call the doses of nature (borrowing a word from medicine). They are such as measure the powers by the quantity of bodies, and point out the effect of the quantity in the degree of power. And in the first place, some powers only subsist in the universal quantity, or such as bears a relation to the confirmation and fabric of the universe. Thus the earth is fixed, its parts fall. The waters in the sea flow and ebb, but not in the rivers, except by the admission of the sea. Then, again, almost all particular powers act according to the greater or less quantity of the body. Large masses cf water are not easily rendered foul, small are. New wine and beer become ripe and drinkable in small skins much more readily than in large casks. If a herb be placed in a considerable quantity of liquid, infusion takes place rather than impregnation; if in less, the reverse. A bath, therefore, and a light sprinkling, produce different effects on the human body. Light dew, again, never falls, but is dissipated and incorporated with the air; thus we see that in breathing on gems, the slight quantity of moisture, like a small cloud in the air, is immediately dissolved. Again, a piece of the same magnet does not attract so much iron as the whole magnet did. There are some powers where the smallness of the quantity is of more arail; as in boring, a sharp point pierces more readily than a blunt one; the diamond, when pointed, makes an impression on glass, and the like.

Here, too, we must not rest contented with a vague result, but inquire into the exact proportion of quantity requisite for a particular exertion of power; for one would be apt to suppose that the power bears an exact proportion Science- Vol. 22-11 
to the quantity; that if a leaden bullet of one ounce, for instance, would fall in a given time, one of two ounces ought to fall twice as rapidly, which is most erroneous. Nor does the same ratio prevail in every kind of power, their difference being considerable. The measure, therefore, must be determined by experiment, and not by probability or conjecture.

Lastly, we must in all our investigations of nature observe what quantity, or dose, of the body is requisite for a given effect, and must at the same time be guarded against estimating it at too much or too little.

XLVIII. In the twenty-fourth rank of prerogative instances we will place wrestling instances, which we are also wont to call instances of predominance. They are such as point out the predominance and submission of powers compared with each other, and which of them is the more energetic and superior, or more weak and inferior. For the motions and effects of bodies are compounded, decomposed, and combined, no less than the bodies themselves. We will exhibit, therefore, the principal kinds of motions or active powers, in order that their comparative strength, and thence a demonstration and definition of the instances in question, may be rendered more clear.

Let the first motion be that of the resistance of matter, which exists in every particle, and completely prevents its annihilation; so that no conflagration, weight, pressure, violence, or length of time can reduce even the smallest portion of matter to nothing, or prevent it from being something, and occupying some space, and delivering itself (whatever straits it be put to), by changing its form or place, or, if that be impossible, remaining as it is; nor can it ever happen that it should either be nothing or nowhere. 
This motion is designated by the schools (which generally name and define everything by its effects and inconveniences rather than by its inherent cause) by the axiom, that two bodies cannot exist in the same place, or they call it a motion to prevent the penetration of dimensions. It is useless to give examples of this motion, since it exists in every body.

Let the second motion be that which we term the motion of connection, by which bodies do not allow themselves to be separated at any point from the contact of another body, delighting, as it were, in the mutual connection and contact. This is called by the schools a motion to prevent a vacuum. It takes place when water is drawn up by suction or a syringe, the flesh by cupping, or when the water remains without escaping from perforated jars, unless the mouth be opened to admit the air, and innumerable instances of a like nature.

Let the third be that which we term the motion of liberty, by which bodies strive to deliver themselves from any unnatural pressure or tension, and to restore themselves to the dimensions suited to their mass; and of which, also, there are innumerable examples. Thus, we have examples of their escaping from pressure, in the water in swimming, in the air in flying, in the water again in rowing, and in the air in the undulation of the winds, and in springs of watches. An exact instance of the motion of compressed air is seen in children's popguns, which they make by scooping out elder-branches or some such matter, and forcing in a piece of some pulpy root or the like, at each end; then they force the root or other pellet with a ramrod to the opposite end, from which the lower pellet is emitted and projected with a report, and that before it is touched 
by the other piece of root or pellet, or by the ramrod. We have examples of their escape from tension, in the motion of the air that remains in glass eggs after suction, in strings, leather, and cloth, which recoil after tension, unless it be long continued. The schools define this by the term of motion from the form of the element; injudiciously enough, since this motion is to be found not only in air, water, or fire, but in every species of solid, as wood, iron, lead, cloth, parchment, etc., each of which has its own proper size, and is with difficulty stretched to any other. Since, however, this motion of liberty is the most obvious of all, and to be seen in an infinite number of cases, it will be as well to distinguish it correctly and clearly; for some most carelessly confound this with the two others of resistance and connection; namely, the freedom from pressure with the former, and that from tension with the latter, as if bodies when compressed yielded or expranded to prevent a penetration of dimensions, and when stretched rebounded and contracted themselves to prevent a vacuum. But if the air, when compressed, could be brought to the density of water, or wood to that of stone, there would be no need of any penetration of dimensions, and yet the compression would be much greater than they actually admit of. So if water could be expanded till it became as rare as air, or stone as rare as wood, there would be no need of a vacuum, and yet the expansion would be much greater than they actually admit of.

We do not, therefore, arrive at a penetration of dimensions or a vacuum before the extremes of condensation and rarefaction, while the motion we speak of stops and exerts itself much within them, and is nothing more than a desire of bodies to preserve their specific density (or, 
if it be preferred, their form), and not to desert them suddenly, but only to change by degrees, and of their own accord. It is, however, much more necessary to intimate to mankind (because many other points depend upon this), that the violent motion which we call mechanical, and Democritus (who, in explaining his primary motions, is to be ranked even below the middling class of philosophers) termed the motion of a blow, is nothing else than this motion of liberty, namely, a tendency to relaxation from compression. For in all simple impulsion or flight through the air, the body is not displaced or moved in space, until its parts are placed in an unnatural state, and compressed by the impelling force. When that takes place, the different parts urging the other in succession, the whole is moved, and that with a rotatory as well as progressive motion, in order that the parts may, by this means also, set themselves at liberty, or more readily submit. Let this suffice for the motion in question.

Let the fourth be that which we term the motion of matter, and which is opposed to the last; for in the motion of liberty, bodies abhor, reject, and avoid a new size or volume, or any new expansion or contraction (for these different terms have the same meaning), and strive, with all their power, to rebound and resume their former density; on the contrary, in the motion of matter, they are anxious to acquire a new volume or dimension, and attempt it willingly and rapidly, and occasionally by a most vigorous effort, as in the example of gunpowder. The most powerful, or at least most frequent, though not the only instruments of this motion, are heat and cold. For instance, the air, if expanded by tension (as by suction in the glass egg), strug. 
gles anxiously to restore itself; but if heat be applied, it strives, on the contrary, to dilate itself, and longs for a larger volume, regularly passing and migrating into it, as into a new form (as it is termed); nor after a certain degree of expansion is it anxious to return, unless it be invited to do so by the application of cold, which is not indeed a return, but a fresh change. So also water, when confined by compression, resists, and wishes to become as it was before, namely, more expanded; but if there happen an intense and continued cold, it changes itself readily, and of its own accord, into the condensed state of ice; and if the cold be long continued, without any intervening warmth (as in grottoes and deep caves), it is changed into crystal or similar matter, and never resumes its form.

Let the fifth be that which we term the motion of continuity. We do not understand by this simple and primary continuity with any other body (for that is the motion of comnection), but the continuity of a particular body in itself; for it is most certain that all bodies abhor a solution of continuity, some more and some less, but all partially. In hard bodies (such as steel and glass) the resist. ance to an interruption of continuity is most powerful and efficacious, while although in liquids it appears to be faint and languid, yet it is not altogether null, but exists in the lowest degree, and shows itself in many experiments, such as bubbles, the round form of drops, the thin threads which drip from roofs, the cohesion of glutinous substances, and the like. It is most conspicuous, however, if an attempt be made to push this separation to still smaller particles. Thus, in mortars, the pestle produces no effect after a certain degree of contusion, water does not penetrate small fissures, and the air itself, notwithstanding its subtilty, 
does not penetrate the pores of solid vessels at once, but only by long-continued insinuation.

Let the sixth be that which we term the motion of acquisition, or the motion of need. ${ }^{81}$ It is that by which bodies placed among others of a heterogeneous and, as it were, hostile nature, if they meet with the means or opportunity of avoiding them, and uniting themselves with others of a more analogous nature, even when these latter are not closely allied to them, immediately seize and, as it were, select them, and appear to consider it as something acquired (whence we derive the name), and to have need of these latter bodies. For instance, gold, or any other metal in leaf, does not like the neighborhood of air; if, therefore, they meet with any tangible and thick substance (such as the finger, paper, or the like), they immediately adhere to it, and are not easily torn from it. Paper, too, and cloth, and the like, do not agree with the air, which is inherent and mixed in their pores. They readily, therefore, imbibe water or other liquids, and get rid of the air. Sugar, or a sponge, dipped in water or wine, and though part of it be out of the water or wine, and at some height above it, will yet gradually absorb them. ${ }^{82}$

Hence an excellent rule is derived for the opening and dissolution of bodies; for (not to mention corrosive and strong waters, which force their way) if a body can be found which is more adapted, suited, and friendly to a given solid, than that with which it is by some necessity united, the given solid immediately opens and dissolves

$81 \mathrm{As}$ far as this motion results from attraction and repul:ion, it is only a simple consequence of the last two.-Ed.

82 These two cases are now resolved into the property of the capillary tubes and present only another feature of the law of attraction. $-E d$. 
itself to receive the former, and excludes or removes the latter. ${ }^{83}$ Nor is the effect or power of this motion confined to contact, for the electric energy (of which Gilbert and others after him have told so many fables) is only the energy excited in a body, by gentle friction, and which does not endure the air, but prefers some tangible substance if there be any at hand.

Let the seventh be that which we term the motion of greater congregation, by which bodies are borne toward masses of a similar nature, for instance, heavy bodies toward the earth, light to the sphere of heaven. The schools termed this natural motion, by a superficial consideration of it, because produced by no external visible agent, which made them consider it innate in the substances; or perhaps because it does not cease, which is little to be wondered at, since heaven and earth are always present, while the causes and sources of many other motions are sometimes absent and sometimes present. They therefore called this perpetual and proper, because it is never interrupted, but instantly takes place when the others are interrupted, and they called the others adscititious. The former, however, is in reality weak and slow, since it yields, and is inferior to the others as long as they act, unless the mass of the body be great; and although this motion have so filled men's minds, as almost to have obscured all others, yet they know but little about it, and commit many errors in its estimate.

Let the eighth be that which we term the motion of lesser congregation, by which the homogeneous parts in

${ }^{83}$ This is one of the most useful practical methods in chemistry at the present day. 
any body separate themselves from the heterogeneous and unite together, and whole bodies of a similar substance coalesce and tend toward each other, and are sometimes congregated, attracted, and meet, from some distance; thus in milk the cream rises after a certain time, and in wine the dregs and tartar sink; which effects are not to be attributed to gravity and levity only, so as to account for the rising of some parts and the sinking of others, but much more to the desire of the homogeneous bodies to meet and unite. This motion differs from that of need in two points: 1st, because the latter is the stimulus of a malignant and contrary nature, while in this of which we treat (if there be no impediment or restraint), the parts are united by their affinity, although there be no foreign nature to create a struggle; 2dly, because the union is closer and more select. For in the other motion, bodies which have no great affinity unite, if they can but avoid the hostile body, while in this, substances which are connected by a decided kindred resemblance come together and are molded into one. It is a motion existing in all compound bodies, and would be readily seen in each, if it were not confined and checked by the other affections and necessities of bodies which disturb the union.

This motion is usually confined in the three following manners: by the torpor of the bodies; by the power of the predominating body; by external motion. With regard to the first, it is certain that there is more or less sluggishness in tangible bodies, and an abhorrence of locomotion; so that unless excited they prefer remaining contented with their actual state, to placing themselves in a better position. There are three means of breaking through this sluggishness-heat; the active power of a similar body; vivid and 
powerful motion. With regard to the first, heat is, on this account, defined as that which separates heterogeneous, and draws together homogeneous substances; a definition of the Peripatetics which is justly ridiculed by Gilbert, who says it is as if one were to define man to be that which sows wheat and plants vineyards; being only a definition deduced from effects, and those but partial. But it is still more to be blamed, because those eiffects, such as they are, are not a peculiar property of heat, but a mere accident (for cold, as we shall afterward show, does the same), arising from the desire of the homogeneous parts to unite; the heat then assists them in breaking through that sluggishness which before restrained their desire. With regard to the assistance derived from the power of a similar body, it is most conspicuous in the magnet when armed with steel, for it excites in the steel a power of adhering to steel, as a homogeneous substance, the power of the magnet breaking through the sluggishness of the steel. With regard to the assistance of motion, it is seen in wooden arrows or points, which penetrate more deeply into wood than if they were tipped with iron, from the similarity of the substance, the swiftness of the motion breaking through the sluggishness of the wood; of which two last experiments we have spoken above in the aphorism on clandestine instances. ${ }^{84}$

The confinement of the motion of lesser congregation, which arises from the power of the predominant body, is shown in the decomposition of blood and urine by cold. For as long as these substances are filled with the active spirit, which regulates and restrains each of their component parts, as the predominant ruler of the whole, the several 
different parts do not collect themselves separately on account of the check; but as soon as that spirit has evaporated, or has been choked by the cold, then the decomposed parts unite, according to their natural desire. Hence it happens, that all bodies which contain a sharp spirit (as salts and the like), last without decomposition, owing to the permanent and durable power of the predominating: and imperious spirit.

The confinement of the motion of lesser congregation, which arises from external motion, is very evident in that agitation of bodies which preserves them from putrefaction. For all putrefaction depends on the congregation of the homogeneous parts, whence, by degrees, there ensues a corruption of the first form (as it is called), and the generation of another. For the decomposition of the original form, which is itself the union of the homogeneous parts, precedes the putrefaction, which prepares the way for the generation of another. This decomposition, if not interrupted, is simple; but if there be various obstacles, putrefactions ensue, which are the rudiments of a new generation. But if (to come to our present point) a frequent agitation be excited by external motion, the motion toward union (which is delicate and gentle, and requires to be free from all external influence) is disturbed, and ceases; which we perceive to be the case in innumerable instances. Thus, the daily agitation or flowing of water prevents putrefaction; winds prevent the air from being pestilent; corn turned about and shaken in granaries continues clean: in short, everything which is externally agitated will with difficulty rot internally.

We must not omit that union of the parts of bodies Which is the principal cause of induration and desiccation. 
When the spirit or moisture, which has evaporated into spirit, has escaped from a porous body (such as wood, bone, parchment, and the like), the thicker parts are drawn together, and united with a greater effort, and induration or desiccation is the consequence; and this we attribute not so much to the motion of connection (in order to prevent a vacuum), as to this motion of friendship and union.

Union from a distance is rare, and yet is to be met with in more instances than are generally observed. We perceive it when one bubble dissolves another, when medicines attract humors from a similarity of substance, when one string moves another in unison with it on different instruments, and the like. We are of opinion that this motion is very prevalent also in animal spirits, but are quite ignorant of the fact. It is, however, conspicuous in the magnet, and magnetized iron. While speaking of the motions of the magnet, we must plainly distinguish them, for there are four distinct powers or effects of the magnet which should not be confounded, although the wonder and astonishment of mankind has classed them together. 1. The attraction of the magnet to the magnet, or of iron to the magnet, or of magnetized iron to iron. 2. Its polarity toward the north and south, and its variation. 3. Its penetration through gold, glass, stone, and all other substances. 4. The communication of power from the mineral to iron, and from iron to iron, without any communication of the substances. Here, however, we only speak of the filst. There is also a singular motion of attraction between quicksilver and gold, so that the gold attracts quicksilver even when made use of in ointment; and those who work surrounded by the vapors of quicksilver, are wont to hold a piece of gold in their mouths, to collect the exhalations, 
which would otherwise attack their heads and bones, and this piece soon grows white. ${ }^{85}$ Let this suffice for the motio $o_{\text {. }}$ of lesser congregation.

Let the ninth be the magnetic motion, which, although of the nature of that last mentioned, yet, when operating at great distances, and on great masses, deserves a separate inquiry, especially if it neither begin in contact, as most motions of congregation do, nor end by bringing the substances into contact, as all do, but only raise them, and make them swell without any further effect. For if the moon raise the waters, or cause moist substances to swell, or if the starry sphere attract the planets toward their apogees, or the sun confine the planets Mercury and Venus to within a certain distance of his mass ${ }^{86}$ these motions do not appear capable of being classed under either of those of congregation, but to be, as it were, intermediately and imperfectly congregative, and thus to form a distinct species.

Let the tenth motion be that of avoidance, or that which is opposed to the motion of lesser congregation, by which bodies, with a kind of antipathy, avoid and disperse, and separate themselves from, or refuse to unite themselves with others of a hostile nature. For although this may sometimes appear to be an accidental motion, necessarily attendant upon that of the lesser congregation, because the homogeneous parts cannot unite, unless the heterogeneous be first removed and excluded, yet it is still to be classed separately, ${ }^{87}$ and considered as a distinct species, because,

\footnotetext{
65 Query?

88 Observe this approximation to Newton's theory.

87 Those differences which are generated by the masses and respective distances of bodies are only differences of quantity, and not specific; consequently those three classes are only one.-Ed.
} 
in many cases, the desire of avoidance appears to be more marked than that of union.

It is very conspicuous in the excrements of animals, nor less, perhaps, in objects odious to particular senses, especially the smell and taste; for a fetid smell is rejected by the nose, so as to produce a sympathetic motion of expulsion at the mouth of the stomach; a bitter and rough taste is rejected by the palate or throat, so as to produce a sympathetic concussion and sbivering of the head. This motion is visible also in other cases. Thus it is observed in some kinds of antiperistasis, as in the middle region of the air, the cold of which appears to be occasioned by the rejection of cold from the regions of the heavenly bodies; and also in the heat and combustion observed in subterranean spots, which appear to be owing to the rejection of heat from the centre of the earth. For heat and cold, when in small quantities, mutually destroy each other, while in larger quantities, like armies equally matched, they remove and eject each other in open conflict. It is said, also that cinnamon and other perfumes retain their odor longer when placed near privies and foul places, because they will not unite and mix with stinks. It is well known that quicksilver, which would otherwise reunite in to a complete mass, is prevented from so doing by man's spittle, pork lard, turpentine and the like, from the little affinity of its parts with those substances, so that when surrounded by them it draws itself back, and its avoidance of these intervening obstacles is greater than its desire of reuniting itself to its homogeneous parts; which is what they term the mortification of quicksilver. Again, the difference in weight of oil and water is not the only reason for their refusing to mix, but it is also owing to the little affinity of the two; for spirits 
of wine, which are lighter than oil, mix very well with water. A very remarkable instance of the motion in question is seen in nitre, and crude bodies of a like nature, which abhor flame, as may be observed in gunpowder, quicksilver and gold. The avoidance of one pole of the magnet by iron is not (as Gilbert has well observed), strictly speaking, an avoidance, but a conformity, or attraction to a more convenient situation.

Let the eleventh motion be that of assimilation, or selfmultiplication, or simple generation, by which latter term we do not mean the simple generation of integral bodies, such as plants or animals, but of homogeneous bodies. $\mathrm{B}_{\mathrm{y}}$ this motion homogeneous bodies convert those which are allied to them, or at least well disposed and prepared, into their own substance and nature. Thus flame multiplies itself over vapors and oily substances and generates fresh flame; the air over water and watery substances multiplies itself and generates fresh air; the vegetable and animal spirit, over the thin particles of a watery or oleaginous spirit contained in its food, multiplies itself and generates fresh spirit; the solid parts of plants and animals, as the leaf, flower, the flesh, bone and the like, each of them assimilate some part of the juices contained in their food, and generate a successive and daily substance. For let none rave with Paracelsus, who (blinded by his distillations) would bave it, that nutrition takes place by mere separation, and that the eye, nose, brain and liver lie concealed in bread and meat, the root, leaf and flower, in the juice of the earth; asserting that just as the artist brings out a leaf, flower, eye, nose, hand, foot and the like, from a rude mass of stone or wood by the separation and rejection of what is superfluous; so the great artist within us 
brings out our several limbs and parts by separation and rejection. But to leave such trifling, it is most certain that all the parts of vegetables and animals, as well the homogeneous as organic, first of all attract those juices contained in their food, which are nearly common, or at least not very different, and then assimilate and convert them into their own nature. Nor does this assimilation, or simple generation, take place in animated bodies only, but the inanimate also participate in the same property (as we have observed of flame and air), and that languid spirit, which is contained in every tangible animated substance, is perpetually working upon the coarser parts, and converting them into spirit, which afterward is exhaled, whence ensues a diminution of weight, and a desiccation of which we have spoken elsewhere. ${ }^{88}$

Nor should we, in speaking of assimilation, neglect to mention the accretion which is usually distinguished from aliment, and which is observed when mud grows into a mass between stones, and is converted into a stony substance, and the scaly substance round the teeth is converted into one no less hard than the teeth themselves; for we are of opinion that there exists in all bodies a desire of assim. ilation, as well as of uniting with homogeneous masses. Each of these powers, however, is confined, although in different manners, and should be diligently investigated, because they are connected with the revival of old age. Lastly, it is worthy of observation, that in the nine preceding motions, bodies appear to aim at the mere preservation of their nature, while in this they attempt its propagation.

88 See the citing instances, Aphorism xl. 
Let the twelfth motion be that of excitement, which appears to be a species of the last, and is sometimes mentioned by us under that name. It is, like that, a diffusive, communicative, transitive and multiplying motion; and they agree remarkably in their effect, although they differ in their mode of action, and in their subject matter. The former proceeds imperiously and with authority; it orders and compels the assimilated to be converted and changed into the assimilating body. The latter proceeds by art, insinuation and stealth, inviting and disposing the excited toward the nature of the exciting body. The former both multiplies and transforms bodies and substances; thus a greater quantity of flame, air, spirit and flesh is formed; but in the latter, the powers only are multiplied and changed, and heat, the magnetic power, and putrefaction, in the above instances, are increased. Heat does not diffuse itself when heating other bodies by any communication of the original heat, but only by exciting the parts of the heated body to that motion which is the form of heat, and of which we spoke in the first vintage of the nature of heat. Heat, therefore, is excited much less rapidly and readily in stone or metal than in air, on account of the inaptitude and sluggishness of those bodies in acquiring that motion, so that it is probable, that there may be some substances, toward the centre of the earth, quite incapable of being heated, on account of their density, which may deprive them of the spirit by which the motion of excitement is usually commenced. Thus also the magnet creates in the iron a new disposition of its parts, and a conformable motion, without losing any of its virtue. So the leaven of bread, yeast, rennet and some poisons, excite and invite successive and continued motion in dough, beer, cheese or 
the human body; not so much from the power of the exciting, as the predisposition and yielding of the excited body.

Let the thirteenth motion be that of impression, which is also a species of motion of assimilation, and the most subtile of diffusive motions. We have thought it right, however, to consider it as a distinct species, on account of its remarkable difference from the last two; for the simple motion of assimilation transforms the bodies themselves, so that if you remove the first agent, you diminish not the effect of those which succeed; thus, neither the first lighting of flame, nor the first conversion into air, are of any importance to the flame or air next generated. So, also, the motion of excitement still continues for a considerable time after the removal of the first agent, as in a heated body on the removal of the original heat, in the excited iron on the removal of the magnet, and in the dough on the removal of the leaven. But the motion of impression, although diffusive and transitive, appears, nevertheless, to depend on the first agent, so that upon the removal of the latter the former immediately fails and perishes; for which reason also it takes effect in a moment, or at least a very short space of time. We are wont to call the two former motions the motions of the generation of Jupiter, because when born they continue to exist; and the latter, the motion of the generation of Saturn, because it is immediately devoured and absorbed. It may be seen in three instances: 1 , in the rays of light; 2 , in the percussions of sounds; 3 , in magnetic attractions as regards communication. For, on the removal of light, colors and all its other images disappear, as on the cessation of the first percussion and the vibration of the body, sound soon fails, and although 
sounds are agitated by the wind, like waves, yet it is to be observed, that the same sound does not last during the whole time of the reverberation. Thus, when a bell is struck, the sound appears to be continued for a considerable time, and one might easily be led into the mistake of supposing it to float and remain in the air during the whole time, which is most erroneous. ${ }^{89}$. For the reverberation is not one identical sound, but the repetition of sounds, which is made manifest by stopping and confining the sonorous body; thus, if a bell be stopped and held tightly, so as to be immovable, the sound fails, and there is no further reverberation, and if a musical string be touched after the first vibration, either with the finger (as in the harp), or a quill (as in the harpsichord), the sound immediately ceases. If the magnet be removed the iron falls. The moon, how. ever, cannot be removed from the sea, nor the earth'from a heavy falling body, and we can, therefore, make no experiment upon them; but the case is the same.

Let the fourteenth motion be that configuration or position, by which bodies appear to desire a peculiar situation, collocation, and configuration with others, rather than union or separation. This is a very abstruse notion, and has not been well investigated; and, in some instances, appears to occur almost without any cause, although we

89 Aristotle's doctrine, that sound takes place when bodies strike the air, which the modern science of acoustics has completely established, was rejected by Bacon in a treatise upon the same subject: "The collision or thrusting of air," he says, "which they will have to be the cause of sound, neither denotes the form nor the latent process of sound, but is a term of iguorance and of superficial contemplation." To get out of the difficulty, he betook himseif to his theory of spirits, a species of phenomena which he constantly introduces to give himself the air of explaining things he could not understand, or would not admit upon the hypothesis of his opponents. $-E d$. 
be mistaken in supposing this to be really the case. For if it be asked, why the heavens revolve from east to west, rather than from west to east, or why they turn on poles situate near the Bears, rather than round Orion or any other part of the heaven, such a question appears to be unreasonable, since these phenomena should be received as determinate and the objects of our experience. There are, indeed, some ultimate and self-existing phenomena in nature, but those which we have just mentioned are not to be referred to that class: for we attribute them to a certain harmony and consent of the universe, which has not yet been properly observed. But if the motion of the earth from west to east be allowed, the same question may be put, for it must also revolve round certain poles, and why should they be placed where they are, rather than elsewhere? The polarity and variation of the needle come under our present head. There is also observed in both natural and artificial bodies, especially solids rather than fluids, a particular collocation and position of parts, resembling hairs or fibres, which should be diligently investigated, since, without a discovery of them, bodies cannot be conveniently controlled or wrought upon. The eddies observable in liquids by which, when compressed, they successively raise different parts of their mass before they can escape, so as to equalize the pressure, is more correctly assigned to the motion of liberty.

Lei the fifteenth motion be that of transmission or of passage, by which the powers of bodies are more or less impeded or advanced by the medium, according to the nature of the bodies and their effective powers, and also according to that of the medium. For one medium is adapted to light, another to sound, another to heat and 
cold, another to magnetic action, and so on with regard to the other actions.

Let the sixteenth be that which we term the royal or political motion, by which the predominant and governing parts of any body check, subdue, reduce, and regulate the others, and force them to unite, separate, stand still, move, or assume a certain position, not from any inclination of their own, but according to a certain order, and as best suits the convenience of the governing part, so that there is a sort of dominion and civil government exercised by the ruling part over its subjects. The motion is very conspicuous in the spirits of animals, where, as long as it is in force, it tempers all the motions of the other parts. It is found in a less degree in other bodies, as we have observed in blood and urine, which are not decomposed until the spirit, which mixed and retained their parts, has been emitted or extinguished. Nor is this motion peculiar to spirits only, although in most bodies the spirit predominates, owing to its rapid motion and penetration; for the grosser parts predominate in denser bodies, which are not filled with a quick and active spirit (such as exists in quicksilver or vitriol), so that unless this check or yoke be thrown off by some contrivance, there is no hope of any transformation of such bodies. And let not any one suppose that we have forgotten our subject, because we speak of predominance in this classification of motions, which is made entirely with the view of assisting the investigation of wrestling instances, or instances of predominance. For we do not now treat of the general predominance of motions or powers, but of that of parts in whole bodies, which constitutes the particular species here considered.

Let the seventeenth motion be the spontaneous motion 
of revolution, by which bodies having a tendency to move, and placed in a favorable situation, enjoy their peculiar nature, pursuing themselves and nothing else, and seeking, as it were, to embrace themselves. For bodies seem either to move without any limit, or to tend toward a limit, arrived at which they either revolve according to their peculiar nature, or rest. Those which are favorably situated, and have a tendency to motion, move in a circle with an eternal and unlimited motion; those which are favor. ably situated and abbor motion, rest. Those which are not favorably situated move in a straight line (as their shortest path), in order to unite with others of a congenial nature. This motion of revolution admits of nine differences: 1, with regard to the centre about which the bodies move; 2 , the poles round which they move; 3 , the circum. ference or orbit relatively to its distance from the centre; 4, the velocity, or greater or less speed with which they revolve; 5, the direction of the motion as from east to west, or the reverse; 6 , the deviation from a perfect circle, by spiral lines at a greater or less distance from the centre; 7 , the deviation from the circle, by spiral lines at a greater or less distance from the poles; 8 , the greater or less distance of these spirals from each other; 9, and lastly, the variation of the poles if they be movable; which, however, only affects revolution when circular. The motion in question is, according to common and long-received opinion, considered to be that of the heavenly bodies. There ex ists, however, with regard to this, a considerable dispute between some of the ancients as well as moderns, who have attributed a motion of revolution to the earth. A much more reasonable controversy, perhaps, exists (if it be not a matter beyond dispute), whether the motion in question (on 
the hypothesis of the earth's being fixed) is confined to the heavens, or rather descends and is communicated to the air and water. The rotation of missiles, as in darts, musketballs, and the like, we refer entirely to the motion of liberty.

Let the eighteenth motion be that of trepidation, ${ }^{00}$ to which (in the sense assigned to it by astronomers) we do not give much credit; but in our serious and general search after the tendencies of natural bodies, this motion occurs, and appears worthy of forming a distinct species. It is the motion of an (as it were) eternal captivity; when bodies, for instance, being placed not altogether according to their nature, and yet not exactly ill, constantly tremble, and are restless, not contented with their position, and yet not daring to advance. Such is the motion of the heart and pulse of animals, and it must necessarily occur in all bodies which are situated in a mean state, between conveniences and inconveniences; so that being removed from their proper position, they strive to escape, are repulsed, and again continue to make the attempt.

Let the nineteenth and last motion be one which can scarcely be termed a motion, and yet is one; and which we may call the motion of repose, or of abhorrence of motion. It is by this motion that the earth stands by its own weight, while its extremes move toward the middle, not to an imaginary centre, but in order to unite. It is owing to the same tendency, that all bodies of considerable density abhor motion, and their only tendency is not to move, which nature they preserve, although excited and urged

90 The motion of trepidation, as Bacon calls it, was attributed by the ancient astronomers to the eight spheres, relative to the precession of the equinoxes. Galileo was the first to observe this kind of lunar motion.-Ed. 
in a variety of ways to motion. But if they be compelled to move, yet do they always appear anxious to recover their former state, and to cease from motion, in which respect they certainly appear active, and attempt it with sufficient swiftness and rapidity, as if fatigued, and impatient of delay. We can only have a partial representation of this tendency, because with us every tangible substance is not only not condensed to the utmost, but even some spirit is added, owing to the action and concocting influence of the heavenly bodies.

We have now, therefore, exhibited the species, or simple elements of the motions, tendencies, and active powers, which are most universal in nature; and no small portion of natural science has been thus sketched out. We do not, however, deny that other instances can perhaps be added, and our divisions changed according to some more natural order of things, and also reduced to a less number; in which respect we do not allude to any abstract classification, as if one were to say, that bodies desire the preservation, exaltation, propagation, or fruition of their nature; or, that motion tends to the preservation and benefit either of the universe (as in the case of those of resistance and connection), or of extensive wholes, as in the case of those of the greater congregation, revolution, and abhorrence of motion, or of particular forms, as in the case of the others. For although such remarks be just, yet, unless they terminate in matter and construction, according to true definitions, they are speculative, and of little use. In the meantime, our classification will suffice, and be of much use in the consideration of the predominance of powers, and examin. ing the wrestling instances which constitute our present subject. 
For of the motions here laid down, some are quite invincible, some more powerful than others, which they confine, check, and modify; others extend to a greater distance, others are more immediate and swift, others strengthen, increase, and accelerate the rest.

The motion of resistance is most adamantine and invin. cible. We are yet in doubt whether such be the nature of that of connection; for we cannot with certainty determine whether there be a vacuum, either extensive or intermixed with matter. Of one thing, however, we are satisfied, that the reason assigned by Leucippus and Democritus for the introduction of a vacuum (namely, that the same bodies could not otherwise comprehend, and fill greater and less spaces) is false. For there is clearly a folding of matter, by which it wraps and unwraps itself in space within certain limits, without the intervention of a vacuum. Nor is there two thousand times more of vacuum in air than in gold, as there should be on this hypothesis; a fact demonstrated by the very powerful energies of fluids (which would otherwise float like fine dust in vacuo), and many other proofs. The other motions direct, anit are directeil by each other, according to their strength, quantity, excitement, emission, or the assistance or impediments they meet with.

For instance; some armed magnets hold and support iron of sixty times their own weight; so far does the motion of lesser congregation predominate over that of the greater; but if the weight be incrensed, it yields. A lever of a certain strength will raise a given weight, and so far the motion of liberty predominates over that of the greater congregation, but if the weight be greater, the former motion yields. A piece of leather stretched to a certain point does not break, and so far the motion of continuity SCIENCE--. Vol. $22-12$ 
predominates over that of tension, but if the tension be greater, the leather breaks, and the motion of continuity yields. A certain quantity of water flows through a chink, and so far the motion of greater congregation predominates over that of continuity, but if the chink be smaller it yields. If a musket be charged with ball and powdered sulphur alone, and fire be applied, the ball is not discharged, in which case the motion of greater congregation overcomes that of matter; but when gunpowder is used, the motion of matter in the sulphur predominates, being assisted by that motion, and the motion of avoidance in the nitre; and so of the rest. For wrestling instances (which show the predominance of powers, and in what manner and proportion they predominate and yield) must be searched for with active and industrious diligence.

The methods and nature of this yielding must also be diligently examined, as for instance, whether the motions completely cease, or exert themselves, but are constrained. For in the bodies with which we are acquainted, there is no real but an apparent rest, either in the whole or in parts. This apparent rest is occasioned either by equilibrium, or the absolute predominance of motions. By equilibrium, as in the scales of the balance, which rest if the weights be equal. By predominance, as in perforated jars, in which the water rests, and is prevented from falling by the pre dominance of the motion of connection. It is, however, to be observed (as we have said before), how far the yielding motions exert themselves. For if a man be held stretched out on the ground against his will, with arms and legs bound down, or otherwise confined, and yet strive with all his power to get up, the struggle is not the less, although ineffectual. The real state of the case (namely, whether 
the yielding motion be, as it were, annihilated by the predominance, or there be rather a continued, although an invisible effort) will, perhaps, appear in the concurrence of motions, although it escape our notice in their conflict. For instance: let an experiment be made with muskets; whether a musket-ball, at its utmost range in a straight line, or (as it is commonly called) point-blank, strike with less force when projected upward, where the motion of the blow is simple, than when projected downward, where the motion of gravity concurs with the blow.

The rules of such instances of predominance as occur should be collected: such as the following; the more general the desired advantage is, the stronger will be the motion; the motion of connection, for instance, which relates to the intercourse of the parts of the universe, is more powerful than that of gravity, which relates to the intercourse of dense bodies only. Again, the desire of a private good does not in gencral prevail against that of a public one, except where the quantities are small. Would that such were the case in civil matters!

XLIX. In the twenty-fifth rank of prerogative instances we will place suggesting instances; such as suggest, or point out, that which is advantageous to mankind; for bare power and knowledge in themselves, exalt rather than enrich human nature. We must, therefore, select from the general store such things as are most useful to mankind. TVe shall have a better opportunity of discussing these when we treat of the application to practice; besides, in the work of interpretation, we leave room, on every subject, for the human or optative chart; for it is a part of science to make judicious inquiries and wishes.

L. In the twenty-sixth rank of prerogative instances we 
will place the generally useful instances. They are such as relate to various points, and frequently occur, sparing by that means considerable labor and new trials. The proper place for treating of instruments and contrivances, will be that in which we speak of the application to practice, and the methods of experiment. All that has hitherto been ascertained, and made use of, will be described in the particular history of each art. At present, we will subjoin a few general examples of the instances in question.

Man acts, then, upon natural bodies (besides merely bringing them together or removing them) by seven principal methods: 1 , by the exclusion of all that impedes and disturbs; 2 , by compression, extension, agitation, and the like; 3 , by heat and cold; 4 , by detention in a suitable place; 5 , by checking or directing motion; 6 , by peculiar harmonies; 7 , by a seasonable and proper alternation, series, and succession of all these, or, at least, of some of them.

1. With regard to the first-common air, which is always at hand, and forces its admission, as also the rays of the heavenly bodies, create much disturbance. Whatever, therefore, tends to exclude them may well be considered as generally useful. The substance and thickness of vessels in which bodies are placed when prepared for operations may be referred to this head. So also may the accurate methods of closing ressels by consolidation, or the lutum supientice, as the chemists call it. The exclusion of air by means of liquids at the extremity is also very useful, as when they pour oil on wine, or the juices of herbs, which by spreading itself upon the top like a cover, preserves them uninjured from the air. Powders, also, are serviceable, for although they contain air mixed up in them, yet they ward off the power of the mass of circumambient air, 
which is seen in the preservation of grapes and other fruits in sand or flour. Wax, honey, pitch, and other resinous bodies, are well used in order to make the exclusion more perfect, and to remove the air and celestial influence. We have sometimes made an experiment by placing a vessel or other bodies in quicksilver, the most dense of all substances capable of being poured round others. Grottoes and subterraneous caves are of great use in keeping off the effects of the sun, and the predatory action of air, and in the north of Germany are used for granaries. The depositing of bodies at the bottom of water may be also mentioned here; and I remember having heard of some bottles of wine being let down into a deep well in order to cool them, but left there by chance, carelessness, and forgetfulness for several years, and then taken out; by which means the wine not only escaped becoming flat or dead, but was much more excellent in flavor, arising (as it appears) from a more complete mixture of its parts. But if the case require that bodies should be sunk to the bottom of water, as in rivers or the sea, and yet should not touch the water, nor be inclosed in sealed vessels, but surrounded only by air, it would be right to use that vessel which has been sometimes employed under water above ships that have sunk, in order to enable the divers to remain below and breathe occasionally by turns. It was of the following nature: A hollow tub of metal was formed, and sunk so as to have its bottom parallel with the surface of the water; it thus carried down with it to the bottom of the sea all the air contained in the tub. It stood upon three feet (like a tripod), being of rather less height than a man, so that, when the diver was in want of breath, he could put his head into the hollow of the tub, breathe, and then continue his work. 
We hear that some sort of boat or vessel has now been invented, capable of carrying men some distance under water. Any bodies, however, can easily be suspended under some such vessel as we have mentioned, which has occasioned our remarks upon the experiment.

Another advantage of the careful and hermetical closing of bodies is this-not only the admission of external air is prevented (of which we have treated), but the spirit of bodies also is prevented from making its escape, which is an internal operation. For any one operating on natural bodies must be certain as to their quantity, and that nothing has evaporated or escaped, since profound alterations take place in bodies, when art prevents the loss or escape of any portion, while nature prevents their annihilation. With regard to this circumstance, a false idea has prevailed (which if true would make us despair of preserving quantity without diminution), namely, that the spirit of bodies, and air when rarefied by a great degree of heat, cannot be so kept in by being inclosed in any vessel as not to escape by the small pores. Men are led into this idea by the common experiments of a cup inverted over water, with a candle or piece of lighted paper in it, by which the water is drawn up, and of those cups which, when heated, draw up the flesh. For they think that in each experiment the rarefied air escapes, and that its quantity is therefore diminished, by which means the water or flesh rises by the motion of connection. This is, however, most incorrect. For the air is not diminished in quantity, but contracted in dimensions, ${ }^{91}$ nor does this motion of the rising of the water

91 Part of the air is expanded and escapes, and part is consumed by th flame. When condensed, therefore, by the cold application, it cannot offer suf- 
begin till the flame is extinguished, or the air cooled, so that physicians place cold sponges, moistened with water, on the cups, in order to increase their attraction. There is, therefore, no reason why men should fear much from the ready escape of air: for although it be true that the most solid bodies have their pores, yet neither air, nor spirit, readily suffers itself to be rarefied to such an extreme degree; just as water will not escape by a small chink.

2. With regard to the second of the seven abovementioned methods, we must especially observe, that compression and similar violence have a most powerful effect either in producing locomotion, and other motions of the same nature, as may be observed in engines and projectiles, or in destroying the organic body, and those qualities, which consist entirely in motion (for all life, and every description of flame and ignition are destroyed by compression, which also injures and deranges every machine); or in destroying those qualities which consist in position and a coarse difference of parts, as in colors; for the color of a flower when whole, differs from that it presents when bruised, and the same may be observed of whole and powdered amber; or in tastes, for the taste of a pear before it is ripe, and of the same pear when bruised and softened, is different, since it becomes perceptibly more sweet. But such violence is of little avail in the more noble transformations and changes of homogeneous bodies, for they do not, by such means, acquire any constantly and permanently new state, but one that is transitory, and always struggling to return to its former habit and freedom. It would not, however, be use-

ficient resistance to the external atmosphere to prevent the liquid or flesh from being forced into the glass. 
less to make some more diligent experiments with regard to this; whether, for instance, the condensation of a perfectly homogeneous body (such as air, water, oil, and the like) or their rarefaction, when effected by violence, can become permanent, fixed, and, as it were, so changed, as to become a nature. This might at first be tried by simple perseverance, and then by means of helps and harmonies. It might readily have been attempted (if we had but thought of it), when we condensed water (as was mentioned above), by hammering and compression, until it burst out. For we ought to have left the flattened globe untouched for some days, and then to have drawn off the water, in order to try whether it would have immediately occupied the same dimensions as it did before the condensation. If it had not done so, either immediately, or soon afterward, the condensation would have appeared to have been rendered constant; if not, it would have appeared that a restitution took place, and that the condensation had been transitory. Something of the same kind might have been tried with the glass eggs; the egg should have been sealed up suddenly and firmly, after a complete exhaustion of the air, and should have been allowed to remain so for some days, and it might then have been tried whether, on opening the aperture, the air would be drawn in with a hissing noise, or whether as much water would be drawn into it when immersed, as would have been drawn into it at first, if it had not continued sealed. For it is probable (or, at least, worth making the experiment) that this might have happened, or might happen, because perseverance has a similar effect upon bodies which are a little less homogeneous. A stick bent together for some time does not rebound, which is not owing to any loss of quantity in the wood during the time, for the same would 
occur (after a larger time) in a plate of steel, which does not evaporate. If the experiment of simple perseverance should fail, the matter should not be given up, but other means should be employed. For it would be no small advantage, if bodies could be endueu with fixed and constant natures by violence. Air could then be converted into water by condensation, with other similar effects; for man is more the master of violent motions than of any other means.

3. The third of our seven methods is referred to that great practical engine of nature, as well as of art, cold and heat. Here, man's power limps, as it were, with one leg. For we possess the heat of fire, which is infinitely more powerful and intense than that of the sun (as it reaches us), and that of animals. But we want cold, ${ }^{92}$ except such as we can obtain in winter, in caverns, or by surrounding objects with snow and ice, which, perhaps, may be compared in degree with the noontide heat of the sun in tropical countries, increased by the reflection of mountains and walls. For this degree of heat and cold can be borne for a short period only by animals, yet it is nothing compared with the heat of a burning furnace, or the corresponding degree of cold. ${ }^{93}$ Everything with us has a tendency to become rarefied, dry and wasted, and noth-

9: licat can now be abstracted by a very simple process, till the degree of cold be of almost any required intensity. $-E d$.

93 It is impossible to compare a degree of heat with a degree of cold, without the assumption of some arbitrary test, to which the degrees are to be referred. In the next sentence Bacon appears to have taken the power of animal life to support heat or cold as the test, and then the comparison can only be between the degree of heat or of cold that will produce death.

The zero must be arbitrary which divides equally a certain degree of heat from a certain degree of cold. $-E d$. 
ing to become condensed or soft, except by mixtures, and, as it were, spurious methods. Instances of cold, therefore, should be searched for most diligently, such as may be found by exposing bodies upon buildings in a hard frost, in subterraneous caverns, by surrounding bodies with snow and ice in deep places excavated for that purpose, by letting bodies down into wells, by burying bodies in quicksilver and metals, by immersing them in streams which petrify wood, by burying them in the earth (which the Chinese are reported to do with their china, masses of which, made for that purpose, are said to remain in the ground for forty or fifty years, and to be transmitted to their heirs as a sort of artificial mine) and the like. The condensations which take place in nature, by means of cold, should also be investigated, that by learning their causes, they may be introluced into the arts; such as are observed in the exudation of marble and stones, in the dew upon the panes of glass in a room toward morning after a frosty night, in the formation and the gathering of vapors under the earth into water, whence spring fountains and the like.

Besides the substances which are cold to the touch, there are others which have also the effect of cold, and condense; they appear, however, to act only upon the bodies of animals, and scarcely any further. Of these we have many instances, in medicines and plasters. Some condense the flesh and tangible parts, such as astringent and inspissating medicines, others the spirits, such as soporifics. There are two modes of condensing the spirits, by soporifics or provocatives to sleep; the one by calming the motion, the other by expelling the spirit. The violet, dried roses, lettuces, and other benign or mild remedies, by their friendly and gently cooling vapors, invite the spirits 
to unite, and restrain their violent and perturbed motion. Rose-water, for instance, applied to the nostrils in fainting fits, causes the resolved and relaxed spirits to recover themselves, and, as it were, cherishes them. But opiates, and the like, banish the spirits by their malignant and hostile quality. If they be applied, therefore, externally, the spirits immediately quit the part and no longer readily How into it; but if they be taken internally, their vapor, mounting to the head, expels, in all directions, the spirits contained in the ventricles of the brain, and since these spirits retreat, but cannot escape, they consequently meet and are condensed, and are sometimes completely extin. guished and suffocated; although the same opiates, when taken in moderation, by a secondary accident (the condensation which succeeds their union), strengthen the spirits, render them more robust, and check their useless and inflammatory motion, by which means they contribute not a little to the cure of diseases, and the prolongation of life.

The preparations of bodies, also, for the reception of cold should not be omitted, such as that water a little warmed is more easily frozen than that which is quite cold, and the like.

Moreover, since nature supplies cold so sparingly, we must act like the apothecaries, who, when they cannot obtain any simple ingredient, take a succedaneum, or quid pro quo, as they term it, such as aloes for xylobalsamum, cassia for cinnamon. In the same manner we should look diligently about us, to ascertain whether there may be any substitutes for cold, that is to say, in what other manner condensation can be effected, which is the peculiar operation of cold. Such condensations appear hitherto to be of four kinds only. 1. By simple compression, which is of lit- 
tle avail toward permanent condensation, on account of the elasticity of substances, but may still, however, be of some assistance. 2. By the contraction of the coarser, after the escape or departure of the finer parts of a given body; as is exemplified in induration by fire, and the repeated heating and extinguishing of metals, and the like. 3. By the cohesion of the most solid homogeneous parts of a given body, which were previously separated, and mixed with others less solid, as in the return of sublimated mercury to its simple state, in which it occupies much less space than it did in powder, and the same may be observed of the cleansing of all metals from their dross. 4. By harmony, or the application of substances which condense by some latent power. These harmonies are as yet but rarely observed, at which we cannot be surprised, since there is little to hope for from their investigation, unless the discovery of forms and confirmation be attained. With regard to animal bodies, it is not to be questioned that there are many internal and external medicines which condense by harmony, as we have before observed, but this action is rare in inanimate bodies. Written accounts, as well as report, have certainly spoken of a tree in one of the Tercera or Canary Islands (for I do not exactly recoliect which) that drips perpetually, so as to supply the inhabitants, in some degree, with water; and Paracelsus says that the herb called ros solis is filled with dew at noon, while the sun gives out its greatest heat, and all other herbs around it are dry. We treat both these accounts as fables; they would, however, if true, be of the most important service, and most worthy of examination. As to the honey-dew, resembling manna, which is found in May on the leaves of the oak, we are of opinion that it is not condensed by any harmony or pecul1- 
arity of the oak leaf, but that while it falls equally upon other leaves it is retained and continues on those of the oak, because their texture is closer, and not so porous as that of most of the other leaves. ${ }^{94}$

With regard to heat, man possesses abundant means and power; but his observation and inquiry are defective in some respects, and those of the greatest importance, notwithstanding the boasting of quacks. For the effects of intense heat are examined and observed, while those of a more gentle degree of heat, being of the most frequent occurrence in the paths of nature, are, on that very account, least known. We see, therefore, the furnaces, which are most esteemed, employed in increasing the spirits of bodies to a great extent, as in the strong acids, and some chemical oils; while the tangible parts are hardened, and, when the volatile part has escaped, become sometimes fixed; the homogeneous parts are separated, and the heterogeneous incorporated and agglomerated in a coarse lump; and (what is chiefly worthy of remark) the junction of compound bodies, and the more delicate conformations are destroyed and confounded. But the operation of a less violent heat should be tried and investigated, by which more delicate mixtures and regular conformations may be produced and elicited, according to the example of nature, and in imitation of the effect of the sun, which we have alluded to in the aphorism on the instances of alliance. For the works of nature are carried on in much smaller portions, and in more delicate and varied positions than those of fire, as we now employ it. But man will then appear to have really augmented his power, when the works of nature can be

94 It may often be observed on the leaves of the lime and other trees. 
imitated in species, perfected in power, and varied in quantity; to which should be added the acceleration in point of time. Rust, for instance, is the result of a long process, but crocus martis is obtained immediately; and the same may be observed of natural verdigris and ceruse. Crystal is formed slowly, while glass is blown immediately: stones increase slowly, while bricks are baked immediately, etc. In the meantime (with regard to our present subject) every different species of heat should, with its peculiar effects, be diligently collected and inquired into; that of the heavenly bodies, whether their rays be direct, reflected, or refracted, or condensed by a burning-glass; that of lightning, flame, and ignited charcoal; that of fire of different materials, either open or confined, straitened or overflowing, qualified by the different forms of the furnaces, excited by the bellows, or quiescent, removed to a greater or less distance, or passing through different media; moist heats, such as the balneum Marice, and the dunghill; the external and internal heat of animals; dry heats, such as the heat of ashes, lime, warm sand; in short, the nature of every kind of heat, and its degrees.

We should, however, particularly attend to the investigation and discovery of the effects and operations of heat, when made to approach and retire by degrees, regularly, periodically, and by proper intervals of space and time. For this systematical inequality is in truth the daughter of heaven and mother of generation, nor can any great result be expected from a vehement, precipitate, or desultory heat. For this is not only most evident in vergetables, but in the wombs of animals also there arises a great inequality of heat, from the motion, sleep, food, and passions of the female. The same inequality prevails in those subterrane- 
ous beds where metals and fossils are perpetually forming, which renders yet more remarkable the ignorance of some of the reformed alchemists, who imagined they could attain their object by the equable heat of lamps, or the like, burning uniformly. Let this suffice concerning the operation and effects of heat; nor is it time for us to investigate them thoroughly before the forms and conformations of bodies have been further examined and brought to light. When we have determined upon our models, we may seek, apply, and arrange our instruments.

4. The fourth mode of action is by continuance, the very steward and almoner, as it were, of nature. We apply the term continuance to the abandonment of a body to itself for an observable time, guarded and protected in the meanwhile from all external force. For the internal motion then commences to betray and exert itself when the external and adventitious is removed. The effects of time, however, are far more delicate than those of fire. Wine, for instance, cannot be clarified by fire as it is by continuance. Nor are the ashes produced by combustion so fine as the particles dissolved or wasted by the lapse of ages. The incorporations and mixtures, which are hurried by fire, are very inferior to those obtained by continuance; and the various conformations assumed by bodies left to themselves, such as mouldiness, ete., are put a stop to by fire or a strong heat. It is not, in the meantime, unimportant to remark that there is a certain degree of violence in the motion of bodies entirely confined; for the confinement impedes the proper motion of the body. Continuance in an open vessel, therefore, is useful for separations, and in one hermetically sealed for mixtures, that in a vessel partly closed, but admitting the air, for putrefaction. But instances of the 
operation and effect of continuance must be collected diligently from every quarter.

5. The direction of motion (which is the fifth method of action) is of no small use. We adopt this term, when speaking of a body which, meeting with another, either arrests, repels, allows, or directs its original motion. This is the case principally in the figure and position of vessels. An upright cone, for instance, promotes the condensation of vapor in alembics, but when reversed, as in inverted vessels, it assists the refining of sugar. Sometimes a curved form, or one alternately contracted and dilated, is required. Strainers may be ranged under this head, where the opposed body opens a way for one portion of another substance and impedes the rest. Nor is this process or any other direction of motion carried on externally only, but sometimes by one body within another. Thus, pebbles are thrown into water to collect the muddy particles, and syrups are refined by the white of an egg, which glues the grosser particles together so as to facilitate their removal. Telesius, indeed, rashly and ignorantly enough attributes the formation of animals to this cause, by means of the channels and folds of the womb. He ought to have observed a similar formation of the young in eggs which have no wrinkles or inequalities. One may obscrve a real result of this direction of motion in casting and modelling.

6. The effects produced by harmony and aversion (which is the sixth method) are frequently buried in obscurity; for these occult and specific properties (as they are termed), the sympathies and antipathies, are for the most part but a corruption of philosophy. Nor can we form any great expectation of the discovery of the harmony which exists between natural objects, before that of their forms and 
simple conformations, for it is nothing more than the symmetry between these forms and conformations.

The greater and more universal species of harmony are not, however, so wholly obscure, and with them, therefore, we must commence. The first and principal distinction between them is this; that some bodies differ considerably in the abundance and rarity of their substance, but correspond in their conformation; others, on the contrary, correspond in the former and differ in the latter. Thus the chemists have well observed, that in their trial of first principles sulphur and mercury, as it were, pervade the universe; their reasoning about salt, however, is absurd, and merely introduced to comprise earthy dry fixed bodies. In the other two, indeed, one of the most universal species of natural harmony manifests itself. Thus there is a correspondence between sulphur, oil, greasy exhalations, flame, and, perhaps, the substance of the stars. On the other hand, there is a like correspondence between mercury, water, aqueous vapor, air, and, perhaps, pure inter-sidereal ether. Yet do these two quaternions, or great natural tribes (each within its own limits), differ immensely in quantity and density of substance, while they generally agree in conformation, as is manifest in many instances. On the other hand, the metals agree in such quantity and density (especially when compared with vegetables, etc.), but differ in many respects in conformation. Animals and vegetables, in like manner, vary in their almost infinite modes of conformation, but range within very limiter degrees of quantity and density of substance.

The next most general correspondence is that between individual bodies and those which supply them by way of menstruum or support. Inquiry, therefore, must be made 
as to the climate, soil, and depth at which each metal is generated, and the same of gems, whether produced in rocks or mines, also as to the soil in which particular trees, shrubs, and herbs, mostly grow and, as it were, delight; and as to the best species of manure, whether dung, chalk, sea sand, or ashes, etc., and their different propriety and advantage according to the variety of soils. So also the grafting and setting of trees and plants (as regards the readiness of grafting one particular species on another) depends very much upon harmony, and it would be amusing to try an experiment I have lately heard of, in grafting forest trees (garden trees alone having hitherto been adopted), by which means the leaves and fruit are enlarged, and the trees produce more shade. The specific food of animals again should be observed, as well as that which cannot be used. Thus the carnivorous cannot be fed on herbs, for which reason the order of feuilletans, the experiment having been made, has nearly vanished; human nature being incapable of supporting their regimen, although the human will has more power over the bodily frame than that of other animals. The different kinds of putrefaction from which animals are generated should be noted.

The harmony of principal bodies with those subordinate to them (such indeed may be deemed those we have alluded to above) are sufficiently manifest, to which may be added those that cxist between different bodies and their objects, and, since these latter are more apparent, they may throw great light when well observed and diligently examined upon those which are more latent.

The more internal harmony and aversion, or friendship and enmity (for superstition and folly have rendered the terms of sympathy and antipathy almost disgusting), have 
been either falsely assigned, or mixed with fable, or most rarely discovered from neglect. For if one.were to allege that there is an enmity between the vine and the cabbage, because they will not come up well when sown together, there is a sufficient reason for it in the succulent and ab. sorbent nature of each plant, so that the one defrauds the other. Again, if one were to say that there is a harmony and friendship between the corn and the corn-flower, or the wild poppy, because the latter seldom grow anywhere but in cultivated soils, he ought rather to say, there is an enmity between them, for the poppy and the corn-flower are produced and created by those juices which the corn has left and rejected, so that the sowing of the corn prepares the ground for their production. And there are a vast number of similar false assertions. As for fables, they must be totally exterminated. There remains, then, but a scanty supply of such species of harmony as has borne the test of experiment, such as that between the magnet and iron, gold and quicksilver, and the like. In chemical experi. ments on metals, however, there are some others worthy of notice, but the greatest abundance (where the whole are so few in numbers) is discovered in certain medicines, which, from their occult and specific qualities (as they are termed), affect particular limbs, humors, diseases, or constitutions. Nor should we omit the harmony between the motion and phenomena of the moon, and their effects on lower bodies, which may be brought together by an accurate and honest selection from the experiments of agriculture, navigation, and medicine, or of other sciences. By as much as these general instances, however, of more latent harmony, are rare, with so much the more diligence are they to be in. quired after, through tradition, and faithful and honest 
reports, but without rashness and credulity, with an anx. ious and, as it were, hesitating degree of reliance. There remains one species of harmony which, though simple in its mode of action, is yet most valuable in its use, and must by no means be omitted, but rather diligently investigated. It is the ready or difficult coition or union of bodies in com. position, or simple juxtaposition. For some bodies readily and willingly mix, and are incorporated, others tardily and perversely; thus powders mix best with water, chalk and ashes with oils, and the like. Nor are these instances of readiness and aversion to mixture to be alone collected, but others, also, of the collocation, distribution, and digestion of the parts when mingled, and the predominance after the mixture is complete.

7. Lastly, there remains the seventh, and last of the seven, modes of action; namely, that by the alternation and interchange of the other six; but of this, it will not be the right time to offer any examples, until some deeper investigation shall have taken place of each of the others. The series, or chain of this alternation, in its mode of application to separate effects, is no less powerful in its operation than difficult to be traced. But men are possessed with the most extreme impatience, both of such inquiries, and their practical application, although it be the clew of the laby. rinth in all greater works. Thus far of the generally useful instances.

LI. The twenty-seventh and last place we will assign to the magical instances, a term which we apply to those where the matter or efficient agent is scanty or small, in comparison with the grandeur of the work or effect produced; so that even when common they appear miraculous, some at first sight, others even upon more attentive obser- 
vation. Nature, however, of herself, supplies these but sparingly. What she will do when her whole store is thrown open, and after the discovery of forms, processes, and conformation, will appear hereafter. As far as we can yet conjecture, these magic effects are produced in three ways, either by self-multiplication, as in fire, and the poisons termed specific, and the motions transferred and multiplied from wheel to wheel; or by the excitement, or, as it were, invitation of another substance, as in the magnet, which excites innumerable needles without losing or diminishing its power; and again in leaven, and the like; or by the excess of rapidity of one species of motion over another, as has been observed in the case of gunpowder, cannon, and mines. The two former require an investigation of harmonies, the latter of a measure of motion. Whether there be any mode of changing bodies per minima (as it is termed), and transferring the delicate conformations of matter, which is of importance in all transformations of bodies, so as to enable art to effect, in a short time, that which nature works out by divers expedients, is a point of which we have as yet no indication. But, as we aspire to the extremest and highest results in that which is solid and true, so do we ever detest, and, as far as in us lies, expel all that is empty and vain.

LII. Let this suffice as to the respective dignity of prerogatives of instances. But it must be noted, that in this our organ, we treat of logic, and not of philosophy. Seeing, however, that our logic instructs and informs the understanding, in order that it may not, with the small hooks, as it were, of the mind, catch at, and grasp mere abstractions, but rather actually penetrate nature, and discover the properties and effects of bodies, and the determinate laws of 
their substance (so that this science of ours springs from the nature of things, as well as from that of the mind); it is not to be wondered at, if it have been continually interspersed and illustrated with natural observations and ex. periments, as instances of our method. The prerogative instances are, as appears from what has preceded, twenty. seven in number, and are termed, solitary instances, migrating instances, conspicuous instances, clandestine instances, constitutive instances, similar instances, singular instances, deviating instances, borlering instances, instances of power, accompanying and hostile instances, subjunctive instances, instances of alliance, instances of the cross, instances of divorce, instances of the gate, citing instances, instances of the road, supplementary instances, lancing instances, in. stances of the rod, instances of the course, doses of nature, wrestling instances, suggesting instances, generally useful instances, and magical instances. The advantage, by which these instances excel the more ordinary, regards specifically either theory or practice, or both. With regard to theory, they assist either the senses or the understanding; the senses, as in the five instances of the lamp; the understanding, either by expediting the exclusive mode of arriving at the form, as in solitary instances, or by confining, and more immediately indicating the affirmative, as in the migrating, conspicuous, accompanying, and subjunctive instances; or by elevating the understanding, and leading it to general and common natures, and that either immediately, as in the clandestine and singular instances, and those of alliance; or very nearly so, as in the constitutive; or still less so, as in the similar instances; or by correcting the understanding of its habits, as in the deviating instances; or by leading to she grand form or fabric of the universo, as in the borderic 
instances; or by guarding it from false forms and causes, as in those of the cross and of divorce. With regard to practice, they either point it out, or measure, or elevate it. They point it out, either by showing where we must commence in order not to repeat the labors of others, as in the instances of power; or by inducing us to aspire to that which may be possible, as in the suggesting instances; the four mathematical instances measure it. The generally useful and the magical elevate it.

Again, out of these twenty-seven instances, some must be collected immediately, without waiting for a particular investigation of properties. Such are the similar, singular, deviating, and bordering instances, those of power, and of the gate, and suggesting, generally useful, and magical instances; for these either assist and cure the understanding and senses, or furnish our general practice. The remainder are to be collected when we finish our synoptical tables for the work of the interpreter, upon any particular nature; for these instances, honored and gifted with such prerogatives, are like the soul amid the vulgar crowd of instances, and (as we from the first observed) a few of them are worth a multitule of the others. When, therefore, we are forming our tables they must be searched out with the greatest zeal, and placed in the table. And, since mention must be made of them in what follows, a treatise upon their nature has necessarily been prefixed. We must next, however, proceed to the supports and corrections of induction, and thence to concretes, the latent process, and latent conformations, and the other matters, which we have enumerated in their order in the twenty-first aphorism, in order that, like good and faithful guardians, we may yield up their fortune to mankind upon the emancipation and majority 
of their understanding; from which must necessarily follow an improvement of their estate, and an increase of their power over nature. For man, by the fall, lost at once his state of innocence, and his empire over creation, both of which can be partially recovered even in this life, the first by religion and faith, the second by the arts and sciences. For creation did not become entirely and utterly rebellious by the curse, but in consequence of the Divine decree, "in the sweat of thy brow shalt thou eat bread," she is compelled by our labors (not assuredly by our disputes or magical ceremonies), at length, to afford mankind in some degree his bread, that is to say, to supply man's daily wants. 



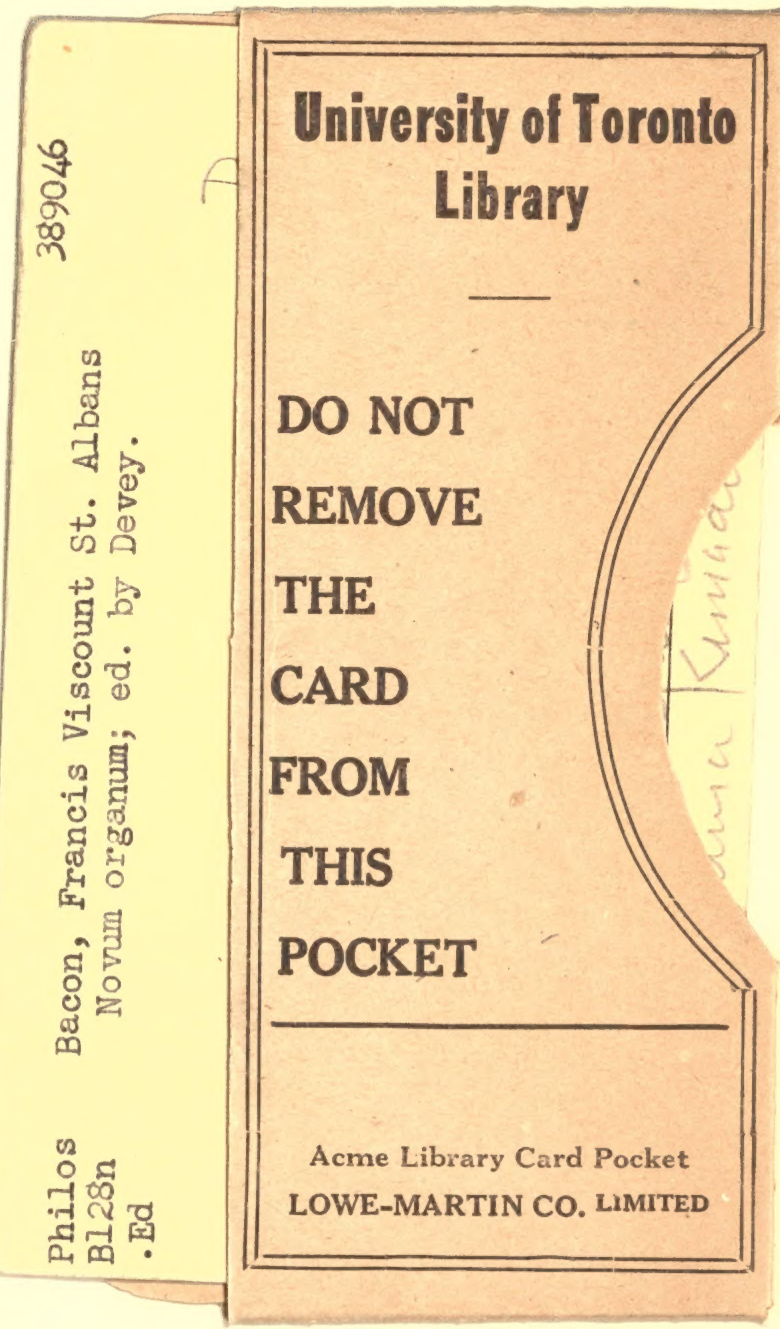


